Review

\title{
Gelatinase B/MMP-9 in Tumour Pathogenesis and Progression
}

\author{
Antonietta Rosella Farina and Andrew Reay Mackay * \\ Department of Applied Clinical and Biotechnological Sciences, University of L'Aquila, Via Vetoio, \\ Coppito 2, L'Aquila 67100, Italy; E-Mail: antonietta.farina@univaq.it
}

* Author to whom correspondence should be addressed; E-Mail: andrewreay.mackay@univaq.it; Tel.: +39-0862-433542; Fax: +39-0862-433523.

Received: 16 December 2013; in revised form: 20 January 2014 / Accepted: 21 January 2014 / Published: 27 January 2014

\begin{abstract}
Since its original identification as a leukocyte gelatinase/type V collagenase and tumour type IV collagenase, gelatinase B/matrix metalloproteinase (MMP)-9 is now recognised as playing a central role in many aspects of tumour progression. In this review, we relate current concepts concerning the many ways in which gelatinase B/MMP-9 influences tumour biology. Following a brief outline of the gelatinase B/MMP-9 gene and protein, we analyse the role(s) of gelatinase B/MMP-9 in different phases of the tumorigenic process, and compare the importance of gelatinase B/MMP-9 source in the carcinogenic process. What becomes apparent is the importance of inflammatory cell-derived gelatinase B/MMP-9 in tumour promotion, early progression and triggering of the "angiogenic switch", the integral relationship between inflammatory, stromal and tumour components with respect to gelatinase B/MMP-9 production and activation, and the fundamental role for gelatinase B/MMP-9 in the formation and maintenance of tumour stem cell and metastatic niches. It is also apparent that gelatinase B/MMP-9 plays important tumour suppressing functions, producing endogenous angiogenesis inhibitors, promoting inflammatory anti-tumour activity, and inducing apoptosis. The fundamental roles of gelatinase B/MMP-9 in cancer biology underpins the need for specific therapeutic inhibitors of gelatinase B/MMP-9 function, the use of which must take into account and substitute for tumour-suppressing gelatinase B/MMP-9 activity and also limit inhibition of physiological gelatinase B/MMP-9 function.
\end{abstract}

Keywords: gelatinase B/MMP-9; tumour progression; angiogenesis; metastasis; inflammation; epithelial-mesenchymal transition; invasion; motility; immune surveillance; gelatinase B/MMP-9 inhibitors 


\section{Introduction}

Since the original identification of galetinase B/matrix metalloproteinase (MMP)-9, as a human leukocyte gelatinase [1-4], its characterisation as a type $\mathrm{V}$ collagenase [5], the observation that malignant tumour cells express an identical enzyme that associates with metastatic behaviour and degrades type IV collagen under certain conditions [6-10] and its subsequent cloning from HT-1080 fibrosarcoma cells [11], research into the physiological and pathological functions of gelatinase B/MMP-9, in contrast to almost all other MMPs, has continued to increase at a steady rate $[12,13]$. Gelatinase B/MMP-9 involvement in malignant tumour progression has now moved on from original concepts of an almost exclusive role in matrix degradation, associated with tumour invasion, to include roles in almost all aspects of tumour biology, ranging from initiation and early progression, to angiogenesis, dissemination, invasion and motility, formation of the cancer stem cell niche, regulation of tumour immunological surveillance, metastatic site preparation and promotion of metastatic growth.

In the present article, following a briefly description of the human gelatinase B/MMP-9 gene, protein and mechanisms that regulate its expression, activation and activity, we review current concepts concerning gelatinase B/MMP-9 involvement in tumour progression, starting with the genetic damage that results in transformation and accompanies tumorigenicity, neoplastic expansion and the accumulation of mutations, increased survival, tumour-associated angiogenesis, adhesive interactions, matrix degradation and the loss of basement membrane, tumour cell invasion, motility, intravasation and extravasation, evasion of immunological surveillance, and regulation of the cancer stem cell and metastatic niches. We also review tumour-associated mechanisms that alter the equilibrium between gelatinase B/MMP-9 and its inhibitors and address novel ways to inhibit gelatinase B/MMP-9 involvement in tumour progression.

\section{The Gelatinase B/MMP-9 Gene and mRNA}

The human gelatinase B/MMP-9 gene localises to chromosome 20q11.2-q13.1, consists of 7,654 bases, starting from 44,637,547 bp from pter to 44,645,200 bp from pter, and is arranged into 13 exons [14]. The $2.2 \mathrm{~kb}$ gelatinase B/MMP-9 promoter resembles that of MMP-1 and MMP-3 rather than the MMP-2 one, and contains a TATA motif at position -29, GC box at position -563, TGF-beta inhibitory element at position -474, AP-1 elements at positions -79 and -209, three Ets binding PEA3 sites between -599 and -531 , an NF- $\kappa$ B element at positions -600 and -328, two AP-2 elements and a (CA)n segment [12]. Gelatinase B/MMP-9 is transcribed as a single $2.4 \mathrm{~kb}$ mRNA species and alternative splice variants have not been reported [15,16]. The gelatinase B/MMP-9 3'-UTR contains functional bindings sites for miR-491-5p, miR-885-5p [17] and miR-211 [18].

\section{Gelatinase B/MMP-9 SNPS}

A single $\mathrm{C}>\mathrm{T}$ nucleotide polymorphism at position -1562 within the gelatinase B/MMP-9 promoter, originally associated with coronary atherosclerosis [19], deregulates gelatinase B/MMP-9 expression and associates with gastric tumour progression [20], susceptibility to oral squamous cell carcinoma [21-23], nasopharyngeal carcinoma [24], squamous cell carcinoma of the lung [25] and oesophageal squamous cell carcinoma [26], and also associates with a higher risk of metastasis in the Asian, but not the 
European population [27]. Polymorphisms in the length of (CA)n sequence within the gelatinase B/MMP-9 promoter have been reported, with lengths of (CA)21 and (CA)23 shown to increase gelatinase B/MMP-9 transcription [28-30]. This region is close to TRE, SP1 and NF- $\mathrm{BB}$ cis elements and may alter their function. The (CA)n element binds a specific DNA binding protein, dependent upon CA number [30]. The gelatinase B/MMP-9 polymorphism Rs1056628CC, detected within the Chinese population, is characterised by a change in base 2182 from A to C within the 3'-UTR miR491-5p binding sequence and increases gelatinase B/MMP-9 expression, potentially through altered miR-491-5p binding [31]. Two gelatinase B/MMP-9 coding region single nucleotide polymorphisms rs2250889 (P574R) and rs17576 (R279Q) have been associated with risk of lung cancer and lung cancer metastasis [32], and with reduced overall survival of patients with loco regionally advanced nasopharyngeal carcinoma, characterised by increased tissue gelatinase B/MMP-9 expression [33,34], lymph node metastasis in gastric cancer [35] and risk of gallbladder cancer [36] but these SNPs do not appear to associate with colon cancer susceptibility in a Chinese cohort study [37]. In addition to these reports, gelatinase B/MMP-9 coding region SNPs Arg279Gln and Arg668Gly may represent potential predictors of survival in Chinese patients with non-small cell lung cancer [38].

\section{The Gelatinase B/MMP-9 Protein}

We direct the reader to the excellent and extensive reviews by Van den Steen and colleagues, and Vandooren and colleagues [12,13], concerning gelatinase B/MMP-9 biochemistry and molecular biology. Briefly, the gelatinase B/MMP-9 protein is a multi-domain metallo-enzyme, with a catalytic site composed of a metal binding domain separated from the active site by three fibronectin repeats that facilitate the degradation of large substrates such as elastin and denatured collagens. Within this region the amino acids Asp309, Asn319, Asp232, Tyr320 and Arg3076 are important for gelatin binding. The catalytic site is maintained inactive by an amino-terminal pro-peptide PRCGXPD, with the cysteine coordinated with the catalytic $\mathrm{Zn}^{2+}$. The $\mathrm{COOH}$ terminus of gelatinase B/MMP-9 contains a hemopexin domain that regulates substrate binding, interacts with inhibitors and facilitates cell surface binding. A central O-glycosylated domain provides molecular flexibility, regulates gelatinase B/MMP-9 substrate specificity, gelatinase B/MMP-9-dependent invasion, interaction with TIMP and cell surface localisation. This domain facilitates the movement of gelatinase B/MMP-9 along macromolecular substrates and unwinds collagen initially cleaved by other enzymes, permitting gelatinase B/MMP-9-mediated degradation $[12,13]$.

\subsection{Gelatinase B/MMP-9 Catalytic Site}

Within the gelatinase B/MMP-9 catalytic domain the amino acid Glu402 and $\mathrm{Zn}^{2+}$ ion are essential for function, amino acids Leu397 and Ala406 are important for general catalytic activity, Asp410 enhances type V collagenolytic activity, Pro415 enhances gelatinolytic activity [39] and Gly substitution of Glu415 renders gelatinase B/MMP-9 collagenolytic [40]. The propeptide domain contains a "cysteine switch" sequence that binds to the catalytic $\mathrm{Zn}^{2+}$ ion, inhibiting catalytic activity. Gelatinase B/MMP-9 activation is achieved by proteolytic removal of this sequence by enzymes that include: trypsin, cathepsin G, kallikrien, elastase, chymase, neutrophil elastase and the MMPs-1, -2, -3, -7, -10 , -13 and -26 [12]. Debate exists, however, as to whether plasmin can directly activate gelatinase 
B/MMP-9 [12,41]. Indirect plasmin-mediated gelatinase B/MMP-9 activation is achieved via MMP-1, MMP-3 and MMP-7 [12]. In addition to proteolytic gelatinase B/MMP-9 activation, agents that modify the interaction between the pro-peptide cysteine and the catalytic site $\mathrm{Zn}^{2+}$ ion, such as ionic detergents, organo-mercurials, oxidising agents, S-nitrosylation and S-glutothiolation can also activate gelatinase B/MMP-9 [12,42-44]. The gelatinase B/MMP-9 catalytic domain contains six disulphide bonds that are necessary for intracellular trafficking and gelatinase B/MMP-9 secretion [45]. The gelatinase B/MMP-9 catalytic site also contains cryptic plasmin degradation sites that are exposed by divalent cation chelators and by the bisphosphonate alendronate (Fosamax) and upon degradation irreversibly inhibit gelatinase B/MMP-9 catalytic activity [41].

\subsection{Gelatinase B/MMP-9 Hemopexin Domain}

The gelatinase B/MMP-9 hemopexin domain exhibits a relatively unique covalent structure in which Cys516 and Cys704 form a disulphide bridge, which is involved in domain function but is not required for gelatinase B/MMP-9 secretion $[45,46]$. This domain facilitates interactions with substrates, gelatinase B/MMP-9 oligomerisation, binds the carboxyl terminal of TIMP-1, binds cell surface proteins such $\mathrm{Ku} 70 / 80$ and LRP, and upon binding appropriate substances, such as heme, also mediates autocatalytic gelatinase B/MMP-9 activation [47]. Divergent disulphide bridging between the 17-cysteine residues within gelatinase B/MMP-9 regulates structure and function. Disulphide bridging within fibronectin repeats are essential for gelatinase B/MMP-9 secretion. Hemopexin domain function depends upon disulphide bridging and disulphide bridging between the $O$-glycosylation or hemopexin domains facilitates gelatinase B/MMP-9 dimerization or oligomerisation, promoting CD44 binding, which results in activation of the EGF receptor and subsequent ERK/1/2 mediated cancer cell migration [46,48]. Gelatinase B/MMP-9 hemopexin domain hetero-dimerization with proteins such as TIMP-1 and NGAL protects gelatinase B/MMP-9 against proteolytic degradation.

\subsection{Gelatinase B/MMP-9 O-Glycosylation Domain}

The O-glycosylated domain of gelatinase B/MMP-9, also known as the type V collagen-like domain, represents a 64 amino acid linker containing 22 proline residues, six glycine residues and approximately 12-14 $O$-linked glycans [49]. This domain is active in hemopexin domain orientation, which is important for molecular interactions with exogenous proteins, including gelatinase B/MMP-9 substrates [49]. The removal of this domain reduces gelatinase B/MMP-9 specificity for macromolecular substrates, including gelatin [13].

\subsection{Truncated Gelatinase B/MMP-9 Isoforms}

Several truncated gelatinase B/MMP-9 isoforms have been described that include proteolytically active fragments derived from autocatalysis and exogenous proteolytic degradation. The $65 \mathrm{kDa}$ gelatinase B/MMP-9 catalytically active fragment generated by MMP-3 is deleted of COOH terminal sequence and escapes TIMP-1 inhibition. KLK7 and meprin- $\alpha$ also remove this domain from gelatinase B/MMP-9 [50-52]. A novel $82 \mathrm{kDa}$ inactive pro-gelatinase B/MMP-9 form has been described in 
human leukaemic cells, which also escapes TIMP inhibition [53,54] and a similar sized human pro-gelatinase B/MMP-9 isoform is generated by the action of plasmin [41].

\section{Gelatinase B/MMP-9 Substrates}

Gelatinase B/MMP-9 was originally characterised as a gelatinase/V collagenase [1-5], and was later attributed type IV collagenolytic activity $[6,11]$. Although there is controversy surrounding the susceptibility [55] or resistance [8,40,56] of triple helical domains of collagens to degradation by gelatinase B/MMP-9, the capacity of gelatinase B/MMP-9 to degrade native type IV collagen may be limited, therefore, to non-triple helical, less-disulphide cross-linked or pre-digested molecular forms of type IV collagen $[8,57,58]$. It remains debatable whether activated gelatinases alone degrade type IV collagen within the context of an insoluble basement membrane [8,57-59]. Gelatinase B/MMP-9 does, however, degrade basement membrane laminin, disrupting basement membrane structure, tissue architecture [60] and inducing apoptosis [61]. In addition to its capacity to degrade extracellular matrix components, recent reports have characterized an ever-increasing array of substrates susceptible to degradation by gelatinase B/MMP-9, dramatically widening the potential physiological and pathological sphere of gelatinase B/MMP-9 influence. Gelatinase B/MMP-9 exhibits substrate specificity for cytokines, chemokines and growth factors within the extracellular compartment and may also degrade nuclear, mitochondrial and cytoplasmic substrates (Table 1). For a broad spectrum of gelatinase B/MMP-9 substrates, both old and new, we direct reader to the following articles [52,55-118].

Table 1. Update of Gelatinase B/MMP-9 substrates. Substrates (sub) and MMP-9 origins are provided: human (hu), mouse (mu), bovine (bo) and rabbit (ra).

\begin{tabular}{|c|c|c|c|}
\hline Class & Substrate & Substrate/MMP-9 source & [Refs] \\
\hline \multirow{19}{*}{ ECM Substrates } & Collagen type I & (bo/mu sub/hu MMP-9) & [55] \\
\hline & Collagen type II & (hu sub/MMP-9) & [56] \\
\hline & Collagen III & (bo sub/hu MMP-9) & [55] \\
\hline & Collagen IV & (hu/mu sub/MMP-9) & {$[8,57,58,66-70]$} \\
\hline & Collagen V & (hu sub/MMP-9) & {$[4,8,68]$} \\
\hline & Collagen VI & (hu sub/MMP-9) & [70] \\
\hline & Collagen $\alpha 1$ and $\alpha 2$ (VI) & (hu sub/MMP-9) & [62] \\
\hline & Collagen $\alpha 1$ (XI) & (hu sub/MMP-9) & [71] \\
\hline & Collagen $\alpha 1$ (XVIII) & (hu sub/MMP-9) & {$[70,72]$} \\
\hline & $\begin{array}{c}\text { Procollgen lysine-2-oxygluterate-5 } \\
\text { dioxygenase- } 1\end{array}$ & (hu sub/MMP-9) & [62] \\
\hline & Periostin & (hu sub/MMP-9) & [70] \\
\hline & Galectin-1 & (hu sub/MMP-9) & {$[62,65]$} \\
\hline & Galectin 3 & (hu sub/MMP-9) & [73] \\
\hline & Fibronectin & (hu sub/MMP-9) & {$[68,70,74]$} \\
\hline & Laminin & (mu sub/hu MMP-9) & {$[60,62,68]$} \\
\hline & Tenascin $\mathrm{C}$ & (hu sub/MMP-9) & {$[70,74,75]$} \\
\hline & Tenascin $\mathrm{X}$ & (hu sub/MMP-9) & {$[70]$} \\
\hline & Thrombospondin-2 & (hu sub/MMP-9) & [65] \\
\hline & $\begin{array}{l}\text { Insulin growth factor binding } \\
\text { protein } 4\end{array}$ & (hu sub/MMP-9) & [65] \\
\hline
\end{tabular}


Table 1. Cont.

\begin{tabular}{|c|c|c|c|}
\hline Class & Substrate & Substrate/MMP-9 source & [Refs] \\
\hline \multirow{5}{*}{ ECM Substrates } & Cystatin C & (hu sub/MMP-9) & [65] \\
\hline & Elastin & (Bo/mu sub/hu/mu MMP-9) & {$[76,77]$} \\
\hline & Vitronectin & (hu sub/MMP-9) & {$[78]$} \\
\hline & Entactin & (mu sub/hu MMP-9) & [79] \\
\hline & Heparan sulphate & (hu sub/MMP-9) & [80] \\
\hline \multirow{19}{*}{$\begin{array}{l}\text { Cell surface } \\
\text { substrates }\end{array}$} & ICAM-1 & (hu sub/MMP-9) & {$[81,82]$} \\
\hline & uPAR & (hu sub/MMP-9) & {$[83]$} \\
\hline & Laminin receptor & (Xenopus sub/hu MMP-9) & [84] \\
\hline & IL2R $\alpha$ & (hu sub/MMP-9) & {$[85,86]$} \\
\hline & $\operatorname{proTNF} \alpha$ & (hu sub/MMP-9) & {$[87]$} \\
\hline & IL-1 $\beta$ & (hu sub/MMP-9) & {$[88,89]$} \\
\hline & Kit ligand & (mu/hu sub/MMP-9) & {$[90,91]$} \\
\hline & $\beta 2$ integrin subunit & (mu sub/MMP-9) & {$[92]$} \\
\hline & proTGF $\beta$ & (mu sub/MMP-9) & [93] \\
\hline & HB-EGF & (hu sub/MMP-9) & [94] \\
\hline & Occludin tight junction protein & (bo sub/huMMP-9) & {$[95]$} \\
\hline & Syndecan 1 and 4 & (mu sub/MMP-9) & {$[96,97]$} \\
\hline & Serpin $\alpha-1$ proteinase inhibitor & (mu sub/MMP-9) & {$[98]$} \\
\hline & myelin basic protein & (hu sub/MMP-9) & [99] \\
\hline & NG2 Proteoglycan & (hu sub/MMP-9) & [100] \\
\hline & $\beta$-distroglycan & (mouse substrate/MMP-9 ?) & [101] \\
\hline & Soluble beta amyloid protein & (hu sub/MMP-9) & {$[102,103]$} \\
\hline & Fibrilar beta amyloid protein & (mu sub/MMP-9 ?) & [103] \\
\hline & ADAMTS-4 (aggrecanase-1) & (hu sub/MMP-9) & [104] \\
\hline \multirow{7}{*}{$\begin{array}{l}\text { Candidate cell } \\
\text { surface } \\
\text { substrates }\end{array}$} & Angiopoetin 1 receptor Tie2 & (hu sub/MMP-9) & [62] \\
\hline & Neuropilin 1 & (hu sub/MMP-9) & [62] \\
\hline & Integrin $\alpha 3$ & (hu sub/MMP-9) & {$[62]$} \\
\hline & Clatherin heavy chain CLH17 & (hu sub/MMP-9) & {$[62]$} \\
\hline & CD166/ALCAM & (hu sub/MMP-9) & {$[62]$} \\
\hline & Saposin A & (hu sub/MMP-9) & {$[62]$} \\
\hline & Semaphorin 7A & (hu sub/MMP-9) & [62] \\
\hline \multirow{3}{*}{ CC Chemokines } & CCL7 & (mu sub/MMP-9) & [105] \\
\hline & CCL11 (Eotaxin) & (mu sub/MMP-9) & [105] \\
\hline & CCL17 (TARC) & (mu sub/MMP-9) & {$[105]$} \\
\hline \multirow{10}{*}{$\begin{array}{c}\text { CXC } \\
\text { Chemokines }\end{array}$} & CXCL1/NAP-3 & (hu sub/MMP-9) & [106] \\
\hline & CXCL4/PF4 & (hu sub/MMP-9) & [106] \\
\hline & CXCL8/IL-8 & (hu sub/MMP-9) & {$[106]$} \\
\hline & CXCL7/CTAP-III & (hu sub/MMP-9) & [106] \\
\hline & CXCL9/MIG & (hu sub/MMP-9) & [107] \\
\hline & CXCL10/IP-10 & (hu sub/MMP-9) & [107] \\
\hline & CXCL6/GCP-2 & (hu/mu sub/hu MMP-9) & [107] \\
\hline & CXCL5/ENA78 & (hu sub/MMP-9) & [107] \\
\hline & CXCL11/ITAC & (hu sub/MMP-9) & [108] \\
\hline & CXCL12/SDF-1 & (hu sub/MMP-9) & [109] \\
\hline
\end{tabular}


Table 1. Cont.

\begin{tabular}{|c|c|c|c|}
\hline Class & Substrate & Substrate/MMP-9 source & [Refs] \\
\hline & Leukaemia inhibitory factor (LIF) & (hu sub/MMP-9) & {$[62]$} \\
\hline & Protease nexin-1 & (hu sub/MMP-9) & {$[62]$} \\
\hline & Granulins precursor acrogranin & (hu sub/MMP-9) & [62] \\
\hline & Hsp90 & (hu sub/MMP-9) & {$[62]$} \\
\hline & uPA precursor & (hu sub/MMP-9) & {$[62]$} \\
\hline & tPA precursor & (hu sub/MMP-9) & {$[62]$} \\
\hline & $\mathrm{C} 1 \mathrm{q}$ & (hu sub/MMP-9) & [110] \\
\hline & C1r-A & (mu sub/hu MMP-9) & {$[65]$} \\
\hline & Pyruvate kinase isoenzymes M1/M2 & (ra sub/hu MMP-9) & [65] \\
\hline & Collagenase 3 (MMP-13) & (hu sub/MMP-9) & [62] \\
\hline & Dickkopf-1 & (hu sub/MMP-9) & [111] \\
\hline & Dickkopf-3 tumour suppressor & (hu sub/MMP-9) & {$[65]$} \\
\hline Other & DJ-1 oncogene & (hu sub/MMP-9) & [111] \\
\hline \multirow[t]{13}{*}{ Substrates } & Follistain-like 3 & (hu sub/MMP-9) & [111] \\
\hline & Neuron specific enolase & (hu sub/MMP-9) & [111] \\
\hline & Nieman-Pick C2 & (hu sub/MMP-9) & [111] \\
\hline & Proglanulins & (hu sub/MMP-9) & [111] \\
\hline & Ym 1 & (mu sub/MMP-9) & [105] \\
\hline & S100A8 proinflammatory protein & (mu sub/MMP-9) & [105] \\
\hline & S100A9 proinflammatory protein & (mu sub/MMP-9) & [105] \\
\hline & Plasminogen & (hu sub/MMP-9) & {$[112,113]$} \\
\hline & Mature NGF & (mu sub/MMP-9) & {$[114]$} \\
\hline & Interferon- $\beta$ & (hu sub/MMP-9) & [115] \\
\hline & KISS- 1 metastasis suppressor & (hu sub/MMP-9) & [116] \\
\hline & Tau & (hu sub/MMP-9) & {$[117]$} \\
\hline & VEGF & (mu sub/MMP-9 not hu MMP-9) & {$[80,118]$} \\
\hline
\end{tabular}

\section{Gelatinase B/MMP-9 Transcription and Translation}

The $2.2 \mathrm{~kb}$ human gelatinase B/MMP-9 promoter contains a TATA-like motif at position -29 but no CAAT-like motif. Relative to the transcriptional start site, functional transcription sites include: an SP1 binding GC box located at -563 , a retinoblastoma binding element or GT box that also binds SP1 at position -54 , and three additional GT boxes. In addition to a TGF- $\beta 1$ inhibitory element at $-474 \mathrm{bp}$ and 4 potential AP-1 binding elements, the functional AP-1 site at position -79 is essential for basal and jun/Fos induced expression in HT-1080 and osteosarcoma cells [119], three functional PEA3/Ets binding sites localise between -599 and -531 are also involved in basal gelatinase B/MMP-9 transcription $[119,120]$. A functional NF- $\kappa B$ binding site is located at -600 and a second site at $-328 \mathrm{bp}$ [121], and potentially functional inhibitory AP-2-like binding sites immediately upstream of the GC-box that interferes with Sp-1 binding [122], an alternating microsatellite CA sequence in close proximity to the AP1 site at position -79 [12] (Figure 1). 
Figure 1. Localisation of functional transcriptional elements within the human MMP-9 promoter, displaying the positions, relative to the MMP-9 translational start site, for E2 protein (E2 BS), nuclear factor-kappa binding (NF-kB), specific protein-1 (Sp1), E26 transformation specific (ETS), CA repeat, activator protein-1 (AP1), GTbox and Tata box binding sites.

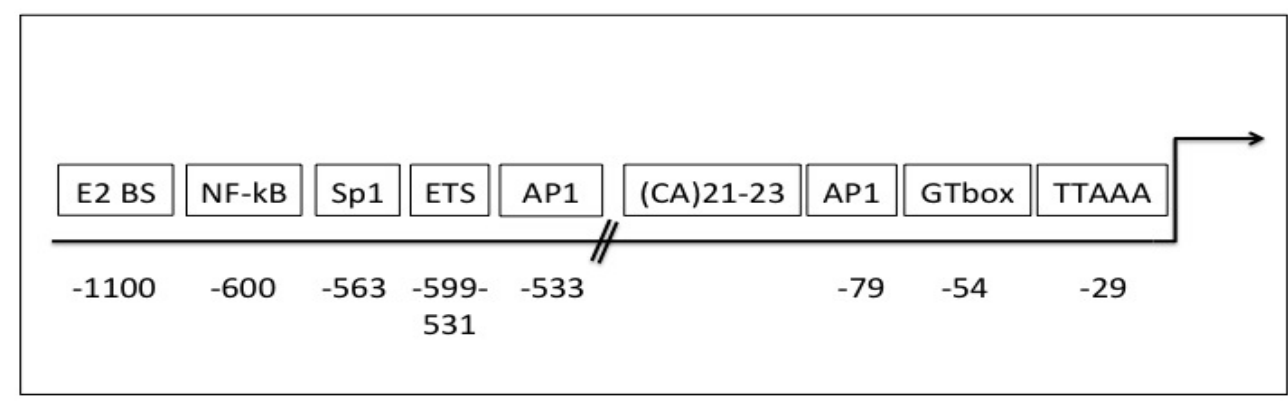

Synergism between transcriptional elements characterises basal-, cytokine- and phorbol ester-induced gelatinase B/MMP-9 transcription, with the AP-1 element at position -79 necessary, but not sufficient for transcription, cooperating with NF- $\mathrm{B}(-600)$ and SP1 (-563) elements, respectively [119]. The $\mathrm{NF}-\kappa \mathrm{B}$ element $(-600)$ is required for gelatinase B/MMP-9 transcription induced during spontaneous epithelial to neuroblast transition and by all-trans-retinoic acid in human neuroblastoma cells [123,124], by TNF- $\alpha$ in HT-1080 fibrosarcoma cells and rabbit fibroblasts [119,125,126], IL1 $\beta$ [127], Bcl2 [128], HIV-1-Tat [129], KiSS1 [130], synergistic combinations of cytokines and growth factors [126,131] and thioredoxin [132], acting in concert with other elements including the AP-1 site at position -79 . The Ets element at -541 acting together with the AP-1 element at position -533 regulates gelatinase B/MMP-9 transcription induced by c-Ha- Ras, EGF and fibroblast cell contact [12,120,133]. Both RBE (-54) and AP-1 (-79) elements regulate v-Src induced gelatinase B/MMP-9 transcription in fibrosarcoma cells, c-Ha-Ras induced gelatinase B/MMP-9 transcription in adenocarcinoma cells and c-Ha-ras/v-myc-induced gelatinase B/MMP-9 transcription in rat embryo cells [133]. The RBE element (-54) also functions together with the NF-אB element $(-600)$ in gelatinase B/MMP-9 transcription induced by spontaneous epithelial to neuroblast conversion exhibited by SK-N-SH neuroblastoma cells [123]. In general, gelatinase B/MMP-9 transcription with few exceptions depends upon the concerted interaction between several transcriptional cis elements and cognate transcription

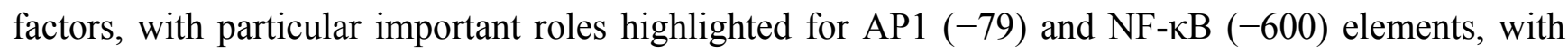
$\mathrm{NF}-\kappa \mathrm{B}$ and SP1 transcription factors specific determinant for gelatinase B/MMP-9 expression. Recently, a functional binding site for the E2 protein expressed by human oncogenic papilloma virus 8 has been characterised at position -1100 of the human MMP-9 promoter and shown to promote MMP-9 transcription [134].

The gelatinase B/MMP-9 protein is constitutively expressed by only a limited number of cell types, such as keratinocytes, macrophages, polymorphonuclear leukocytes and some malignant tumour cell lines, including MDA-MB-231 breast cancer, HT-1080 fibrosarcoma and A2058 melanoma cell lines $[12,15]$ and is readily induced in wide range of normal and tumour cell types by pro-inflammatory cytokines, activators of PKC and growth factors with gelatinase B/MMP-9 expression regulated 
through inhibitory STAT and SMAD pathways and stimulatory PKC, Ras/MAPK, TRAD/TRAF, MEK/JNK, ASK/MKK and IRAK/TRAF pathways [12,13,15].

Gelatinase B/MMP-9 expression is also regulated at the level of mRNA stability, translation and protein secretion [135-141].

\section{Gelatinase B/MMP-9 Expression, Bioavailability, Activity and Endogenous Inhibitors}

Gelatinase B/MMP-9 expression is up-regulated in vitro by pro-inflammatory cytokines and PKC activators in human melanoma, neuroblastoma, teratocarcinoma, lung cancer and fibrosarcoma cells $[15,16]$ and in rabbit fibroblasts [131], by chemokines in prostate cancer cells [142] and by growth factors, such as TGF $\beta$ in human breast cancer cells [143], EGF in human prostate [144], squamous cell carcinoma [145] and renal carcinoma cells [146], HGF in colon [147], renal [148], hepatocellular carcinoma [149], mesothelioma [150], lung cancer [151] and pancreatic tumour cells [152], by FGF in rabbit fibroblasts [131], human osteosarcoma cells [153], human bladder cancer cells [154] and human breast cancer cells [155,156], by neuropeptides in prostate cancer cell lines [157] and by haemoglobin in malignant melanoma and bladder cancer cells [158]. Gelatinase B/MMP-9 is also induced in neuroblastoma cells in association with spontaneous epithelial to neuroblast phenotype conversion and following treatment with all-trans-retinoic acid [123,124] and released from IL-8 stimulated neutrophils [159].

Gelatinase B/MMP-9 enzymatic activity is inhibited by the universal systemic protease inhibitor $\alpha 2$-macrogloblin [160], members of the tissue inhibitors of metalloproteinases (TIMPs) family [161,162] and is also antagonized by its own isolated hemopexin domain [41,163]. TIMPs 1-4 are 20-30 kDa glycoprotein MMP inhibitors that depend upon disulphide bridges between 6 cysteine pairs for their inhibitory activity [161,162,164]. TIMP-1 exhibits a unique binding interaction with gelatinase B/MMP-9 and, with the exception of human neutrophils, exhibits a high level of coordinated expression with TIMP-1, is frequently secreted as a TIMP-1/gelatinase B/MMP-9 complex and binds gelatinase B/MMP-9 with high affinity, in contrast to TIMP-2 and TIMP-3 [12,15,41,123,157,162]. The interaction between pro-form gelatinase B/MMP-9 and TIMP-1 involves the $C$-terminal domains of both proteins and in this form TIMP-1 is available to inhibit other MMPs. Upon gelatinase B/MMP-9 activation, TIMP-1 inhibits gelatinase B/MMP-9 catalytic activity through $N$-terminal interaction with the gelatinase B/MMP-9 catalytic site, with inhibition facilitated by the gelatinase B/MMP-9 $C$-terminus, since it does not readily occur in gelatinase B/MMP-9 C-terminus deletion mutants. In contrast to TIMP-1, TIMP-2 inhibition of gelatinase B/MMP-9 depends upon the $N$-terminal domain, but does not involve $C$-terminal interaction and is less effective that TIMP-1. TIMP-3 is a matrix-associated inhibitor that interacts with and inhibits gelatinase B/MMP-9 to a lesser extent than either TIMP-1 or TIMP-2 [161,162].

The bioavailability of gelatinase B/MMP-9 is regulated by forming complexes with low-density lipoprotein receptor-related proteins (LRP)-1 and LRP2 via functional endocytosis, promoting intracellular gelatinase B/MMP-9 uptake and leupeptin-sensitive degradation [49,165]. Autocatalytic gelatinase B/MMP-9 degradation is prevented when monomeric gelatinase B/MMP-9 is complexed with Neutrophil gelatinase-associated lipocalin (NGAL) in an interaction that does not result in gelatinase B/MMP-9 inhibition, effectively prolonging enzymatic activity $[166,167]$. 


\section{The Gelatinase B/MMP-9/TIMP-1 Protease-Antiprotease Equilibrium}

Mechanisms that alter the equilibrium between gelatinase B/MMP-9 and its TIMP-1 inhibitor in favour of protease activity, facilitate gelatinase B/MMP-9 involvement in tumour pathology, and include differential expression, evasion from TIMP inhibition, and TIMP-1 inactivation.

Gelatinase B/MMP-9 and TIMP-1 are frequently co-ordinately expressed in a large number of cell types and secreted as a pro-gelatinase B/MMP-9/TIMP-1 complex [12,15]. The tumor environment is however complex, and composed of tumor, stromal and inflammatory elements that also contribute to the modulation of this important equilibrium. Tumor infiltrating neutrophils release gelatinase B/MMP-9 in TIMP-free form, facilitating tumor-associated differential gelatinase B/MMP-9 and TIMP-1 expression [168,169] Furthermore, the differential up-regulation of gelatinase B/MMP-9 but not TIMP-1 expression has been reported in human ovarian cancer [170], skin cancer [171], squamous cell carcinoma of the hypopharynx [172] and colon and rectal tumours in vivo [173], and has also been demonstrated in malignant melanomas induced in metallothionin/RET transgenic mice [174]. In vitro, differential up-regulation of gelatinase B/MMP-9 but not TIMP-1 expression characterises PC-3 prostate tumor cell/stromal cell co-cultures and endothelial cells co-cultured with fibroblasts $[175,176]$, cervical carcinoma cells in response to CD40L activation [177], human head and neck squamous carcinoma cells in response to c-erbB ligands [178], spontaneous epithelial to neuroblast transformation of human neuroblastoma cells [123], retinoic acid treatment of differentiation resistant human neuroblastoma cells [124], peroxiredoxin expression in metastatic human MDA-MB-231 breast cancer cells [179], thioredoxin expression in human MDA-MB-231 breast cancer cells [132] and bFGF treatment of human retinoblastoma cells [180].

Differential gelatinase B/MMP-9 and TIMP-1 regulation may also involve promoter SNPs and/or 3'-UTR micro RNA binding sites. Indeed, gelatinase B/MMP-9 SNPs that augment gelatinase B/MMP-9 expression have been associated with increased risk of different forms of cancer (See Section Gelatinase B/MMP-9 SNPs on page 241), as have altered levels of miRs that bind miR binding sites within the 3'-UTR region of gelatinase B/MMP-9. The miRs -211, 491-5p and 885-5p target and inhibit gelatinase B/MMP-9 expression and are down regulated in human glioblastoma multiforme, in association with increased gelatinase B/MMP-9 expression [17,18], and miR-19a has been reported to regulate gelatinase B/MMP-9 expression in colon cancer cells [181]. Furthermore, a recent report has shown that miR-17 targets the TIMP-1 protein-coding region and its inhibition enhances TIMP-1 expression and decreases gelatinase B/MMP-9 activity [182]. It is likely, therefore, that altered patterns of miR expression may also facilitate the differential expression of gelatinase B/MMP-9 and TIMP-1 in malignant tumours.

Extracellular activation of the thioredoxin redox system, up-regulated in malignant tumours, has been shown to inhibit TIMP but not MMP activity in vitro and in models of human neuroblastoma and UV irradiated dermal fibroblasts [164,183]. Furthermore, the myeloperoxidase $/ \mathrm{H}_{2} \mathrm{O}_{2} /$ hypochlorous acid ( $\mathrm{HOCl})$ system of inflammation induces the oxidative inactivation of TIMPs, whilst promoting the activation of MMPs, at concentrations found during inflammation [184,185], providing mechanisms through which the gelatinase B/MMP-9/TIMP equilibrium within tumours can be altered in favour of proteolytic activity even under conditions of high level TIMP expression [186]. TIMP MMP-inhibitory activity, furthermore, can be destroyed by neutrophil elastase, trypsin and $\alpha$-chymotrypsin, all of which 
activate gelatinase B/MMP-9 [12,187,188], providing an additional mechanism for irreversible TIMP inhibition combined with gelatinase B/MMP-9 activation within inflammatory tumour environments and also environments such as the pancreas, in which trypsin and trypsin-like enzymes are expressed [189]. Finally, truncated gelatinase B/MMP-9 isoforms generated by enzymatic digestion or present on the cell surface of human leukemic cells have been shown to escape TIMP inhibition (see Section 3.4).

\section{Gelatinase B/MMP-9, Tumour Initiation/Promotion and Genetic Instability}

Potential pro-oncogenic roles for gelatinase B/MMP-9 have been reported, implicating gelatinase B/MMP-9 in neoplastic transformation, tumour initiation/promotion and genetic instability (Figure 2). Gelatinase B/MMP-9 localises to the nucleus, despite lack of classical nuclear localisation signal [190,191] and nuclear gelatinase activity associates with increased levels of DNA fragmentation [192-194]. Indeed, nuclear gelatinase degrades the nuclear matrix protein poly-ADP-ribose-polymerase (PARP), hindering DNA repair [193,195]. Furthermore, gelatinase B/MMP-9 binds the DNA damage heterodimer $\mathrm{Ku} 70 / 80$, providing a potential mechanism for its nuclear translocation [196]. Nuclear gelatinase B/MMP-9 has been reported in human gliomas, astrocytomas and neuroblastomas [197,198].

Figure 2. Representation of the role of inflammatory polymorphonuclear leukocyte (PMN)-derived tissue inhibitor of metalloproteinase (TIMP)-free gelatinase B/MMP-9 in tumour initiation and promotion of genetic instability through degradation of extracellular matrices (ECM) release and activation of cytokines, chemokines and growth factors.

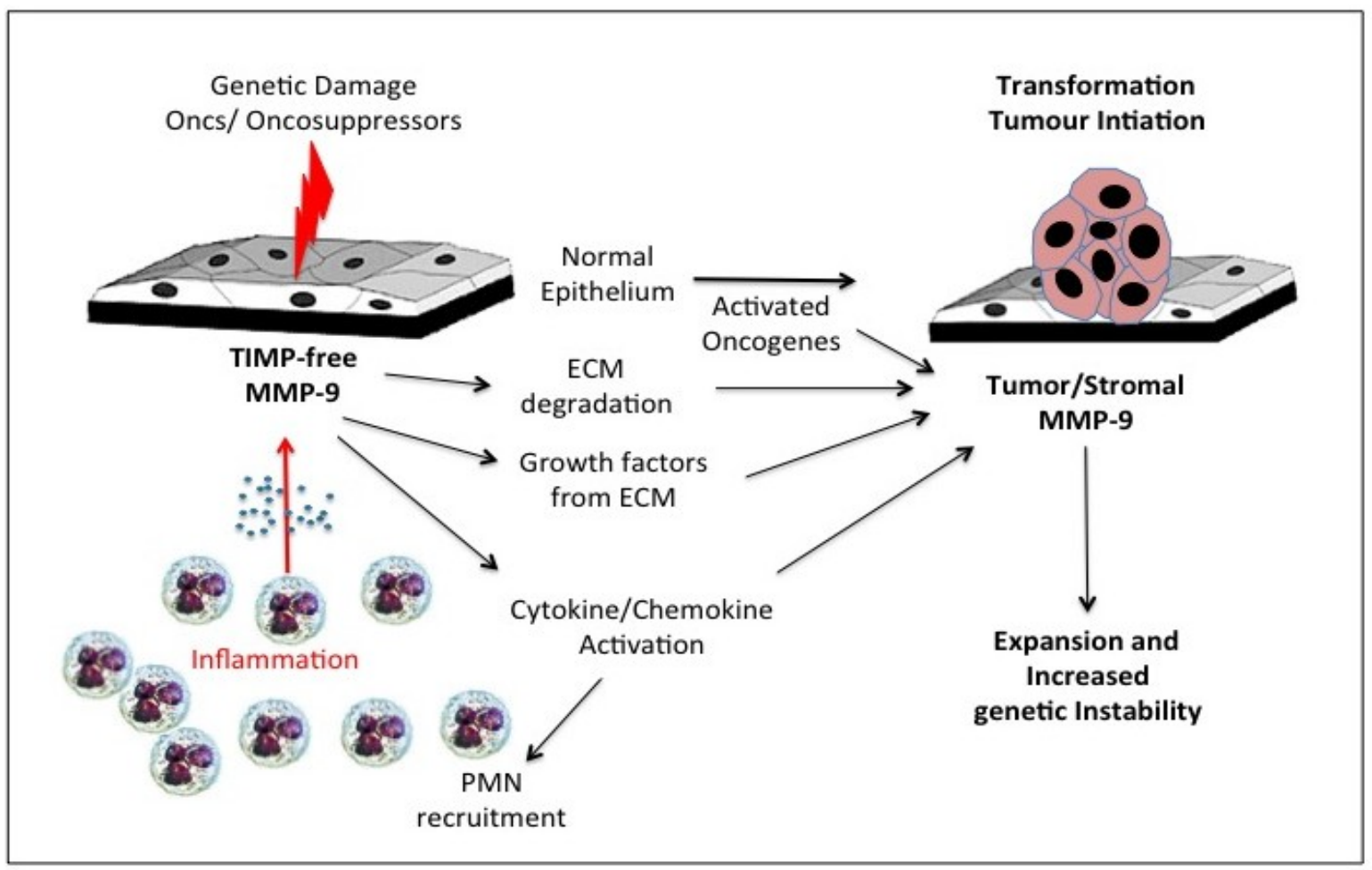

Gelatinase B/MMP-9 has been reported to protect colorectal cancer cells against microsatellite instability, with reduced gelatinase B/MMP-9 activity associated with increased microsatellite instability. This has been attributed to inhibitory mutations within the promoter of the gelatinase B/MMP-9 activator MMP-3 and is associated with better prognosis [199-201]. Microsatellite instability, 
furthermore, down-regulates gelatinase B/MMP-9 expression by introducing polymorphisms that reduce the number of $(\mathrm{CA}) \mathrm{n}$ repeats within gelatinase B/MMP-9 regulatory domain to below 22 [28].

A role for inflammatory neutrophil-derived gelatinase B/MMP-9 in intestinal adenoma initiation has been described in heterozygous APC (APC-min) knockout mice, with a 40\% reduction in adenoma formation observed upon gelatinase B/MMP-9 knockout [202]. Increased gelatinase B/MMP-9 activity provided by inflammatory neutrophils, furthermore, augments neutrophil recruitment via gelatinase B/MMP-9-mediated degradation and super-activation of IL-8 [106], augmenting neutrophil-mediated genetic instability [106,203]. Gelatinase B/MMP-9 also induces Rac1b alternative splice variant expression, which promotes chromosomal instability by increased reactive oxygen species levels and activating Snail-mediated transcription, resulting in increased oxidative DNA damage [204,205].

Gelatinase B/MMP-9 has also been reported to promote liver tumour initiation by the proteolytic release and activation of matrix-associated TGF $\beta$ and VEGF [206], and in human mammary epithelial cells induces cell surface expression of the HER2/Neu oncoprotein, inhibiting apoptosis and shifting normal mammary cells towards a transformed phenotype, in the presence of oestrogen [207].

In contrast, gelatinase B/MMP-9 optimises non-homologous end joining (NHEJ) DNA repair in human glioma cells. Indeed, down-regulation of gelatinase B/MMP-9 expression, combined with either urokinase or cathepsin B, delays DNA repair by lowering KU70/80 recruitment to damaged DNA. This reduces NHEJ DNA repair function, increases the levels of DNA damage and promotes apoptosis [208].

\section{Gelatinase B/MMP-9 and Tumour Initiating Cell Proliferation and Expansion}

Clonal expansion of transformed cells is also an essential step in tumour progression and is facilitated by inflammation and involves a change in equilibrium between proliferation, apoptosis and angiogenesis [209,210].

In the heterozygous APC knockout mouse model (APC-min), neutrophil-derived gelatinase B/MMP-9 stimulates adenoma initiating cell proliferation, promoting adenoma expansion, and implicating gelatinase B/MMP-9 in the expansion of tumour cell populations that lack full APC function. It is likely that this involves gelatinase B/MMP-9-mediated release and activation of non-matrix cytokines, such as TNF $\alpha$ and IL- $\beta$ and matrix-associated growth factors, such as VEGF, TGF $\beta$ and FGFs and/or the degradation of growth inhibitors [211-214]. Indeed, gelatinase B/MMP-9 degrades IGF-BPs augmenting the circulating levels of IGF, promoting astrocytoma growth [215], and increasing circulating VEGF and EGF levels [216], which also promote adenoma cell proliferation in APC-min mice. Furthermore, transcriptional silencing of gelatinase B/MMP-9 inhibits human glioma cells proliferation [208] and Wnt signalling induced by hypoxia stimulating gelatinase B/MMP-9 expression and promotes neural stem cell proliferation [217], suggesting that a hypoxia/Wnt/gelatinase B/MMP-9 axis may also promote proliferation of the cancer stem/progenitor cell component of neural-related tumours.

\section{Gelatinase B/MMP-9, Stem Cells and the Cancer Stem Cell Niche}

The stem cell niche is a unique, specialised location responsible for maintaining stem cells. Stem cells within the niche are anchored by intracellular and cell matrix adhesive interactions, which 
regulate stem cell numbers, stem cell self-renewal and potentially asymmetrical stem cell division. Normal stem cells and cancer stem cells exhibit similar behaviour [218,219]. Cancer stem cell niches have been identified in tumours and implicated in tumour heterogeneity, metastatic progression and therapeutic resistance, and are regulated by conditions within the tumour and promoted by tumour associated stress such as hypoxia [220,221]. Gelatinase B/MMP-9 has been implicated in regulating stem cell niche behaviour and within the bone marrow, degrading extracellular matrices within the stem cell niche, resulting in the activation and mobilisation of haemopoetic stem cells. This is facilitated by the conversion of stem cell factor from its membrane bound to free form, promoting c-Kit receptor-mediated stem cell proliferation [90]. Gelatinase B/MMP-9 also releases circulating endothelial precursor stem cells from the bone marrow, contributing to angiogenesis [90]. Interaction between stroma-derived factor (SDF)-1 and the chemokine receptor CXCR4 is essential for stem/progenitor cell function [222] and induces gelatinase B/MMP-9 expression. A similar interaction induces gelatinase B/MMP-9 expression in cancer cells, promoting dissemination and metastasis to bone [222-224]. Wnt signalling induces gelatinase B/MMP-9 expression and maintains stem cell niche integrity $[225,226]$. Wnt signalling is up regulated in cancer, and also stimulates cancer stem cell proliferation, resistance to apoptosis, tumour invasion and metastasis [227-229]. Furthermore, Wnt-induced gelatinase B/MMP-9 expression has been implicated in embryonic neural stem cells proliferation in conditions of hypoxia [217], a similar mechanism may, therefore, regulate cancer stem cells proliferation within neural tumours [218].

\section{Gelatinase B/MMP-9 and Epithelial to Mesenchymal Transition (EMT)}

Epithelial to mesenchymal transition (EMT) represents the conversion of polarized immotile epithelial cells into motile mesenchymal progenitor cells. This mechanism is important in development (type 1), normal wound healing or pathological fibrosis (type 2) and in the metastatic transformation of cancer cells (type 3) [230]. Type 3 EMT is fundamental for tumour progression to metastasis, and is either re-activated in de-differentiated epithelial cancer cells or activated in epithelial cancer stem cells, inducing a more motile and invasive phenotype [228]. It may also be transient, with metastatic cells reverting back to an epithelial phenotype at destination.

Gelatinase B/MMP-9 is an important EMT-related gene, and is not only a consequence but also a cause of EMT (Figure 3). Gelatinase B/MMP-9 cooperates with Snail transcription factor to induce EMT in epidermoid carcinoma cells [231], is involved in medulloblastoma cell EMT [232], is induced by Twist transcription factor an essential inducer of EMT [233-235] and by krupple like factor (KLF)-8, a critical component of FAK-regulated breast cancer EMT, which induces gelatinase B/MMP-9 expression in human breast cancer cells, promoting migration, invasion, angiogenesis and metastasis [234-236]. EMT in gastric cancer involves a Shh/PI3K/Akt/gelatinase B/MMP-9 pathway, which promotes metastatic dissemination to lymph nodes [237]. In human neuroblastoma cells, spontaneous EMT-like phenotypic conversion from a less invasive epithelial to more invasive neuroblast phenotype, associates with the induction of gelatinase B/MMP-9 expression and increased gelatinase B/MMP-9-mediated invasion [123]. 
Figure 3. Representation of the role played by inflammatory polymorphonuclear leukocyte (PMN), stromal and tumour cell-derived gelatinase B/MMP-9 in epithelial-mesenchymal transition (EMT) and formation of the stem cell niche through degradation of extracellular matrices $(\mathrm{ECM})$ release and activation of cytokines and growth factors.

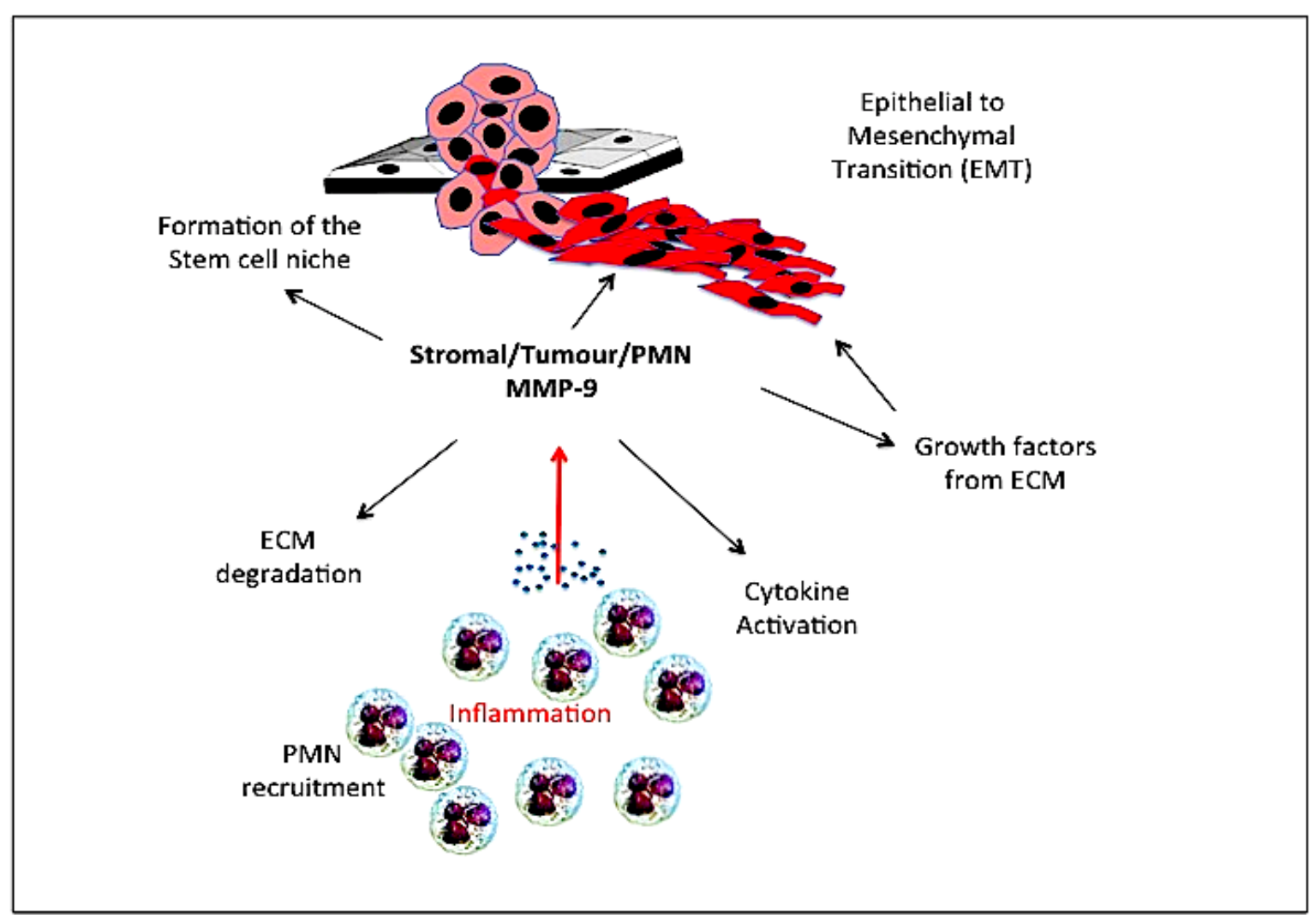

\section{Gelatinase B/MMP-9 and Cancer-Related Inflammation}

Inflammation is now considered to be a hallmark of tumour progression, and regulates tumour-associated angiogenesis, tumour cell proliferation, invasion and metastasis [209,210]. Gelatinase B/MMP-9 is considered to be a tuner and amplifier of inflammatory and immune functions [106,238] and is up regulated by pro-inflammatory cytokines such as TNF $\alpha$, IL-1 $\beta$, IL- 6 and TGF $\beta$ in a wide variety of human tumour cells, stromal and endothelial cells [12,13,15]. Gelatinase B/MMP-9 activates pro-inflammatory cytokines TNF $\alpha$ and IL-1 $\beta$, increases the activity of chemokines CXCL1, CXCL4, CXCL7 and CXCL8, releases TGF $\beta$ from matrix stores, is released by activated neutrophils in TIMP-1-free form and acts as a nanomolar effector of tumour associated inflammation [12,13]. Neutrophil-derived gelatinase B/MMP-9 also interacts with neutrophil NGAL, which prevent autolytic gelatinase B/MMP-9 processing but does not impair gelatinase B/MMP-9 activity, promoting tumour progression [130,161]. CXCL8 interaction with the chemokine receptor CXCR2 induces gelatinase B/MMP-9 release from neutrophils [239], and activation of the chemokine receptor CXCR4 up-regulates gelatinase B/MMP-9 expression in prostate tumour cells, promoting invasion and metastasis [240]. Furthermore, myeloperoxidase $/ \mathrm{H}_{2} \mathrm{O}_{2} / \mathrm{HOCl}$ system activation in neutrophils activates gelatinase B/MMP-9 and inhibits TIMP activity [184,185]. Gelatinase B/MMP-9, therefore, exhibits an integral relationship with tumour-associated inflammation. Indeed, the inhibition of gelatinase B/MMP-9 expression by inhibitors of pro-inflammatory cyclooxygenase-2 reduces tumour cell 
proliferation, invasion and metastasis [241,242]. In addition to its relationship with neutrophils, gelatinase B/MMP-9 also promotes macrophage and tumour cell invasion by cleaving the TGF- $\beta$-induced protein $\beta i g-h 3$, releasing it from the extracellular matrix, whereas non-degraded $\beta$ ig-h3 inhibits cell migration by promoting cell-cell contact and cell-extracellular matrix interactions [243].

In contrast to its tumour-promoting effects, high-level gelatinase B/MMP-9 expression has also been reported to promote tumour regression in a breast cancer model, augmenting neutrophil infiltration and promoting tumour-associated macrophage anti-tumour activity [244].

\section{Gelatinase B/MMP-9 and Angiogenesis}

The formation of new blood vessels is a highly orchestrated process that depends upon mitogenic and non-mitogenic angiogenic factors and involves matrix remodelling, cell migration, and regulated adhesive interactions between vascular cells and with the matrix. Tumour neovascularisation is fundamental for primary tumour expansion, metastatic progression and metastatic growth, and occurs via processes including sprouting angiogenesis, vasculogenesis, co-option inter-susception and/or vascular mimicry. Unlike normal vessels, blood vessels within tumours are abnormal, immature and inflammatory in nature [245].

Gelatinase B/MMP-9 is a critical pro-angiogenic molecule [246] and triggers the "angiogenic switch" in the quiescent vasculature [247,248] (Figure 4). Both host inflammatory and vascular gelatinase B/MMP-9 has been shown to be crucial for the development of the tumour angiogenic vasculature in models of pancreatic, ovarian and skin cancer [170,211,249]. Neutrophil gelatinase B/MMP-9 regulates pericyte proliferation, apoptosis and recruitment during angiogenesis [170] and mobilises the recruitment of bone marrow-derived angiogenic precursors to the tumour stroma enhancing the tumour angiogenic and vasculargenic process [90,250-252]. Gelatinase B/MMP-9 also triggers "the angiogenic switch" by mobilising and activating angiogenic mitogens from matrix stores at the onset of tumour-associated angiogenesis [169,211,251,253]. This process is facilitated by the release of TIMP-1-free gelatinase B/MMP-9 from neutrophils, which acts as an exceptionally potent nanomolar angiogenic factor, releasing both FGF and VEGF from matrices [169,254].

The gelatinase B/MMP-9/VEGF axis not only supports angiogenesis but also promotes hyperactive haematopoiesis, [255,256], which also promotes tumour progression by expanding myeloid-derived suppressors that suppress T-lymphocyte proliferation and activation, promoting tumour evasion of immune surveillance [257-259]. Mouse gelatinase B/MMP-9 has been shown to cleave VEGF to a truncated $\mathrm{VEGF}_{121}$ form that promotes irregular neovascularisation by altering interactions with heparan sulphate and other matrix components [118]. This, however, does not appear to extend to human gelatinase B/MMP-9 [80].

In addition to promoting pericyte recruitment, gelatinase B/MMP-9 also promotes the recruitment of pro-angiogenic monocytes and $\mathrm{CD}_{3} 4^{+}$endothelial cell progenitors, which express VE-cadherin and VEGFR2, to tumours, markedly influencing angiogenesis [252,260-263] and induces the release of circulating endothelial precursor stem cells from the bone marrow by degrading c-kit ligand, contributing to both angiogenesis and vasculogenesis [90]. In human neuroblastoma, gelatinase B/MMP-9 recruits bone marrow-derived leukocytes and support cells to tumour vessels, regulating vessel maturation [264] and the VEGF/gelatinase B/MMP-9 axis has been implicated in the 
robust angiogenic response associated with TrkAIII oncogene promotion of neuroblastoma tumorigenicity [265]. In gelatinase B/MMP-9 knockout mice, impaired vascularisation associates with reduced pericyte-recruitment [266] and vascular pericytes have been shown to express gelatinase B/MMP-9 in human breast tumours [267]. In general, knockout technology has implicated MMP9

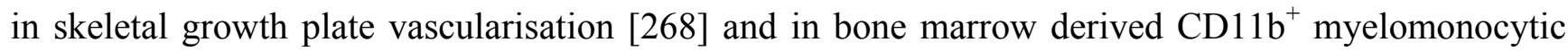
cell-mediated vasculogenesis in irradiated tumour tissues, with the absence of gelatinase B/MMP-9 associated with small tumours containing mature vessels [269]. Gelatinase B/MMP-9 has also been implicated in capillary branching during ischemia-induced revascularisation [270].

Figure 4. Representation of the roles played by inflammatory polymorphonuclear leukocyte (PMN)-derived tissue inhibitor of metalloproteinase (TIMP)-free gelatinase B/MMP-9, gelatinase B/MMP-9 of stromal and tumour origin, oncogenes and hypoxia in activating the tumour angiogenic switch required for tumour progression.

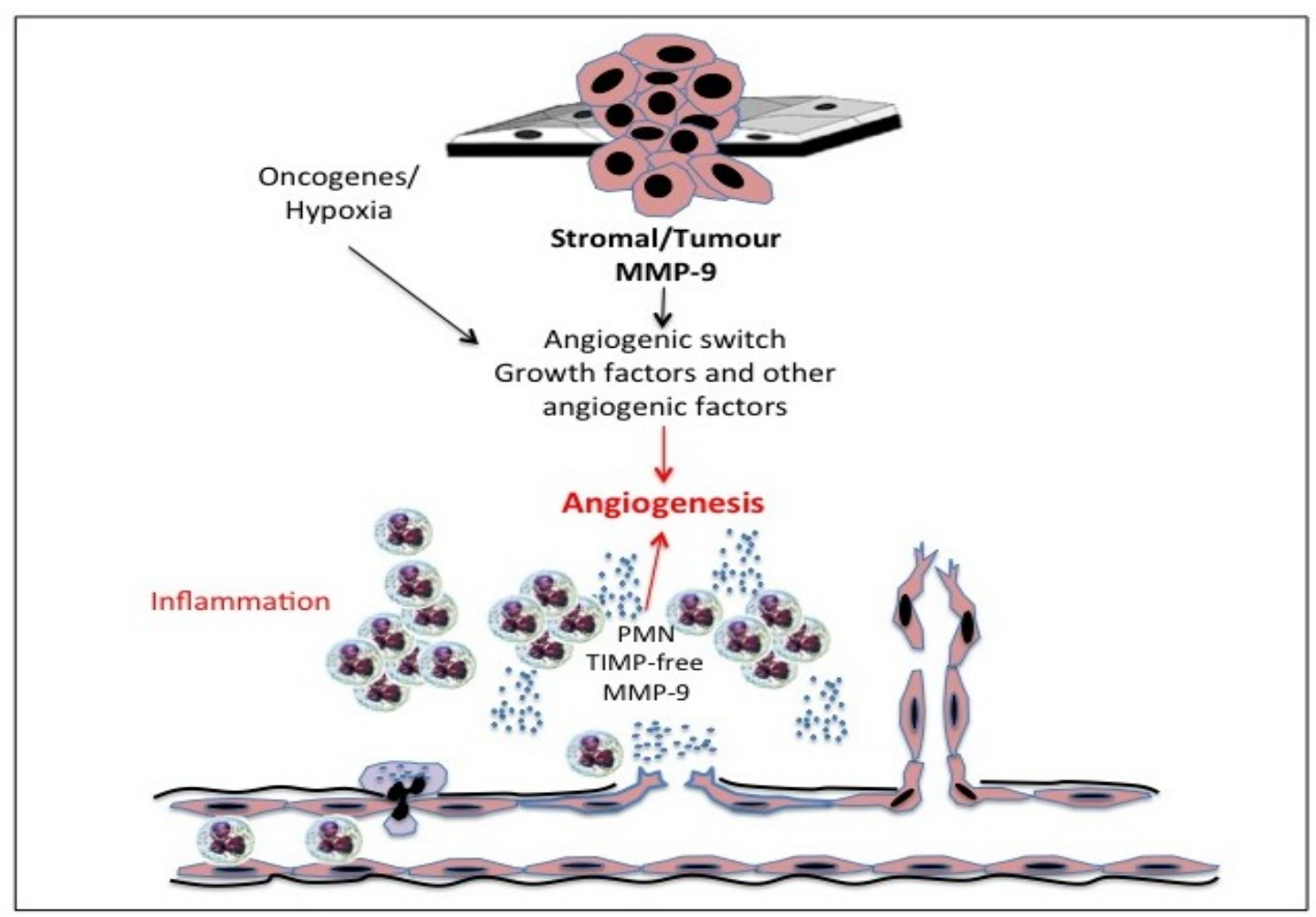

Although, bone marrow-cell derived gelatinase B/MMP-9 appears to be sufficient for tumour vasculogenesis, it is not essential and can be substituted by gelatinase B/MMP-9 from either stromal, smooth muscle or tumour cell components. Indeed, fibroblast gelatinase B/MMP-9 enhances endothelial cell survival and function [271], gelatinase B/MMP-9 from circulating macrophages promotes angiogenesis in a model of pancreatic cancer [272] and increased tumour cell gelatinase B/MMP-9 promotes angiogenesis in a model of neuroblastoma [265].

Tumour-associated hypoxia is a major stimulus for angiogenesis and hypoxia exhibits an overall tendency to increase vascular gelatinase B/MMP-9 expression [273,274]. Neovascularization induced by hypoxia involves Nox2-derived ROS-mediated gelatinase B/MMP-9 activation [275] and under conditions of hypoxia gelatinase B/MMP-9 modulates endothelial cell behaviour, promoting human microvascular endothelial cell invasive and angiogenic capacity [276]. Inflammatory cytokines TNF $\alpha$, 
IL-17 and IL-18 promote gelatinase B/MMP-9 regulated migration of pericyte and vascular smooth muscle cell migration during angiogenesis [277-280] and gelatinase B/MMP-9 knockout impairs both pericyte and vascular smooth muscle cell migration, decreasing intimal vascular hyperplasia $[281,282]$. Furthermore, in addition to mobilising bone marrow $\mathrm{CD}_{3} 4^{+}$stem cells, gelatinase B/MMP-9 also promotes endothelial cell progenitor proliferation [262,263], degrades basement membrane type IV collagen, exposing cryptic $\alpha \mathrm{V} \beta 3$ integrin binding sites that promote angiogenesis [283] and releases VEGF from matrices in angiogenic islets, promoting angiogenesis [211,251].

In contrast to autocrine angiogenesis stimulating effects of gelatinase B/MMP-9 [212], gelatinase B/MMP-9 also exhibits capacity to negatively regulate angiogenesis by producing endogenous anti-angiogenic factors such as endostatin, tumstatin and angiostatin [72,112,284,285]. Endostatin, formed by gelatinase B/MMP-9 digestion of the type XVIII collagen $\alpha 1$ chain [72], blocks VEGFR2 and $\alpha 5 \beta 1$-mediated angiogenesis, inhibits gelatinase B/MMP-9 activity [286-289] and reduces metastasis in patients with high-grade transitional cell carcinoma of the bladder [290]. Tumstatin, formed by gelatinase B/MMP-9 digestion of the collagen IV $\alpha 3$ chain, inhibits endothelial cells proliferation and promotes $\alpha \mathrm{V} \beta 3$-mediated endothelial cell apoptosis [235,239]. Angiostatin, formed by gelatinase B/MMP-9 digestion of plasminogen and plasmin [112,113], acts as a competitive inhibitor of tissue-type plasminogen activator and single chain urokinase-mediated plasminogen activation, inhibits plasmin-mediated laminin degradation, impairs plasminogen association with the tumour cell surface, and inhibits plasmin-dependent tumour invasion and angiogenesis [113,285]. The gelatinase B/MMP-9 hemopexin domain, which can be generated by plasmin-mediated degradation of cryptic sites within the gelatinase B/MMP-9 catalytic domain, also inhibits gelatinase B/MMP-9 activity and angiogenesis [41,163,291].

Other interactions involving gelatinase B/MMP-9 that regulate angiogenesis include: thrombospondin-1 induction of gelatinase B/MMP-9 expression but inhibition of gelatinase B/MMP-9 activation [292], and gelatinase B/MMP-9 interaction with syndecan-1, which promotes syndecan-1 shedding and enhances medulloblastoma cells tube forming capacity. This involves an gelatinase B/MMP-9/syndecan-1/miR-494 regulatory loop, involved in regulating irradiation-induced angiogenesis, in which syndecan and gelatinase B/MMP-9 activity negatively feedback to regulate miR494 expression, which promotes angiogenesis [293]. Interaction between angiogenic endothelial cells and prostate cancer cells has also been reported to activate an IL-6/androgen receptor/TGF $\beta /$ gelatinase B/MMP-9 signal pathway that augments prostate cancer invasion in association with angiogenesis [294].

Angiogenic factors stimulate and/or associate with gelatinase B/MMP-9 expression. Ang2 expression correlates with that of gelatinase B/MMP-9 [295]. VEGF induces gelatinase B/MMP-9 expression in vascular cells and some malignant tumour cell types [296-298]. Hypoxia induces VEGF-A expression resulting in the recruitment of pro-angiogenic neutrophils that deliver the gelatinase B/MMP-9 and trigger the "angiogenic switch" [299]. Angiogenic fibroblast growth factors induce gelatinase B/MMP-9 expression in tumour and stromal tissues [153,300,301], and agents that inhibit MMP9 expression and/or gelatinase B/MMP-9 activity, such as DMBT [302], propofol [303], secreted protein acidic and rich in cysteine (SPARC) [304], S100A4 [305], xylitol [306], wortmanin [235], BMP4 [307], and aloe emodin [308], down regulate angiogenesis in different models.

Vasculargenic mimicry by tumour cells has been equated to tumour-associated angiogenesis [309]. Gelatinase B/MMP-9 has been also implicated in the vasculargenic mimicry exhibited by 
Adriamycin-resistant MCF-7 breast cancer cells, promoting tubular network formation through a VEGF receptors VEGFR-2 and VEGFR-3-mediated mechanism, implicating gelatinase B/MMP-9 in tumour-associated vascular mimicry [310].

\section{Gelatinase B/MMP-9 and Lymphangiogenesis}

Lymphagiogenesis is also an important component of tumour progression, with lymphatic vessels providing important routes for metastatic dissemination [311,312]. Although gelatinase B/MMP-9 is not required for normal skin lymphangiogenesis [313], tumour induced lymphangiogenesis has been reported to involve a sonic hedgehog/PI3K/Akt/gelatinase B/MMP-9 pathway, leading to lymph node metastases in gastric cancer [237]. Furthermore, neutrophil-derived gelatinase B/MMP-9 has been implicated in inflammation-associated lymphangiogenesis, promoting VEGF-A bioavailability and bioactivity [314] and, together with VEGF-C, has been implicated in lymphangiogenesis and lymph node metastasis in breast cancer [315].

\section{Gelatinase B/MMP-9 and Disruption of Tissue Architecture}

The loss of tissue architecture is one of the earliest hallmarks of premalignant epithelial cancer and results in tumour proliferation, local invasion and angiogenesis [316]. In malignant breast cancer, tumour cells loose their capacity to form ordered structures and proliferate as disorganised colonies [317]. Raf/MEK/ERK-mediated induction of gelatinase B/MMP-9 expression results in the destruction of breast tissue architecture, during breast cancer initiation, by degrading basement membrane laminin and destroying basement membrane integrity. This results in de-regulated tissue polarity and the loss of growth control (Figure 4). Gelatinase B/MMP-9 inhibition halts this process by preserving basement membrane integrity, which in turn reverses phenotype, arrests growth and re-establishes a differentiated acinar polarity [60].

\section{Gelatinase B/MMP-9 Induction of Intracellular Signalling}

Gelatinase B/MMP-9 interacts with the cellular surface through either Ku70/80 [196], CD44 [48,318] or via integrins [318]. Gelatinase B/MMP-9 interacts with $\alpha \mathrm{L}, \beta 5, \alpha 4$ and $\beta 1$ subunits through its catalytic site and interacts with $\mathrm{CD} 44, \alpha 4, \beta 5$ and $\beta 1$ subunits through the hemopexin domain [319,320]. These interactions stimulate migration, promote survival, increase both proteolytic and non-proteolytic invasion [318,320-322] and promote angiogenesis [169]. Signalling events in these interactions include, JNK involvement in gelatinase B/MMP-9-mediated dendritic cell migration, which is blocked by the JNK inhibitor SP600125 [323], and MAPK and IP3K involvement in gelatinase B/MMP-9-induced endothelial cell migration, which is blocked by the MAPK inhibitor PD98059 and by the IP3K inhibitor LY294002. Apoptosis in medulloblastoma, associated with loss of gelatinase B/MMP-9 expression, involves $\beta 1$ integrin, ERK signalling and NF- $\kappa \mathrm{B}$ activation $[324,325]$. Gelatinase B/MMP-9 interaction with $\alpha 4 \beta 1$ and CD44 induces survival signalling in CLL cells, activating lyn kinase, phosphorylating STAT and up-regulating Mcl-1 expression [322]. Interaction between gelatinase B/MMP-9 and CD44 results in EGF receptor activation and signalling through 
ERK, Akt and FAK, which promotes tumour cell invasion and migration [326], with FAK coordinating adhesion, polarisation, migration, invasion, survival and death [327].

\section{Gelatinase B/MMP-9, Tumour Cell Invasion and Motility}

Within the tumour context, gelatinase B/MMP-9 was originally identified as a novel type IV collagenolytic protease secreted by metastatic Ras transformed fibroblasts and implicated in basement membrane disruption required for tumour invasion and metastasis [6,7]. Although it remains debatable as to whether gelatinase B/MMP-9 alone can effectively degrade type IV collagen within the context of an insoluble basement membrane matrix, gelatinase B/MMP-9 promotes invasion by disrupting basement membrane structure by degrading basement membrane laminin and type IV collagen, in concert with other enzyme systems $[8,57,59,60]$. Interaction between tumour cells and stroma at the invasive edge regulates gelatinase B/MMP-9 expression, which combined with gelatinase B/MMP-9 released by tumour-associated neutrophils and macrophages, increases invasiveness [175,328-330] (Figure 5).

Figure 5. Representation of the roles played by inflammatory polymorphonuclear leukocyte (PMN)-derived tissue inhibitor of metalloproteinase (TIMP)-free gelatinase B/MMP-9, gelatinase B/MMP-9 of stromal and tumour origin, in the loss of tissue architecture and local invasion associated with tumour progression.

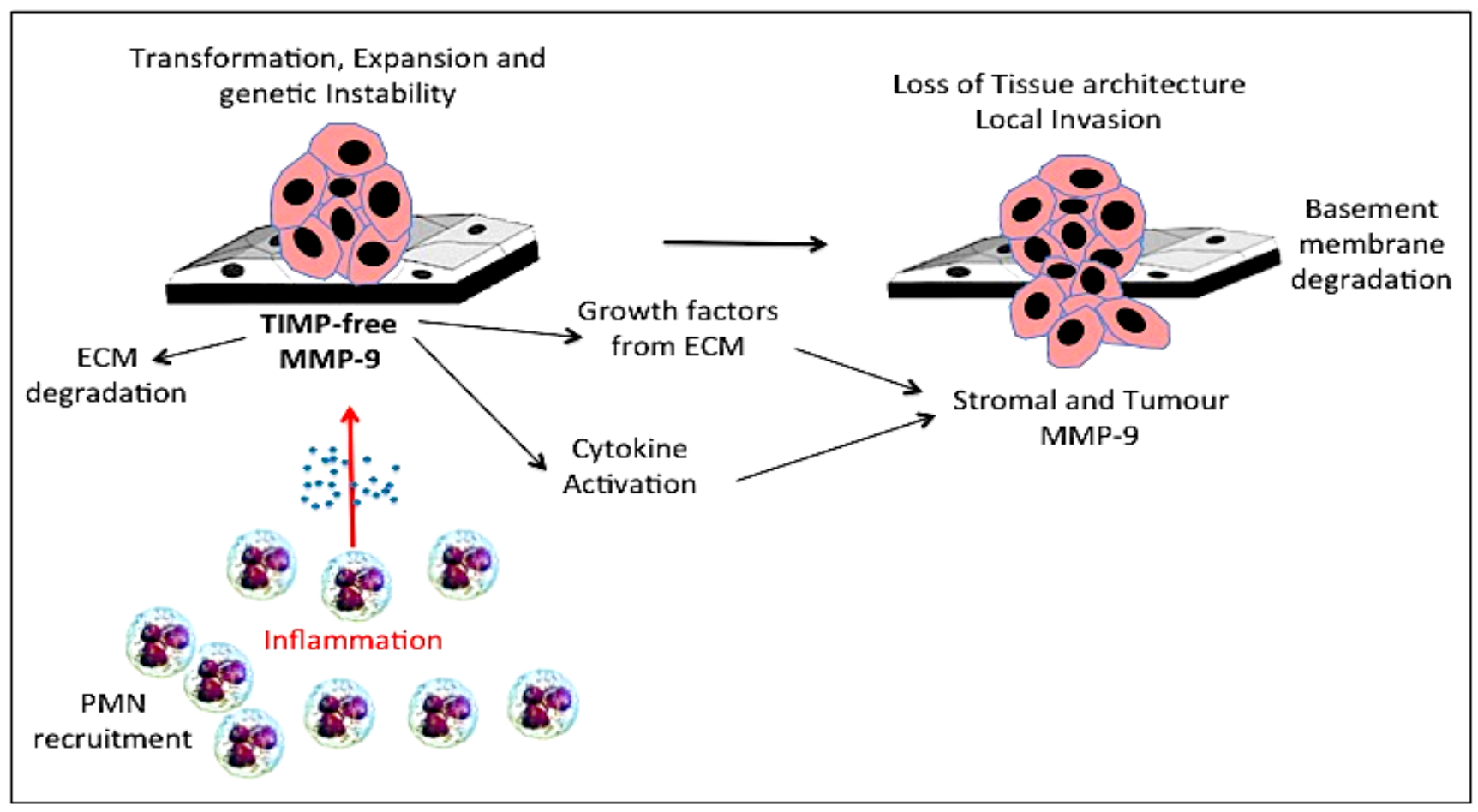

Tumor cell invasion is, however, a complex process that depends upon alterations in protein expression, interaction between tumour, inflammatory and stromal cells, altered intercellular and extracellular adhesive interactions, and changes in the tumour microenvironment. It is regulated by pro-inflammatory cytokines, chemokines, growth factors, matrix components, integrin and non-integrin receptors, proteases and inhibitors, and depends upon the cellular motile response. Cellular motility is 
achieved by different mechanisms and can reversibly switch between mesenchymal and amoeboid migration, which promote invasion as either single cells or collective chains, sheets, columns, tubes or clusters [331].

Protease involvement in migration and invasion is relatively restricted to mesenchymal motility, whereas amoeboid motility does not require proteolytic activity but involves a high level of cellular deformability, low affinity substrate binding and cycles of morphological contraction and expansion [331,332]. Mesenchymal migration, on the other hand, requires high affinity binding to integrin and non-integrin receptors. During mesenchymal migration, integrin or non-integrin receptors concentrate to membrane lamellipodia, filopodia, pseudopodia and invadopodia, promoting adapter protein-mediated intracellular interaction with the actin cytoskeleton. This results in the formation of focal contacts and adhesions with extracellular matrix components, the maturation of which activates intracellular focal adhesion kinases (FAKs) that form transient signalling complexes with Src kinases, promoting movement by inducing the turnover of focal contact providing the propulsive force for movement by continually modifying of cell-matrix interactions. These events depend upon proteolytic activity and involve the fibronectin integrin receptors $\alpha 5 \beta 1$ or $\alpha \mathrm{V} \beta 6$, the laminin integrin receptors $\alpha 6 \beta 1$ or $\alpha 6 \beta 4$, the fibronectin/vitronectin integrin receptor $\alpha \mathrm{V} \beta 3$ and the fibrillar collagen receptor $\alpha 2 \beta 1[331]$.

Gelatinase B/MMP-9 regulates mesenchymal migration, co-localises with integrins at lamellipodia on migrating cells [333] and co-operates with $\alpha \mathrm{V} \beta 3$ integrin to increase breast cancer cell migration and metastatic capacity [334]. FAK-Src signalling through JNK transcriptionally upregulates gelatinase B/MMP-9 expression, promoting gelatinase B/MMP-9-mediated invasion [335-337], and $\alpha \mathrm{V} \beta 6$ or $\alpha 5 \beta 1$ interaction with fibronectin also increases gelatinase B/MMP-9 expression, and gelatinase B/MMP-9-mediated migration and invasion of squamous cell carcinoma and melanoma cells [338-340]. Fibronectin also induces gelatinase B/MMP-9 expression in ovarian cancer cells through FAK and ras activation [335] and laminin has been shown to up-regulate gelatinase B/MMP-9 expression in macrophages and in A2058 melanoma cells but not in other malignant tumour cells [341,342]. Gelatinase B/MMP-9 promotes chain migration of neural crest cells [343] and collective migration of epithelial cancer cells, in association with EMT [344].

Gelatinase B/MMP-9 also interacts with the non-integrin receptor CD44, concentrating gelatinase B/MMP-9 to cell extensions, which control the turnover of adhesive interactions and extracellular matrix degradation required for motility, in a coordinated process that also involves ezrin, actin and Krp1 [336]. Gelatinase B/MMP-9 interaction with CD44 also promotes breast cancer cell migration and invasion in association with EGFR activation [48]. An $N$-cadherin/FGFR/gelatinase B/MMP-9 axis has been implicated in breast cancer cell invasion and metastasis, bypassing E-cadherin invasion and metastasis suppressing signals [155]. Gelatinase B/MMP-9 degradation of protease nexin-1 has also been implicated in a novel pathway through which gelatinase B/MMP-9 regulates tumour cell invasion, impairing the capacity of nexin to bind and down-regulate the activity of uPA [345].

In contrast to these reports, gelatinase B/MMP-9 has also been shown to degrade the $\beta 4$ component of $\alpha 6 \beta 4$ integrin, de-regulating sheet migration of epithelial cells [346]. Furthermore, gelatinase B/MMP-9 interaction with $\alpha 4 \beta 1$ integrin and CD44 on the surface of chronic leukemic cells has been shown to inhibit migration in response to chemotactic gradients [318]. Tumour cells, furthermore, can undergo mesenchymal to amoeboid transition (MAT). Gelatinase B/MMP-9 is not required for 
amoeboid movement through 3D interstitial matrices [332] and MAT has been shown to increase metastatic capacity in association with reduced gelatinase B/MMP-9 expression [347].

\section{Gelatinase B/MMP-9 and Primary Tumour Cell Escape}

In order to escape the constraints of the primary tumour, tumor cells invade, move and alter their adhesive interactions. Chemotactic motile responses may direct tumour cells to lymphatic or blood vessels and tumour interaction, with tumour associated macrophages facilitating directional movement within tumours [348]. HGF activation of tumour cell c-met induces gelatinase B/MMP-9 expression, increasing tumor cell motility and scattering [349].

\section{Gelatinase B/MMP-9 and Immunological Surveillance}

The capacity to evade elimination by immunological/inflammatory mechanisms is an essential feature of tumour progression to metastasis. Gelatinase B/MMP-9 is an important regulator of both innate and tumour immune responses [12]. This is illustrated in gelatinase B/MMP-9 knockout mice, which do not resolve contact hypersensitivity reactions, implicating gelatinase B/MMP-9 in the down regulation of the immune response [350], suggesting an analogous role for gelatinase B/MMP-9 in cancer. In support of this, gelatinase B/MMP-9 expression associates with that of anti-pathogen immune-response-related genes in late stage compared to early stage lung tumours, although it remains to be determined whether any of these represent novel gelatinase B/MMP-9 substrates [351]. Gelatinase B/MMP-9 degrades ICAM-1, down-regulating leukocyte homing [80] and promotes evasion of the immune system by chronic myeloid leukemia cells by solubilizing cell membrane ICAM-1 [352]. Gelatinase B/MMP-9 degrades the IL-2 receptor $\alpha$, repressing activation and proliferation of tumour infiltrating T-lymphocytes in cervical cancer $[85,86]$. Gelatinase B/MMP-9 degrades Surfactant protein D (SP-D), an important component of innate immune defence, leading to loss of innate immune function, limiting SP-D involvement in tumour immunology and renders oncology patients more susceptible to infection [353]. Gelatinase B/MMP-9 digests C1q complement component at a site required for interaction with the $\mathrm{C}_{1 \mathrm{qR}} \mathrm{R}_{02}$ receptor, repressing $\mathrm{C} 1 \mathrm{q} / \mathrm{C} 1 \mathrm{qR}_{02}$ involvement in tumour immunology [109] and may also degrade complement component C1r [65]. C5a induces the expression of the gelatinase B/MMP-9 stimulator IL-1 $\beta$ in monocytes $[15,354]$ and the complement membrane attack complex induces gelatinase B/MMP-9 expression in cells protected against MAC-mediated lysis by CD59 [355], suggesting that activation of the complement system may promote tumour-associated gelatinase B/MMP-9 expression. Gelatinase B/MMP-9 also degrades the $\beta 2$ subunit of macrophage CD18 integrin receptor, important for macrophage recruitment [91].

A role for gelatinase B/MMP-9 has also been reported in the development of tumour tolerance. This has been attributed to gelatinase B/MMP-9 induction of tolerogenic dendritic cells (tDC), through the release and activation of TGF $\beta$, which increases the number of regulatory $\mathrm{T}$ (Treg) lymphocytes that promote tumour tolerance by suppressing CD8+ cytotoxic T cells [356-358]. In support of this, inhibition of gelatinase B/MMP-9 expression blocks tDC development and increases tDC and Treg numbers in cancer tissues [356,358-361]. Furthermore, the VEGF/gelatinase B/MMP-9 axis promotes hyperactive haematopoiesis, expanding myeloid-derived suppressors of T-lymphocyte proliferation 
and activation, which results in the repression tumour immune surveillance, which promotes tumour progression [255-259].

\section{Gelatinase B/MMP-9 Haematogenous and Lymphatic Metastatic Dispersal}

Tumour cell intravasation represents an important mechanism for haematogenous metastatic dissemination. The breaching of the vascular wall is considered to represent a rate limiting step for intravasation and consequently for haematogenous metastasis [311].

Gelatinase B/MMP-9 has been implicated in intravasation and subsequent metastasis formation [362] (Figure 6), with a particular role for inflammatory neutrophil-derived gelatinase B/MMP-9 highlighted in the promotion of haematogenous tumour cell dispersion of HT1080 fibrosarcoma and PC3 prostate carcinoma cells in xenograft models [12]. Neutrophil-derived gelatinase B/MMP-9 involvement in tumour-associated intravasation requires neutrophil attraction to the activated endothelial cell surface, neutrophil activation and release of TIMP-1-free gelatinase B/MMP-9. Activation of TIMP-1 free gelatinase B/MMP-9 releases angiogenic factors stored within the extracellular matrix, which promote endothelial sprouting and new vessel formation, and gelatinase B/MMP-9-assisted tumour cell intravasation and dissemination [363]. In support of this, gelatinase B/MMP-9 expression correlates with the intravasation and metastatic dissemination of HT-1080 fibrosarcoma cells, which is inhibited by the gelatinase B/MMP-9 inhibitor marimistat [362]. Furthermore, keratinocyte growth factor induces gelatinase B/MMP-9 expression and venous invasion by pancreatic cancer cells [364].

Figure 6. Representation of the roles played by inflammatory polymorphonuclear leukocyte (PMN)-derived tissue inhibitor of metalloproteinase (TIMP)-free gelatinase B/MMP-9, and gelatinase B/MMP-9 of stromal and tumour origin, in epithelial-mesenchymal transition (EMT) and subsequent integrin and non-integrin mediated mesenchymal motility and invasion and immature tumour blood vessels.

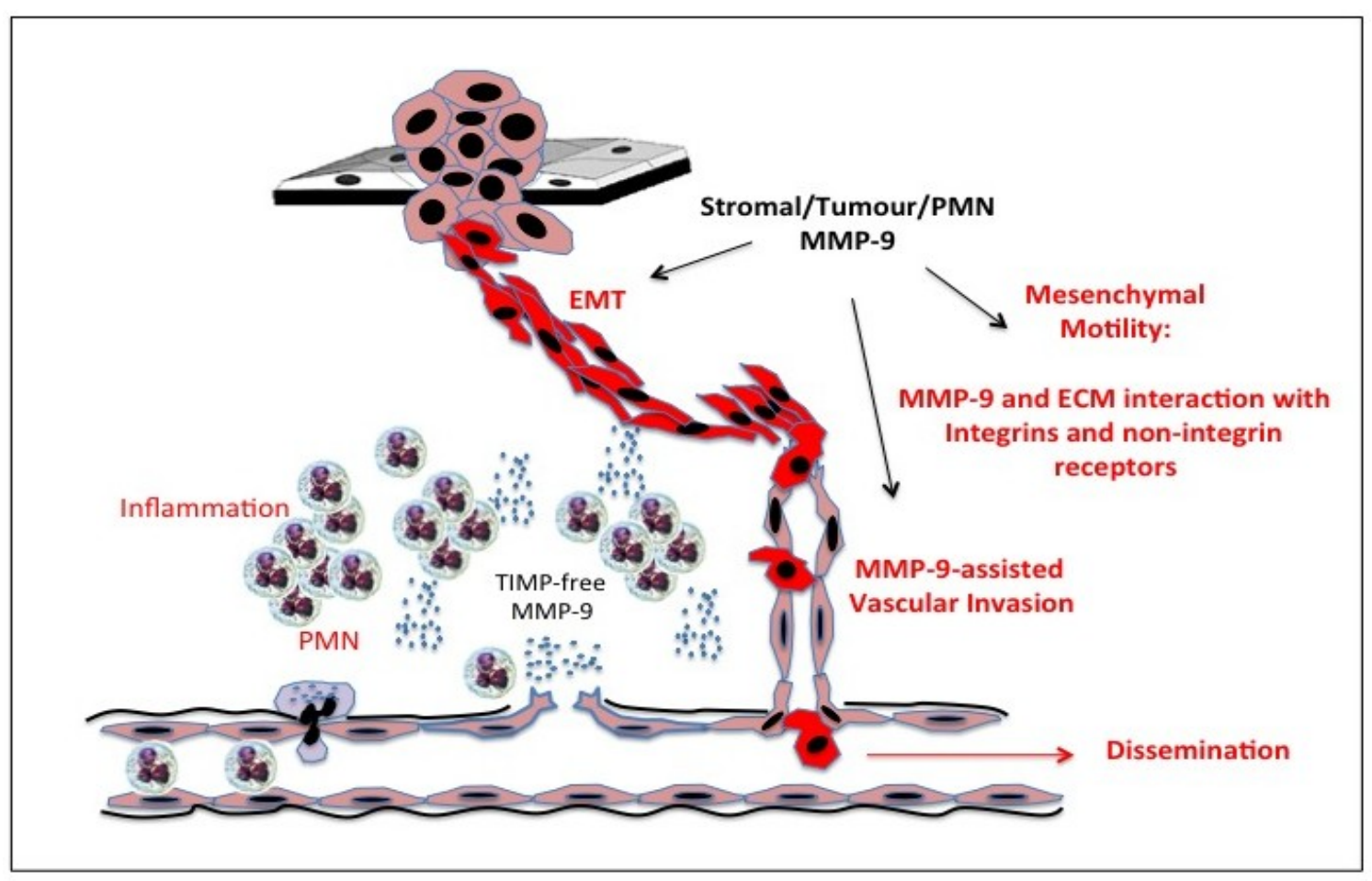


Gelatinase B/MMP-9 has also been implicated in lymphatic dissemination of colon cancer to lymph nodes. This mechanism involves gelatinase B/MMP-9 and the chemokine receptor CCR7. C-C chemokine interaction with CCR7 promotes gelatinase B/MMP-9 expression and lymphatic dissemination of colon cancer, whereas CCR7 knockdown reduces gelatinase B/MMP-9 expression lymphatic dissemination and lymph node metastases, implicating the CCR7/gelatinase B/MMP-9 axis in lymphatic metastatic dissemination of colon cancer [365]. In gastric cancer, lymphatic dissemination and lymph-node metastasis associate with increased expression of both Twist and gelatinase B/MMP-9 [233].

\section{Gelatinase B/MMP-9 and Extravasation}

After tumour cells that arrest in the microvasculature of distant organs they either extravasate or grow within vessels [366,367], adding to the debate as to whether extravasation is indeed a critical step in the metastatic process [368,369]. Due to the positive contribution made by inflammatory cells to the metastatic process, inflammatory cell-derived gelatinase B/MMP-9 may promote extravasation, as may tumour cell derived gelatinase B/MMP-9. Alternatively, endothelial cell clusters within metastatic sites may be primed to produce gelatinase B/MMP-9 by circulating VEGF through VEGF receptors [296], which may facilitate tumour cell extravasation across an already compromised vascular BM.

\section{Gelatinase B/MMP-9 and the Metastatic Niche}

Gelatinase B/MMP-9 appears to be one of the genes required for tumor metastasis $[6,9,10,12,369]$. Organ specific metastatic tropism characterises the metastatic process and is a complex process that involves interaction between infiltrating cancer cells and the local environment [220]. Within the bone marrow, gelatinase B/MMP-9 regulates the recruitment and mobilization of hematopoietic stem and progenitor cells from the quiescent bone marrow niche to the proliferative niche, suggesting that gelatinase B/MMP-9 may play a similar role in cancer stem behaviour within the bone environment. In this process, gelatinase B/MMP-9 activated within the bone marrow, degrades anchorage proteins enabling haematopoietic stem cell (HSC) migration from the osteoblastic to the vascular niche, which promotes their proliferation [90]. This involves gelatinase B/MMP-9 degradation of soluble kit-ligand mobilizing factor from its membrane-associated moiety and also degradation of osteopontin, which together induce stem cell cycling and reduces anchorage to the osteoblastic niche [370]. Furthermore, osteoclasts activated within bone enhance gelatinase B/MMP-9 proteolytic activity, inducing further degradation of the endosteal-niche components osteopontin and membrane bound-stem cell factor [371]. Since cancer stem and normal stem cells share molecular machinery and cancer stem cells hijack physiological stem cell trafficking mechanisms [218], gelatinase B/MMP-9 is likely to play a similar role in stimulating the proliferation cancer stem cells that locate to the bone metastatic niche.

Within non-bone metastatic niches, increased circulating levels of gelatinase B/MMP-9 have been shown to enhance the frequency of colon cancer metastasis to lung in a mouse model. This also associates with reduced size of metastases resulting from reduced tumour vascularisation associated with increased circulating angiostatin levels [372]. Furthermore, distant primary tumours have been shown to induce gelatinase B/MMP-9 in pre-metastatic lung endothelial cell clusters via VEGF receptor-1 signalling, pre-conditioning lungs to metastatic growth, indicating that distant tumours can aggressively 
determine specific metastatic sites by activating endothelial cells at secondary sites [296,373], in a process involving gelatinase B/MMP-9 expressed by endothelial cells and tumor-associated macrophages that fertilizes the soil necessary for metastatic growth [374]. Many metastatic tumours also release membrane vesicles that gain access to the circulation. Micro-vesicles shed by renal cancer stem cells contain pro-angiogenic factors, including gelatinase B/MMP-9, and promote the formation of a pre-metastatic niche, which is associated with unfavourable outcome [375]. Circulating hematopoietic CD45 and Colla positive fibrocytes have also been shown to predispose the lung to B16/F10 metastases by recruiting Ly-6C (+) monocytes, in a chemokine and gelatinase B/MMP-9-dependent manner [376]. Furthermore, stromal derived factor (SDF)-1 interaction with the chemokine receptor CXCR4, which is essential for normal stem/progenitor cell function, promotes carcinogenesis, metastasis [377] and trans-endothelial migration of cancer cells by stimulating gelatinase B/MMP-9 secretion, disrupting basement membrane and inducing vascular permeability, promoting tumour cell extravasation. This mechanism promotes cancer stem cell homing to specific metastatic niches and in particular to the bone metastatic niche [222,378].

\section{Gelatinase B/MMP-9, Apoptosis, Survival and the Mitochondria}

Gelatinase B/MMP-9 regulates cellular survival and apoptosis [195,379]. Pro apoptotic effects have been described for gelatinase B/MMP-9 in the presence of proneurotrophins [380], in cerebellar neurons and retinal ganglion apoptosis [381,382], in hypertrophic growth plate chondrocytes [268] and in HL60 pro-myelocytic leukaemia cells [383]. Pro-survival effects of gelatinase B/MMP-9 have also been described during angiogenesis, through the release and activation of mitogens from matrix stores [211]. Gelatinase B/MMP-9 localises to mitochondria via Hsp70/Hsp60, and can disrupt mitochondrial structure, function and induce mitochondrial mtDNA damage, leading to diabetic retinal capillary cell apoptosis and gelatinase B/MMP-9 inhibition protects mitochondria from ultra-structural, functional and DNA damage [384-386], suggesting that gelatinase B/MMP-9 inhibitors may protect against mitochondrial apoptosis. Within the extracellular environment, gelatinase B/MMP-9 promotes neuronal apoptosis by degrading basement membrane laminin [61]. In contrast, siRNA down regulation of gelatinase B/MMP-9 expression induces apoptosis in human glioblastoma cells in association with Fas death receptor-mediated caspase 3 and caspase 8 cleavage, implicating gelatinase B/MMP-9 in protecting glioblastoma cells against Fas ligand-mediated apoptosis [387]. Methylation of the miR-211 gene up-regulates gelatinase B/MMP-9 expression in glioblastoma stem cells and increases their resistance to radiotherapy and chemotherapy-induced death [18]. The activation of $\alpha 4 \beta 1$ and CD44 bound gelatinase B/MMP-9 induces lyn/STAT/MCL-1 signalling and apoptosis in chronic lymphocytic leukemia cells, that depends upon gelatinase B/MMP-9 hemopexin and $O$-glycosylation domains [318,322] and in human medulloblastoma cells inhibition of gelatinase B/MMP-9 expression promotes apoptosis through $\beta 1$ integrin and ERK activation [325]. In human mammary epithelial cells gelatinase B/MMP-9 expression reduces apoptosis by up regulating cell surface Her2/Neu expression [207].

\section{Lessons from Gelatinase B/MMP-9 Knockout and Transgenics}

Gelatinase B/MMP-9 knockout reduces intestinal adenoma formation and progression within the context of the APC-min mouse model, and has identified an important role for gelatinase B/MMP-9 
released by inflammatory neutrophils in the formation, proliferation and progression of intestinal adenomas in cells, exhibiting compromised APC oncosoppressor function [202]. In contrast, gelatinase B/MMP-9 elimination in Myc/BclXl and RIP1-Tag2 models of pancreatic neuroendocrine carcinogenesis impairs tumour angiogenesis but promotes tumor invasion in association with a shift in inflammatory cell content to cathepsin expressing $\mathrm{CD} 11 \mathrm{~b} / \mathrm{Gr} 1$ positive cells at the invasive front. Plasticity in tumour inflammatory infiltrates, therefore, can alter tumour-associated protease expression to compensate for gelatinase B/MMP-9 loss, helping to explain the MMP inhibitor-induced tumour progression described in human late stage tumor clinical trials [388]. Tumours, unable to grow in gelatinase B/MMP-9 knockout mice, grow readily following auto-transplantiation of normal mouse bone marrow by a mechanism independent of endothelial cell progenitors but involving CD11b positive myelomonocytic cells. In this model gelatinase B/MMP-9 is required for tumor-associated vasculogenesis [269]. Human pancreatic cancer cell growth, impaired in gelatinase B/MMP-9 knockout mice, is promoted by gelatinase B/MMP-9 produced by parabiosed normal stromal cells, implicating stromal gelatinase B/MMP-9 in tumour progression [272]. Gelatinase B/MMP-9 knockout mice also exhibit substantial inhibition of spontaneous metastasis due to impaired triggering of the "angiogenic switch" [389], and in experimental metastasis models, lung metastasis formation by both melanoma and lung carcinoma cells is reduced [390,391]. The inhibition of skin and ovarian cancer metastasis formation in gelatinase B/MMP-9 knockout mice can be reversed by transplantation of normal bone marrow cells, implicating inflammatory cell gelatinase B/MMP-9 in the metastatic process and adding to the role of gelatinase B/MMP-9 in primary tumour initiation, promotion and expansion [170,390].

In contrast to these reports, transgenic $\alpha 1$ integrin mice exhibit increased gelatinase B/MMP-9 expression and produce high level of circulating angiostatin, which reduces primary and metastatic growth of orthotopic cancers, in association with reduced angiogenesis. This identifies an anti-angiogenic, tumour suppressing function for gelatinase B/MMP-9 [392-394].

In mice transgenic for the gelatinase B/MMP-9 inhibitor TIMP-1, paradoxical effects have been described, with high circulating TIMP-1 inhibiting DMBA-induced mammary tumour growth, blocking tumorigenesis at an early stage [395]. In contrast, high circulating TIMP-1 promotes subcutaneous B16 melanoma growth in association with increased angiogenesis, whilst suppressing metastatic lung colonisation [396]. High circulating TIMP-1 levels, furthermore, strongly promote liver fibrosis [397], implicating gelatinase B/MMP-9 in normal liver physiology, adding to its physiological roles in the nervous system, inflammation and immunology [12,13,398].

\section{Gelatinase B/MMP-9 Inhibitors and Future Directions}

More than 50 broad-spectrum MMP inhibitors have been subjected to clinical trials. However, despite impressive results in non-randomized clinical trials, phase II and III clinical trials in patients with a range of different cancers have not been positive, due to a combination of factors that include a lack of understanding of the complexities of MMP involvement in tumour pathogenesis and progression, the lack of inhibitor specificity, drug intolerance and problems with drug dosage [399-401]. This was somewhat expected considering reports that several MMPs, including gelatinase B/MMP-9, display anti-tumor activity [72,112,113,284,285,402,403], different MMPs may be involved in different stages 
of tumour progression and the most potent endogenous gelatinase B/MMP-9 inhibitor, TIMP-1 may promote scattered micro-metastases in the liver [404]. Therefore, the detailed characterisation of exact roles played by the different MMPs within tumour pathogenesis and progression is required, as is the development of highly specific MMP inhibitors.

The impressive quantity of data concerning gelatinase B/MMP-9 involvement in the different phases of tumor progression, reviewed in this article, highlights particularly important roles for inflammatory leukocyte-derived gelatinase B/MMP-9 in tumour initiation and early progression and a more complex involvement of gelatinase B/MMP-9 from inflammatory, stromal and tumour sources in the continued progression of tumours to metastasis. Furthermore, reports also suggest that under certain conditions gelatinase B/MMP-9 may also protect against tumour progression by promoting the formation of systemic inhibitors of angiogenesis, may promote apoptosis and also facilitate anti-tumor inflammatory and immunological reactions (see Sections 11 and 16). Furthermore, it is also evident that under conditions of MMP inhibition malignant tumour cells compensate by undergoing mesenchymal to amoeboid transition, facilitating protease-independent progression [405].

Current gelatinase B/MMP-9 inhibitors can be divided into those that inhibit gelatinase B/MMP-9 expression or catalytic activity. NSAIDs and $\mathrm{HMG}-\mathrm{CoA}$ reductase inhibitors inhibit gelatinase B/MMP-9 transcription [238]. Gelatinase B/MMP-9 inhibitory siRNA inhibits gelatinase B/MMP-9 expression and tumorigenicity in a model of medulloblastoma [325] and miR-491-5p, miR-885-5p and miR-211 inhibit gelatinase B/MMP-9 expression and involvement in models of human glioblastoma [17,18]. Gelatinase B/MMP-9 activity can be blocked by the broad range MMP inhibitors d-penicillamine, hydroxamates, bisphosphonates and tetracyclins, [406]. An active site-specific gelatinase B/MMP-9 inhibitory antibody REGA-3G12 has been reported [407], and bisphosphonates inhibit both gelatinase B/MMP-9 expression and activity $[41,255]$. Zoledronic acid has been shown to inhibit macrophage gelatinase B/MMP-9 and reduces angiogenesis in a model of papillomavirus-induced cervical cancer [255]. Alendronate inhibits gelatinase B/MMP-9 activity and promotes plasmin-mediated destruction of the gelatinase B/MMP-9 catalytic domain, promoting irreversible gelatinase B/MMP-9 inhibition and producing inhibitory gelatinase B/MMP-9 hemopexin fragments, suggesting a novel rational for Alendronate use in pathology dependent upon gelatinase B/MMP-9 activity and plasminogen activation [41].

However, with the exception of REGA-3G12, there are few specific inhibitors of gelatinase B/MMP-9 catalytic activity, attesting to the close similarity exhibited by MMP catalytic sites. A HFDDDE motif of the gelatinase B/MMP-9 catalytic domain interferes with pro-gelatinase B/MMP-9 binding of $\beta 2$ integrin, inhibits OCI-AML3 leukemia cells transmigration across a human endothelial cell layers and inhibits gelatinase B/MMP-9-mediated extracellular matrix degradation, suggesting potential use in therapeutic reduction of acute myeloid leukemia cells extra medullary infiltration [408]. The peptides CTTHWGFTLC and GRENYHGCTTHWGHTLC also inhibit gelatinase B/MMP-9 catalytic activity but not gelatinase B/MMP-9 activation and inhibit primary HSC-3 tongue carcinoma growth but not tumor spread in a mouse model [409].

Recent approaches have also focussed on molecules that interfere with gelatinase B/MMP-9 activity mediated by the hemopexin and/or $\mathrm{O}$ glycosylation domains. Recombinant or isolated gelatinase B/MMP-9 hemopexin domain inhibits gelatinase B/MMP-9 activity [41,163], hampers colorectal cancer cell adhesion and migration [410], inhibits gelatinase B/MMP-9-induced functions in chronic 
lymphocytic Leukemia B cells [411], and inhibits angiogenesis in glioblastoma xenografts [291]. A peptide mimic of integrin beta chain that binds the gelatinase B/MMP-9 hemopexin domain inhibits gelatinase B/MMP-9 binding to $\alpha \mathrm{V} \beta 5$ integrin, prevents progelatinase B/MMP-9 activation, inhibits HT-1080 fibrosarcoma cell invasion in vitro and HSC-3 tongue carcinoma xenograft growth in vivo but does not inhibit gelatinase B/MMP-9 activity [412]. Peptide mimics of the first and fourth blades of the gelatinase B/MMP-9 hemopexin domain block gelatinase B/MMP-9 dimerization and inhibit HT-1080 and MDA-MB-435 tumour cell motility [48]. The compound $N$-[4-(difluoromethoxy) phenyl]-2-[(4-oxo-6-propyl-1H-pyrimidin-2-yl) sulfanyl]-acetamide also binds to the gelatinase B/MMP-9 hemopexin domain, inhibits gelatinase B/MMP-9 homo-dimerization, blocks gelatinase B/MMP-9 mediated migration and reduces xenograft tumorigenicity and metastasis of MDA-MB-435 human breast cancer cells [46]. Deletion of the $O$-glycosylation domain inhibits macromolecular substrate specificity of gelatinase B/MMP-9 [413], suggesting that inhibitors of $O$-glycosylation domain function may also be effective inhibitors of gelatinase B/MMP-9 function. Therefore, molecules that interact, interfere or compete with these two domains hold some promise in the development of specific therapeutic inhibitors of gelatinase B/MMP-9 activity and function. When considering the potential therapeutic use of specific gelatinase B/MMP-9 inhibitors, however, potential anti-tumor activity of gelatinase B/MMP-9 (i.e., production of anti-angiogenic molecules) must be taken into account and attempts made also to limit inhibitor interference with physiological gelatinase B/MMP-9 functions.

\section{Conclusions}

There is no doubt that gelatinase B/MMP-9 plays a fundamental role in tumour biology, ranging from initiation/promotion to angiogenesis, dissemination, immunological surveillance and metastatic growth. Gelatinase B/MMP-9, however, also exhibits anti-tumor activity and plays important physiological functions. It is therefore essential that specific inhibitors of gelatinase B/MMP-9 proteolytic and non-proteolytic functions are developed in order to determine the potential therapeutic efficacy of inhibiting gelatinase B/MMP-9 function in cancer therapy. The difficulty will be to inhibit the tumour promoting functions of gelatinase B/MMP-9, whilst substituting for anti-tumor gelatinase B/MMP-9 effects and minimising the inhibition of physiological gelatinase B/MMP-9 function.

\section{Acknowledgments}

This work was supported by grants from AIRC, Italian Ministry of University Research and the Maugeri Foundation.

\section{Conflicts of Interest}

The authors declare no conflicts of interest. 


\section{References}

1. Sopata, I.; Dancewicz, A.M. Presence of a gelatin-specific proteinase and its latent form in human leukocytes. Biochim. Biophys. Acta 1974, 370, 510-523.

2. Murphy, G.; Bretz, U.; Baggiolini, M.; Reynolds, J.J. The latent collagenase and gelatinase of human polymorphonuclear neutrophil leukocytes. Biochem. J. 1980, 192, 517-525.

3. Dewald, B.; Bretz, U.; Baggiolini, M. Release of gelatinase from a novel secretory compartment of human neutrophils. J. Clin. Investig. 1982, 70, 518-525.

4. Hibbs, M.A.; Hasty, K.A.; Seyer, J.M.; Kang, A.H.; Mainardi, C.L. Biochemical characterisation of the secreted forms of human neutrophil gelatinase. J. Biol. Chem. 1985, 260, 2493-2500.

5. Hibbs, M.A.; Hoidal, J.R.; Kang, A.H. Expression of a metalloproteinase that degrades native type $\mathrm{V}$ collagen and denatured collagens by cultured human alveolar macrophages. J. Clin. Investig. 1987, 80, 1644-1650.

6. Ballin M.; Gomez, D.E.; Sinha, C.C.; Thorgeirsson, U.P. Ras oncogene mediated induction of a $92 \mathrm{kDa}$ metalloproteinase; strong correlation with the malignant phenotype. Biochem. Biophys. Res. Commun. 1988, 154, 832-838.

7. Ballin, M.; Mackay, A.R.; Hartzler, J.L.; Nason, A.; Pelina, M.D.; Thorgeirsson, U.P. Ras levels and metalloproteinase activity in normal versus neoplastic rat mammary tissues. Clin. Exp. Metastasis 1991, 9, 179-189.

8. Mackay, A.R.; Hartzler, J.L.; Pelina, M.D.; Thorgeirsson, U.P. Studies on the ability of 65-kDa and 92-kDa tumor cell gelatinases to degrade type IV collagen. J. Biol. Chem. 1990, 265, 21929-21934.

9. Bernhardt, E.J.; Gruber, S.B.; Muschel, R.J. Direct evidence linking expression of matrix metalloproteinase 9 (92 kDa gelatinase/collagenase) to the metastatic phenotype in transformed rat embryo cells. Proc. Natl. Acad. Sci. USA 1994, 91, 4293-4297.

10. Bernhardt, E.J.; Muschel, R.J.; Hughes, E.N. Mr 92,000 gelatinase release correlates with the metastatic phenotype in transformed rat embryo cells. Cancer Res. 1990, 50, 3872-3877.

11. Wilhelm, S.M.; Collier, I.M.; Marmer, B.L.; Eisen, A.Z.; Grant, G.A.; Goldberg, G.I. SV40-transformed human lung fibroblasts secrete a 92-kDa type IV collagenase, which is identical to that secreted by normal human macrophages. J. Biol. Chem. 1989, 264, 17213-17221.

12. Van den Steen, P.E.; Dubois, B.; Nelissen, I.; Rudd, P.M.; Dwek, R.A.; Opdenakker, G. Biochemistry and Molecular biology of gelatinase B or matrix metalloproteinase-9 (gelatinase B/MMP-9). Crit. Rev. Biochem. Mol. Biol. 2002, 37, 375-536.

13. Vandooren, J.; van den Steen, P.E.; Opdenakker, G. Biochemistry and molecular biology of gelatinase B or matrix metalloproteinase-9 (gelatinase B/MMP-9): The next decade. Crit. Rev. Biochem. Mol. Biol. 2013, 48, 222-272.

14. Hutala, P.; Tuuttila, A.; Chow, L.T.; Lohi, J.; Keski. O.J.; Tryggvason, K. Complete structure of the human gene for 92-kDa type IV collagenase. Divergent regulation of expression of the 92- and 72- kilodalton enzyme genes in HT-180 cells. J. Biol. Chem. 1991, 266, 16485-16490. 
15. Mackay, A.R.; Ballin, M.; Pelina, M.D.; Farina, A.R.; Nason, A.M.; Hartzler, J.L.; Thorgeirsson, U.P. Effect of phorbol ester and cytokines on matrix metalloproteinase expression and tissue inhibitor of metalloproteinase expression in tumor and normal cell lines. Invasion Metastasis 1992, 12, 168-184.

16. Masure, S.; Billiau, A.; van Damme, J.; Opdenakker, G. Human hepatoma cells produce an $85 \mathrm{kDa}$ gelatinase regulated by phorbol 12-myristate 13-acetate. Biochim. Biophys. Acta 1990, 1054, 317-325.

17. Yan, W.; Zhang, W.; Sun, L.; Liu, L.; You, G.; Wang, Y.; Kang, C.; You, Y.; Jiang, T. Identification of gelatinase B/MMP-9 specific microRNA expression profile as potential targets of anti-invasion therapy in glioblastoma multiforme. Brain Res. 2011, 1411, 108-115.

18. Asuthkar, S.; Velpula, K.K.; Chetty, C.; Gorantla, B.; Rao, J.S. Epigenetic regulation of miRNA-211 by gelatinase B/MMP-9 governs glioma cell apoptosis, chemosensitivity and radiosensitivity. Oncotarget 2012, 3, 1439-1454.

19. Zhang, B.; Ye, S.; Herrmann, S.M.; Eriksson, P.; de Maat, M.; Evans, A.; Arveiler, D.; Luc, G.; Cambien, F.; Hamsten, A.; et al. Functional polymorphism in the regulatory region of gelatinase B gene in relation to severity of coronary atherosclerosis. Circulation 1999, 99, 1788-1794.

20. Matsumura, S.; Oue, N.; Nakayama, H.; Kitadai, Y.; Yoshida, K.; Yamaguchi, Y.; Imai, K.; Nakachi, K.; Matsusaki, K.; Chayama, K.; et al. A single nucleotide polymorphism in the gelatinase B/MMP-9 promoter affects tumor progression and invasive phenotype of gastric cancer. J. Cancer Res. Clin. Oncol. 2005, 131, 19-25.

21. Tu, H.F.; Wu, C.H.; Kao, S.Y.; Liu, C.J.; Liu, T.Y.; Liu, M.T. Functional -1562 C to T polymorphism in matrix metalloproteinase-9 (MMP-9) promoter is associated with the risk for oral squamous cell carcinoma in younger male area users. J. Oral Pathol. Med. 2007, 36, 409-414.

22. Vairaktaris, E.; Vassiliou, S.; Nkenke, E.; Serefoglou, Z.; Derka, S.; Tsigris, C.; Vylliotis, A.; Yapijakis, C.; Neukam, F.W.; Patsouris, E. A metalloproteinase-9 polymorphism which affects expression is associated with increased risk of oral squamous cell carcinoma. Eur. J. Surg. Oncol. 2008, 34, 450-455.

23. Vairaktaris, E.; Serefoglou, Z.; Avgoustidis, D.; Yapijakis, C.; Critselis, E.; Vylliotis, A.; Spyridonidou, S.; Derka, S.; Vassiliou, S.; Nkenke, E.; et al. Gene polymorphisms related to angiogenesis, inflammation and thrombosis that influence risk for oral cancer. Oral Oncol. 2009, 45, 247-253.

24. Nasr, H.B.; Mestiri, S.; Chahed, K.; Bounaouina, N.; Gabbouj, S.; Jalbout, M.; Chouchane, L. Matrix metalloproteinase-1 (-16076) $1 \mathrm{G} / 2 \mathrm{G}$ and -9 (-1562) C/T promoter polymorphisms: Susceptibility and prognostic implications in nasopharyngeal carcinomas. Clin. Chim. Acta 2007, 384, 57-63.

25. Rollin, J.; Regina, S.; Vourc'h, P.; Lochman, S.; Blechet, C.; Reverdiau, P.; Gruel, Y. Influence of MMP-2 and MMP-9 promoter polymorphisms on gene expression and clinical outcome of non-small cell lung cancer. Lung Cancer 2007, 56, 273-280.

26. Wu, J.; Zhang, L.; Luo, H.; Zhu, Z.; Zhang, C.; Hou, Y. Association of matrix metalloproteinase-9 gene polymorphisms with genetic susceptibility to oesophageal squamous cell carcinoma. DNA Cell. Biol. 2008, 27, 553-557. 
27. Liu, D.; Guo, H.; Li, Y.; Xu, X.; Yang, K.; Bai, Y. Association between polymorphisms in the promoter regions of matrix metalloproteinases (MMPs) and risk of cancer metastasis: A meta-analysis. PLoS One 2012, 7, e31251.

28. Shimajiri, S.; Arima, N.; Tanimoto, A.; Murata, Y.; Hamada, T.; Wang, K.Y.; Sasaguri, Y. Shortened microsatellite $\mathrm{d}(\mathrm{CA}) 21$ sequence down-regulates promoter activity of matrix metalloproteinase 9 gene. FEBS Lett. 1999, 455, 70-74.

29. Maeda, S.; Haneda, M.; Guo, B.; Koya, D.; Hayashi, K.; Sugimoto, T.; Isshiki, K.; Yasuda, H.; Kashiwagi, A.; Kikkawa, R. Dinucleotide repeat polymorphism of matrix metalloproteinase-9 gene is associated with diabetic nephropathy. Kidney Int. 2001, 60, 1428-1434.

30. Peters, D.G.; Kassam, A.; St. Jean, P.L.; Yonas, H.; Ferrell, R.E. Functional polymorphism in the matrix metalloproteinase-9 promoter as a potential risk factor for intracranial aneurysm. Stroke 1999, 30, 2612-2616.

31. Yuan, M.; Zhan, Q.; Duan, X.; Song, B.; Zeng, S.; Chen, X.; Yang, Q.; Xia, J. A functional polymorphism at miR-491-5p binding site in the 3'-UTR of gelatinase B/MMP-9 gene confers increased risk for atherosclerotic cerebral infarction in a Chinese population. Atherosclerosis 2013, 226, 447-452.

32. Hu, Z.; Huo, X.; Lu, D.; Qian, J.; Zhou, J.; Chen, Y.; Xu, L.; Ma, H.; Zhu, J.; Wei, Q.; et al. Functional polymorphisms of matrix metalloproteinase-9 are associated with risk of occurrence and metastasis of lung cancer. Clin. Cancer Res. 2005, 11, 5433-5439.

33. Liu, H.; Huang, P.Y.; Tang, L.Q.; Chen, Q.Y.; Zhang, H.; Zhang, L.; Guo, L.; Luo, D.H.; Mo, H.Y.; Xiang, Y.Q.; et al. Functional polymorphisms of matrix metalloproteinase-9 and survival in patients with locoregionally advanced nasopharyngeal carcinoma treated with radiotherapy. Med. Oncol. 2013, 30, 685 .

34. Liu, Z.; Li, L.; Yang, Z.; Luo, W.; Li, X.; Yang, H.; Yao, K.; Wu, B.; Feng, W. Increased expression of gelatinase B/MMP-9 is correlated with poor prognosis of nasopharyngeal carcinoma. BMC Cancer 2010, 10, 270.

35. Tang, Y.; Zhu, J.; Chen, L.; Chen, L.; Zhang, S.; Lin, J. Associations of matrix metalloproteinase-9 protein polymorphisms with lymph node metastasis but not invasion of gastric cancer. Clin. Cancer Res. 2008, 14, 2870-2877.

36. Sharma, K.L.; Misra, S.; Kumar, A.; Mittal, B. Higher risk of matrix metalloproteinase (MMP-2, $7,9)$ and tissue inhibitor of metalloproteinase (TIMP-2) genetic variants in gallbladder cancer. Liver Int. 2012, 32, 1278-1286.

37. Yang, Z.H.; Li, S.N.; Liu, J.X.; Guo, Q.X.; Sun, X.W. MMP-9 polymorphisms are related to serum lipids levels but not associated with colorectal cancer susceptibility in Chinese population. Mol. Biol. Rep. 2012, 39, 9399-9404.

38. Jin, G.; Miao, R.; Hu, Z.; Xu, L.; Huang, X.; Chen, Y.; Tian, T.; Wei, Q.; Boffetta, P.; Shen, H. Putative functional polymorphisms of MMP-9 predict survival of NSCLC in a Chinese population. Int. J. Cancer 2009, 124, 2172-2178.

39. O'Farrell, T.J.; Pourmotabbed, T. Identification of structural elements important for matrix metalloproteinase type $\mathrm{V}$ collagenolytic activity as revealed by chimeric enzymes. Role of fibronectin-like domain and active site of gelatinase B. J. Biol. Chem. 2000, 275, 27964-27972. 
40. O’Farrell, T.J.; Guo, R.; Hasegawa, H.; Pourmotabbed, T. Matrix metalloproteinase-1 takes advantage of the induced fit mechanism to cleave the triple-helical type I collagen molecule. Biochemistry 2006, 45, 15411-15418.

41. Farina, A.R.; Cappabianca, L.; di Ianni, N.; Ruggeri, P.; Ragone, M.; Merolla, S.; Gulino, A.; Mackay, A.R. Alendronate promotes plasmin-mediated MMP-9 inactivation by exposing cryptic plasmin degradation sites within the MMP-9 catalytic domain. FEBS Lett. 2012, 586, 2366-2374.

42. Triebel, S.; Blaser, J.; Reinke, H.; Knauper, V.; Tschesche, H. Mercurial activation of human PMN leukocyte type IV procollagenase (gelatinase). FEBS Lett. 1992, 298, 280-284.

43. Okamoto, T.; Akaike, T.; Sawa, T.; Miyamoto, Y.; van del Vliet, A.; Maeda, H. Activation of matrix metalloproteinases by peroxynitrite-induced protein S-glutothiolation via disulphide S-oxide formation. J. Biol. Chem. 2001, 276, 29596-29602.

44. Gu, Z.; Kaul, M.; Yan, B.; Kridel, S.J.; Cui, J.; Strongin, A.; Smith, J.W.; Liddington, R.C.; Lipton, S.A.S. nitrosylation of matrix metalloproteinases: Signalling pathway to neuronal cell death. Science 2002, 297, 1186-1190.

45. Kahn, M.M.G.; Simizu, S.; Suzuli, T.; Masuda, A.; Kawatani, M.; Muroi, M.; Dohmae, N.; Nad Osada, H. Protein disulphide isomerase-mediated disulphide binds regulate gelatinolytic activity and secretion of matrix metalloproteinase-9. Exp. Cell Res. 2012, 318, 904-911.

46. Dufour, A.; Sampson, N.S.; Li, J.; Kuscu, C.; Rizzo, R.C.; Deleon, J.L.; Zhi, J.; Jaber, N.; Liu, E.; Zucker, S.; et al. Small-molecule anticancer compounds selectively target the hemopexin domain of matrix metalloproteinase-9. Cancer Res. 2011, 71, 4977-4988.

47. Geurts, N.; Martens, E.; van Aelst, I.; Proost, P.; Opdenakker, G.; van den Steen, P.E. Beta-haematin interaction with the hemopexin domain of gelatinase B/MMP-9 provokes autocatalytic processing of the propeptide, thereby priming activation by MMP-3. Biochemistry 2008, 47, 2689-2699.

48. Dufour, A.; Zucker, S.; Sampson, N.S.; Kuscu, C.; Cao, J. Role of matrix metalloproteinase-9 dimers in cell migration: Design of inhibitory peptides. J. Biol. Chem. 2010, 285, 35944-35956.

49. Van den Steen, P.E.; van Aelst, I.; Hvidberg, V.; Piccard, H.; Fiten, P.; Jacobsen, C.; Moestrup, S.K.; Fry, S.; Royle, L.; Wormald, M.R.; et al. The hemopexin and $O$-glycosylated domains tune gelatinase B/MMP-9 bioavailability via inhibition of binding to cargo receptors. J. Biol. Chem. 2006, 281, 18626-18637.

50. Bellini, T.; Trentini, A.; Manfrinato, M.C.; Tamborino, C.; Volta, C.A.; di Foggia, V.; Fainardi, E.; Dallocchio, F.; Castellazzi, M. Matrix metalloproteinase-9 activity detected in body fluids is the result of two different enzyme forms. J. Biochem. 2012, 151, 493-499.

51. Geurts, N.; Becker-Pauly, C.; Martens, E.; Proost, P.; van den Steen, P.E.; Stoker, W.; Opdenakker, G. Meprins process matrix metalloproteinase-9 (gelatinase B/MMP-9)/gelatinase B and enhance the activation kinetics by MMP-3. FEBS Lett. 2012, 586, 4264-4269.

52. Ramani, V.C.; Kaushal, G.P.; Haun, R.S. Proteolytic activation of kallikrien-related peptidase 7 produces unique active matrix metalloproteinase-9 lacking the $C$-terminal domains. Biochim. Biophys. Acta 2011, 1813, 1525-1531. 
53. Reis, C.; Lottspeich, F.; Dittmann, K.H.; Petrides, P.E. HL60 leukemia cells produce an autocatalytically truncated form of matrix metalloproteinase- 9 with impaired sensitivity to inhibition by tissue inhibitors of metalloproteinases. Leukemia 1996, 10, 1520-1526.

54. Reis, C.; Pitsch, T.; Mentele, R.; Zahler, S.; Egea, V.; Nagase, H.; Jochum, M. Identification of a novel $82 \mathrm{kDa}$ proMMP-9 species associated with the surface of leukaemic cells: (Auto-) catalytic activation and resistance to inhibition by TIMP-1. Biochem. J. 2007, 405, 547-558.

55. Bigg, H.F.; Rowan, A.D.; Barker, M.D.; Cawston, T.E. Activity of matrix metalloproteinase-9 against native collagen I and II. FEBS J. 2007, 274, 1246-1255.

56. Van den Steen, P.E.; Proost, P.; Brand, D.D.; Kang, A.H.; van Damme, J.; Opdenakker, G. Generation of glycosylated remnant epitopes from human type II collagen by gelatinase B. Biochemistry 2004, 43, 10809-10816.

57. Eble, J.A.; Ries, A.; Lichy, A.; Mann, K.; Stanton, H.; Gavrilovic, J.; Murphy, G.; Kuhn, K. The recognition sites of the integrins $\alpha 1 \beta 1$ and $\alpha 2 \beta 1$ within collagen IV are protected against gelatinase A attack in the native protein. J. Biol. Chem. 1996, 271, 30964-30970.

58. Shoji A.; Kabeya, M.; Sugawara, M. Real-time monitoring of matrix metalloproteinase-9 collagenolytic activity with a surface plasmon resonance biosensor. Anal. Biochem. 2011, 419, 53-60.

59. Mackay, A.R.; Corbitt, R.H.; Hartzler, J.L.; Thorgeirsson, U.P. Basement membrane type IV collagen degradation: Evidence for the involvement of a proteolytic cascade independent of metalloproteinases. Cancer Res. 1990, 50, 5997-6001.

60. Beliveau, A.; Mott, J.D.; Lo, A.; Chen, E.I.; Koller, A.A.; Yaswen, P.; Muschler, J.; Bissel, M.J. Raf-induced MMP-9 disrupts tissue architecture of human breast cells in three-dimensional culture and is necessary for tumor growth in vitro. Genes Dev. 2010, 24, 2800-2811.

61. Gu, Z.; Cui, J.; Brown, S.; Fridman, R.; Mobashery, S.; Strongin, A.Y.; Lipton, S.A. A highly specific inhibitor of matrix metalloproteinase-9 rescues laminin from proteolysis and neurons from apoptosis in transient focal cerebral ischemia. J. Neurosci. 2005, 25, 6401-6408.

62. Xu, D.; Suenaga, N.; Edelman, J.; Fridman, R.; Muschel, R.; Kessler, B.M. Novel MMP-9 substrates in cancer cells revealed by a label-free quantitative proteomics approach. Mol. Cell. Proteomics 2008, 7, 2215-2228.

63. Cauwe, B.; van den Steen, P.E.; Opdenakker, G. The biochemical, biological, and pathological kaleidoscope of cell surface substrates processed by matrix metalloproteinases. Crit. Rev. Biochem. Mol. Biol. 2007, 42, 113-115.

64. Cauwe, B.; Opdenakker, G. Intracellular substrate cleavage: A novel dimension in the biochemistry, biology and pathology of matrix metalloproteinases. Crit. Rev. Biochem. Mol. Biol. 2010, 45, 351-423.

65. Prudova, A.; auf dem Keller, U.; Butler, G.S.; Overall, C.M. Multiplex N-terminome analysis of MMP-2 and MMP-9 substrate degradomes by iTRAQ-TAILS quantitative proteomics. Mol. Cell. Proteomics 2010, 9, 894-911.

66. Gioia, M.; Monaco, S.; van den Steen, P.E.; Sbardella, D.; Grasso, G.; Marini, S.; Overall, C.M.; Opdenakker, G.; Coletta, M. The collagen binding domain of gelatinase A modulates degradation of collagen IV by gelatinase B. J. Mol. Biol. 2009, 386, 419-434. 
67. Murphy, G.; Reynolds, J.J.; Bretz, U.; Baggiolini, M. Partial purification of collagenase and gelatinase from human polymorphonuclear leucocytes. Analysis of their actions on soluble and insoluble collagens. Biochem. J. 1982, 203, 209-221.

68. Morodomi, T.; Ogata, Y.; Sasaguri, Y.; Morimatsu, M.; Nagase, H. Purification and characterization of matrix metalloproteinase 9 from U937 monocytic leukaemia and HT-1080 fibrosarcoma cells. Biochem. J. 1992, 285, 603-611.

69. Kridel, S.J.; Chen, E.; Kotra, L.P.; Howard, E.W.; Mobashery, S.; Smith, J.W. Substrate hydrolysis by matrix metalloproteinase-9. J. Biol. Chem. 2001, 276, 20572-20578.

70. Stegemann, C.; Didangelos, A.; Ballarobre-Barriero, J.; Langley, S.R.; Mandal, K.; Jahangiri, M.; Mayr, M. Proteomic identification of matrix metalloproteinase substrates in the human vasculature. Circ. Cardiovasc. Genet. 2013, 6, 106-117.

71. O'Farrell, T.J.; Pourmattabbed, T. The fibronectin-like domain is required for the type V and XI collagenolytic activity of gelatinase B. Arch. Biochem. Biophys. 1998, 354, 24-30.

72. Ferreras, M.; Felbor, U.; Lenhard, T.; Olsen, B.R.; Delaissé, J. Generation and degradation of human endostatin proteins by various proteinases. FEBS Lett. 2000, 486, 247-251.

73. Ochieng, J.; Fridman, R.; Nagia-Makker, P.; Kleiner, D.E.; Liotta, L.A.; Stetler-Stevenson, W.G.; Raz, A. Galectin-3 is a novel substrate for human matrix metalloproteinase-2 and 9. Biochemistry 1994, 33, 14109-14114.

74. Zampila, R.; Lopez, E.F.; Chiao, Y.A.; Dai, Q.; Escobar, G.P.; Hakala, K.; Weintraub, S.T.; Lindsey, M.L. Proteomic analysis identifies in vivo candidate matrix metalloproteinase-9 substrates in the left ventrical post-myocardial infaction. Proteomics 2010, 10, 2214-2223.

75. Siri, A.; Knauper, V.; Veirana, N.; Caocci, F.; Murphy, G.; Zardi, L. Different susceptibility of small and large human tenascin-C isoforms to degradation by matrix metalloproteinases. J. Biol. Chem. 1995, 270, 8650-8654.

76. Katsuda, S.; Okada, Y.; Okada, Y.; Imai, K.; Nakanishi, I. Matrix metalloproteinase-9 (92-kd gelatinase/type IV collagenase equals gelatinase B) can degrade arterial elastin. Am. J. Pathol. 1994, 145, 1208-1218.

77. Lau, A.C.; Duong, T.T.; Ito, S.; Yeung, R.S. Matrix metalloproteinase 9 activity leads to elastin breakdown in an animal model of Kawasaki disease. Arthritis Rheum. 2008, 58, 854-863.

78. Imai, K.; Shikata, H.; Okada, Y. Degradation of vitronectin by matrix metalloproteinases-1, -2, -3, -7 and -9. FEBS Lett. 1995, 369, 249-251.

79. Sires, U.I.; Griffin, G.L.; Broekelmann, T.J.; Mecham, R.P.; Murphy, G.; Chung, A.E.; Welgus, H.G.; Senior, R.M. Degradation of entactin by matrix metalloproteinases. J. Biol. Chem. 1993, 268, 2069-2074.

80. Hawinkels, L.J.A.C.; Ziudwijk, K.; Verspaget, H.W.; de Jong-Muller, E.S.M.; van Duijin, W.; Ferreira, V.; Fontijn, R.D.; David, G.; Hommes, D.W.; Lamers, C.B.H.W.; et al. VEGF release by MMP-9 mediated heparin sulphate cleavage induces colorectal cancer angiogenesis. Eur. J. Cancer 2008, 44, 1904-1913.

81. Fiore, E.; Fusco, C.; Romero, P.; Stamenkovic, I. Matrix metalloproteinase 9 (MMP-9/gelatinase B) proteolytically cleaves ICAM-1 and participates in tumor cell resistance to natural killer cell-mediated cytotoxicity. Oncogene 2002, 21, 5213-5223. 
82. Sultan, S.; Gosling, M.; Nagase, H.; Powell, J.T. Shear stress-induced shedding of soluble intercellular adhesion molecule-1 from saphenous vein endothelium. FEBS Lett. 2004, $564,161-165$.

83. Andolfo, A.; English, W.R.; Resnati, M.; Murphy, G.; Blasi, F.; Sidenius, N. Metalloproteinase cleave the urokinase-type plasminogen activator receptor in the D1-D2 linker region and expose epitopes not present in the intact soluble receptor. Thromb. Haemost. 2002, 88, 298-306.

84. Amano, T.; Kwak, O.; Fu, L.; Marshak, A.; Shi, Y.B. The matrix metalloproteinase stromelysin-3 cleaves laminin receptor at two distinct sites between the transmembrane domain and laminin binding sequence within the extracellular domain. Cell Res. 2005, 15, 150-159.

85. Sheu, B.C.; Hsu, S.M.; Ho, H.N.; Lien, H.C.; Huang, S.C.; Lin, R.H. A novel role of metalloproteinase in cancer-mediated immunosuppression. Cancer Res. 2001, 61, 237-242.

86. De Paiva, C.S.; Yoon, K.-C.; Pangelinan, S.B.; Pham, S.; Puthenparambi, L.M.; Chuang, E.Y.; Farley, W.J.; Stern, M.E.; Li, D.-C.; Pflugfelder, S.C. Cleavage of functional IL-2 receptor alpha chain (CD25) from murine corneal and conjunctival epithelial by MMP-9. J. Inflamm. Lond. 2009, 6, 31 .

87. Mohan, M.J.; Seaton, T.; Mitchell, J.; Howe, A.; Blackburn, K.; Burkhart, W.; Moyer, M.; Patel, I.; Waitt, G.M.; Becherer, J.D.; et al. The tumor necrosis factor-alpha converting enzyme (TACE): A unique metalloproteinase with highly defined substrate selectivity. Biochemistry 2002, 41, 9462-9469.

88. Ito, A.; Mukaiyama, A.; Itoh, Y.; Nagase, H.; Thogersen, I.B.; Enghild, J.J.; Sasaguri, Y.; Mori, Y. Degradation of interleukin 1 beta by matrix metalloproteinases. J. Biol. Chem. 1996, 271, 14657-1460.

89. Schonbeck, U.; Mach, F.; Libby, P. Generation of biologically active IL-1 beta by matrix metalloproteinases: A novel caspase-1-independent pathway of IL-1 beta processing. J. Immunol. 1998, 161, 3340-3346.

90. Heissig, B.; Hattori, K.; Dias, S.; Friedrich, M.; Ferris, B.; Hackett, N.R.; Crystal, R.G.; Besmer, P.; Lyden, D.; Moore, M.A.; et al. Recruitment of stem and progenitor cells from the bone marrow niche requires MMP-9 mediate release of kit-ligand. Cell 2002, 109, 625-637.

91. Hollenbeck, S.T.; Sakakibara, K.; Faries, P.L.; Workhu, B.; Liu, B.; Kent, K.C. Stem cell factor and c-kit are expressed by and may affect vascular SMCs through an autocrine pathway. J. Surg. Res. 2004, 120, 288-294.

92. Vaisar, T.; Kassim, S.Y.; Gomez, I.G.; Green, P.S.; Hargarten, S.; Gough, P.J.; Parks, W.C.; Wilson, C.L.; Raines, E.W.; Heinecke, J.W. MMP-9 sheds the beta2 integrin subunit (CD18) from macrophages. Mol. Cell. Proteomics 2009, 8, 1044-1060.

93. Yu, Q.; Stamenkovic, I. Localization of matrix metalloproteinase 9 to the cell surface provides a mechanism for CD-44-mediated tumor invasion. Genes Dev. 1999, 13, 35-48.

94. Lue, H.-W.; Yang, X.; Wang, R.; Qian, W.; Xu, R.Z.H.; Lyles, R.; Osunkoya, A.O.; Zhou, B.P.; Vessella, R.L.; Zayzafoon, M.; et al. LIV-1 promotes prostate cancer epithelial-to-mesenchymal transition and metastasis through HB-EGF shedding and EGFR-mediated Erk signalling. PLoS One 2011, 6, e27720. 
95. Giebel, J. S.; Menicucci, G.; McGuire, P. G.; Das, A. Matrix metalloproteinases in early diabetic retinopathy and their role in alteration of the blood-retinal barrier. Lab. Invest. 2005, 85, 597-607.

96. Fitzgerald, M.L.; Wang, Z.; Park, P.W.; Murphy, G.; Bernfield, M. Shedding of syndecan-1 and -4 ectodomains is regulated by multiple signalling pathways and mediated by a TIMP-3-sensitive metalloproteinase. J. Cell. Biol. 2000, 148, 811-824.

97. Brule, S.; Charnaux, N.; Sutton, A.; Ledoux, D.; Chaigneau, T.; Saffar, L.; Gattegno, L. The shedding of syndecan-4 and syndecan-1 from HeLa cells and human primary macrophages is accelerated by SDF-1/CXCL12 and mediated by the matrix metalloproteinase-9. Glycobiology 2006, 16, 488-501.

98. Liu, Z.; Zhou, X.; Shapiro, S.D.; Shipley, J.M.; Twining, S.S.; Diaz, L.A.; Senior, R.M.; Werb, Z. The serpin alpha-1 proteinase inhibitor is a critical substrate for gelatinase B/MMP-9 in vivo. Cell 2000, 102, 647-655.

99. Proost, P.; van Damme, J.; Opdenakker, G. Leukocyte gelatinase B cleavage releases encephalitogens from human myelin basic protein. Biochem. Biophys. Res. Commun. 1993, 192, 1175-1181.

100. Larsen, P.H.; Wells, J.E.; Stallcup, W.B.; Opdenakker, G.; Young, V.W. Matrix metalloproteinase-9 facilitates remyelination in part by processing the inhibitory NG2 proteoglycan. $J$. Neurosci. 2003, 23, 11127-11135.

101. Agrawal, S.; Anderson, P.; Durbeej, M.; van Rooijen, N.; Ivars, F.; Opdenakker, G.; Sorokin, L.M. Dystroglycan is selectively cleaved at the parenchymal basement membrane at sites of leukocyte extravasation in experimental autoimmune encephalomyelitis. J. Exp. Med. 2006, 203, 1007-1019.

102. Backstrom, J.R.; Lim, G.P.; Cullen, M.J.; Tokes, Z.A. Matrix metalloproteinase-9 (MMP-9) is synthesized in neurons of the human hippocampus and is capable of degrading amyloid-beta peptide (1-40). J. Neurosci. 1996, 16, 7910-7919.

103. Yan, P.; Hu, X.; Song, H.; Yin, K.; Bateman, R.J.; Cirrito, J.R.; Xiao, Q.; Hsu, F.F.; Turk, J.W.; $\mathrm{Xu}$, J.; Hsu, C.Y.; Holtzman, D.M.; Lee, J.M. Matrix metalloproteinase-9 degrades amyloid-beta fibrils in vitro and compact plaques in situ. J. Biol. Chem. 2006, 281, 24566-24574.

104. Tortorella, M.D.; Arner, E.C.; Hills, R.; Gormley, J.; Fok, K.; Pegg, L.; Munie, G.; Malfait, A.-M. ADAMTS-4 (aggreganase-1): $N$-terminal activation mechanisms. Arch. Biochem. Biophys. 2005, 444, 34-44.

105. Greenlee, K.J.; Corry, D.B.; Engler, D.A.; Matsunami, R.K.; Tessier, P.; Cook, R.G.; Werb, Z.; Kheradmand, F. Proteomic identification of in vivo substrates from matrix metalloproteinase 2 and 9 reveals a mechanism for resolution of inflammation. J. Immunol. 2006, 177, 7312-7321.

106. Van den Steen, P.E.; Proost, P.; Wuyts, A.; van Damme, J.; Opdenakker, G. Neutrophil gelatinase $\mathrm{B}$ potentiates interleukin- 8 tenfold by aminoterminal processing, whereas it degrades CTAP-III, PF-4 and GRO-alpha and leaves RANTES and MCP-2 intact. Blood 2000, 275, 34335-34343. 
107. Van den Steen, P.E.; Wuyts, A.; Husson, S.J.; Proost, P.; van Damme, J.; Opdenakker, G. Gelatinase B/MMP-9 and neutrophil collagenase/MMP-8 process the chemokines human GCP-2/CXCL6, ENA-78/CXCL5 and mouse GCP-2/LIX and modulate their physiological activities. Eur. J. Biochem. 2003, 270, 3739-3749.

108. Cox, J.H.; Dean, R.A.; Roberts, C.R.; Overall, C.M. Matrix metalloproteinase processing of CXCL11/I-TAC results in loss of chemoattractant activity and altered glycosaminoglycan binding. J. Biol. Chem. 2008, 283, 19389-19399.

109. Jin, F.; Zhai, Q.; Qui, L.; Meng, H.; Zou, D.; Wang, Y.; Li, Q.; Yu, Z.; Han, J.; Li, Q.; et al. Degradation of BM SDF-1 by MMP-9: The role in G-CSF-induced hematopoietic stem/progenitor cell mobilization. Bone Marrow Transplant. 2008, 42, 581-588.

110. Ruiz, S.; Henschen-Edman, A.H.; Nagase, H.; Tenner, A.J. Digestion of C1q collagen like domains by MMPs-1, $-2,-3$, and -9 further defines the sequence involved in the stimulation of neutrophil superoxide production. J. Leukoc. Biol. 1999, 66, 416-422.

111. Butler, G.S.; Dean, R.A.; Tam, E.M.; Overall, C.M. Pharmacoproteomics of a metalloproteinase hydroxamates inhibitor in breast cancer cells: Dynamics of membrane type 1 matrix metalloproteinase-mediated protein shedding. Mol. Cell. Biol. 2008, 28, 4896-4914.

112. Patterson, B.C.; Sang, Q.A. Angiostatin-converting enzyme activities of human matrilysin (MMP-7) and gelatinase B/type IV collagenase (MMP-9). J. Biol. Chem. 1997, 272, 28823-28825.

113. Farina, A.R.; Tacconelli, A.; Cappabianca, L.; Gulino, A.; Mackay, A.R. Inhibition of human MDA-MB-231 breast cancer invasion by matrix metalloproteinase 3 involves degradation of plasminogen. Eur. J. Biochem. 2002, 269, 4476-4483.

114. Bruno, M.A.; Cuello, C.A. Activity-dependent release of precursor nerve growth factor, conversion to mature nerve growth factor, and its degradation by a protease cascade. Proc. Natl. Acad. Sci. USA 2006, 103, 6735-6740.

115. Nelissen, I.; Martens, E.; van den Steen, P.E.; Proost, P.; Ronsse, I.; Opdenakker, G. Gelatinase B/Matrix metalloproteinase-9 cleaves interferon-b and is a target for immunotherapy. Brain 2003, 126, 1371-1381.

116. Takino, T.; Koshikawa, N.; Miyamori, H.; Tanaka, M.; Sasaki, T.; Okada, Y.; Seiki, M.; Sato, H. Cleavage of metastasis suppressor gene product KiSS-1 protein/metastin by matrix metalloproteinases. Oncogene 2003, 22, 4617-4626.

117. Nubling, G.; Levin, J.; Brader, B.; Isreal, L.; Bitzel, K.; Lorenzi, S.; Giese, A. Limited cleavage of tau with matrix metalloproteinase gelatinase B/MMP-9, but not MMP-3, enhances tau oligomer formation. Exp. Neurol. 2012, 237, 470-476.

118. Lee, S.; Jilani, S.M.; Nikolova, G.V.; Carpizo, D.; Iruela-Arispe, M.L. Processing of VEGF-A by matrix metalloproteinases regulates bioavailability and vascular patterning in tumor. J. Cell. Biol. 2005, 169, 681-691.

119. Sato, H.; Kita, M.; Seiki, M. v-Src activates the expression of 92-kDa type IV collagenase gene through the AP-1 site and the GT box homologous to retinoblastoma control elements. A mechanism regulating gene expression independent of that by inflammatory cytokines. $J$. Biol. Chem. 1993, 268, 23460-23468. 
120. Gum, R.; Lengyel, E.; Juarez, J.; Chen, J.H.; Seiki, M.; Boyd, D. Stimulation of 92-kDa gelatinase $\mathrm{B}$ promoter activity by ras is mitogen-activated protein kinase 1-independent and requires multiple transcription factor binding sites including closely speced PEA3/ets and AP-1 sequences. J. Biol. Chem. 1996, 271, 10672-10680.

121. Han, Y.P.; Tuan, T.L.; Hughes, M.; Wu, H.; Garner, W.L. Transforming growth factor-beta-and tumor necrosis factor-alpha-mediated induction and activation of MMP-9 in human skin. J. Biol. Chem. 2001, 276, 22341-22350.

122. Schwarzt, B.; Melnikova, V.O.; Tellez, C.; Mourad-Zeidan, A.; Blehm, K.; Zhao, Y.-J.; McCarty, M.; Adam, L.; Bar-Eli, M. Loss of AP-2a results in deregulation of E-caherin and MMP-9 and an increase in tumorigenicity of colon cancer cells in vivo. Oncogene 2007, 26, 4049-4058.

123. Farina, A.R.; Tacconelli, A.; Vacca, A.; Maroder, M.; Gulino, A.; Mackay, A.R. Transcriptional up-regulation of matrix metalloproteinase-9 expression during spontaneous epithelial to neuroblast phenotype conversion by SH-N-SH neuroblastoma cells, involved in enhanced invasivity, depends upon GT-box and nuclear factor kappaB elements. Cell Growth Differ. 1999, 10, 353-367.

124. Farina, A.R.; Masciulli, M.-P.; Tacconelli, A.; Cappabianca, L.; de Santis, G.; Gulino, A.; Mackay, A.R. All-trans-retinoic acid induces nuclear factor $\kappa \mathrm{B}$ activation and matrix metalloproteinase- 9 expression and enhances basement membrane invasivity of differentiation-resistant human SK-N-BE 9N neuroblastoma cells. Cell Growth Differ. 2002, 13, 343-354.

125. Hozumi, A.; Nishimura, Y.; Nishiuma, T.; Kotani, Y.; Yokoyama, M. Induction of MMP-9 in normal human bronchial epithelial cells by TNF-alpha via NF-kappa B-mediated pathway. Am. J. Physiol. Lung Cell Mol. Physiol. 2001, 281, L1444-L1452.

126. Bond, M.; Chase, A.J.; Baker, A.H.; Newby, A.C. Inhibition of transcription factor NF-kappaB reduces matrix metalloproteinase-1, -3 and -9 production by vascular smooth muscle cells. Cardiovasc. Res. 2001, 50, 556-565.

127. Yokoo, T.; Kitamura, M. Dual regulation of Il-1 beta-mediated matrix metalloproteinase-9 expression in mesangial cells by NF-kappaB and AP-1. Am. J. Physiol. 1996, 270, F123-F130.

128. Ricca, A.; Biroccio, A.; Del Bufalo, D.; Mackay, A.R.; Santoni, A.; Cipitelli, M. Bcl-2 over-expression enhances NF-kappaB activity and induces mmp-9 transcription in human MCF7 (ADR) breast-cancer cells. Int. J. Cancer 2000, 86, 188-196.

129. Kumar, A.; Dhawan, S.; Mukhopadhyay, A.; Arrarwal, B.B. Human immunodeficiency virus-1-tat induces matrix metalloproteinase-9 in monocytes through protein tyrosine phosphatase-mediated activation of nuclear transcription factor NF-kappaB. FEBS Lett. 1999, 462, 140-144.

130. Yan, L.; Borregaard, N.; Kjeldsen, L.; Moses, M.A. The high molecular weight urinary matrix metalloproteinase (MMP) activity is a complex of gelatinase B/MMP-9 and neutrophil gelatinase-associated lipocalin (NGAL). Modulation of MMP-9 activity by NGAL. J. Biol. Chem. 2001, 276, 37258-37265.

131. Bond, M.; Fabunmi, R.P.; Baker, A.H.; Newby, A.C. Synergistic upregulation of metalloproteinase-9 by growth factors and inflammatory cytokines: An absolute requirement for transcription factor NF-kappa B. FEBS Lett. 1998, 435, 29-34. 
132. Farina, A.R.; Cappabianca, L.; DeSantis, G.; di Ianni, N.; Ruggeri, P.; Ragone, M.; Merolla, S.; Tonissen, K.F.; Gulino, A.; Mackay, A.R. Thioredoxin stimulates MMP-9 expression, de-regulates the MMP-9/TIMP-1 equilibrium and promotes MMP-9 dependent invasion by human MDA-MB-231 breast cancer cells. FEBS Lett. 2011, 585, 3328-3336.

133. Himelstein, B.P.; Lee, E.J.; Sato, H.; Seike, M.; Muschel, R.J. Transcriptional activation of the matrix metalloproteinase-9 gene in an H-ras and v-myc transformed rat embryo cell lines. Oncogene 1997, 14, 1995-1998.

134. Akgul B.; Garcia-Escudero, R.; Ekechi, C.; Steger, G.; Navsaria, H.; Pfister, H.; Storey, A. The E2 protein of human papillomavirus type 8 increases the expression of matrix metalloproteinase- 9 in human keratinocytes and organotypic skin cultures. Med. Microbiol. Immunol. 2011, 200, 127-135.

135. Akool, el-S.; Kleinert, H.; Hamada, F.M.; Abdelwahab, M.H.; Forstermann, U.; Pfeilschifter, J.; Eberhardt, W. Nitric oxide increases the decay of matrix metalloproteinase 9 mRNA by inhibiting the expression of mRNA-stabilizing factor HuR. Mol. Cell. Biol. 2003, 23, 4901-4916.

136. Eberhardt, W.; Akool, el-S.; Rebhan, J.; Frank, S.; Beck, K.F.; Franzen, R.; Hamada, F.M.; Pfeilschifter, J. Inhibition of cytokine-induced matrix metalloproteinase 9 expression by peroxisome proliferator-activated receptor alpha agonists is indirect and due to a NO-mediated reduction of mRNA stability. J. Biol. Chem. 2012, 277, 33518-33528.

137. Jiang, Y.; Muschel, R.J. Regulation of matrix metalloproteinase-9 (MMP-9) by translational efficiency in murine prostate carcinoma cells. Cancer Res. 2002, 62, 1910-1914.

138. Morini, M.; Mottolese, M.; Ferrari, N.; Ghiorzo, F.; Buglioni, S.; Mortarini, R.; Noonan, D.M.; Natali, P.G.; Albini, A. The alpha 3 beta 1 integrin is associated with mammary carcinoma cell metastasis, invasion and gelatinase B (MMP-9) activity. Int. J. Cancer 2000, 87, 336-342.

139. Sehgal, I.; Thompson, T.C. Novel regulation of type IV collagenase (matrix metalloproteinase-9 and -2) activities by transforming growth factor-betal in human prostate cancer cells. Mol. Biol. Cell 1999, 10, 407-416.

140. Thant, A.A.; Nawa, A.; Nikkawa, F.; Ichigotani, Y.; Zhang, Y.; Sein, T.T.; Amin, A.R.; Hamaguchi, M. Fibronectin activates matrix metalloproteinase-9 secretion via the MEK-1-MAPK and the PI3K-Akt pathways in ovarian cancer cells. Clin. Exp. Metastasis 2000, 18, 423-428.

141. Iyer, V.; Pumiglia, K.; DiPersio, C.M. Alpha3beta1 integrin regulates MMP-9 mRNA stability in immortalized keratinocytes: A novel mechanism of integrin-mediated MMP gene expression. J. Cell Sci. 2005, 118, 1185-1195.

142. Zhang, S.; Qi, L.; Li, M.; Zhang, D.; Xu, S.; Wang, N.; Sun, B.J. Chemokine CXCL12 and its receptor CXCR4 expression are associated with perineural invasion of prostate cancer. J. Exp. Clin. Cancer Res. 2008, 27, 62.

143. Farina, A.R.; Coppa, A.; Tiberio, A.; Tacconelli, A.; Turco, A.; Colletta, G.; Gulino, A.; Mackay, A.R. Transforming growth factor-betal enhances the invasiveness of human MDA-MB-231 breast cancer cells by up-regulating urokinase activity. Int. J. Cancer 1998, 75, 721-730.

144. Festuccia, C.; Bologna, M.; Vicentini, C.; Tacconelli, A.; Miano, R.; Violini, S.; Mackay, A.R. Increased matrix metalloproteinase- 9 secretion in short term tissue cultures of prostatic tumor cells. Int. J. Cancer 1996, 69, 386-393. 
145. Shima, I.; Sasaguri, Y.; Kusukawa, J.; Nakano, R.; Yamana, H.; Fujita, H.; Kagegawa, T.; Morimatsu, M. Production of matrix metalloproteinase 9 (92 kDa gelatinase) by human oesophageal squamous cell carcinoma in response to epidermal growth factor. Br. J. Cancer 1993, 67, 721-727.

146. Price, T.J.; Wilson, H.M.; Haites, N.E. Epidermal growth factor (EGF) increases the in vitro invasion, motility and adhesion interactions of the primary renal carcinoma cell line, A704. Eur. J. Cancer 1996, 32A, 1977-1982.

147. Uchiyama, A.; Essner, R.; Dol, F.; Nguyen, T.; Ramming, K.P.; Nakamura, T.; Morton, D.L.; Hoon, D.S. Interleukin 4 inhibits hepatocyte growth factor-induced invasion and migration of colon carcinomas. J. Cell Biochem. 1996, 62, 443-453.

148. Horie, S.; Aruga, S.; Kawamata, H.; Okui, N.; Kakizoe, T.; Kitamura, T. Biological role of HGF/MET pathway in renal cell carcinoma. J. Urol. 1999, 161, 990-997.

149. Jiang, Y.; Xu, W.; Lu, J.; He, F.; Yang, X. Invasiveness of hepatocellular carcinoma cell lines: Contribution of hepatocyte growth factor, c-met, and transcription factor Est-1. Biochem. Biophys. Res. Commun. 2001, 286, 1123-1130.

150. Harvey, P.; Clark, I.M.; Jaurand, M.C.; Warn, R.M.; Edwards, D.R. Hepatocyte growth factor/scatter factor enhances the invasion of mesothelioma cell lines and the expression of matrix metalloproteinases. Br. J. Cancer 2000, 83, 1147-1153.

151. To, Y.; Dohi, M.; Matsumoto, K.; Tanaka, R.; Sato, A.; Nakagome, K.; Nakamura, T.; Yamamoto, K. A two-way interaction between hepatocyte growth factor and interleukin-6 in tissue invasion of lung cancer cell line. Am. J. Resp. Cell. Mol. Biol. 2002, 27, 220-226.

152. Lee, K.H.; Hyun, M.S.; Kim, J.R. Growth factor-dependent activation of the MAPK pathway in human pancreatic cancer: MEK/ERK and p38 MAP kinase interaction in uPA synthesis. Clin. Exp. Metastasis 2003, 20, 499-505.

153. Kurogi, T.; Nabeshima, K.; Kataoka, H.; Okada, Y.; Koono, M. Stimulation of gelatinase B and tissue inhibitor of metalloproteinase (TIMP) production in co-culture of human osteosarcoma cells and human fibroblasts: Gelatinase B production was stimulated via up-regulation of fibroblast growth factor (FGF) receptor. Int. J. Cancer 1996, 66, 82-90.

154. Miyake, H.; Yoshimura, K.; Hara, I.; Eto, H.; Arakawa, S.; Kamidono, S. Basic fibroblast growth factor regulates matrix metalloproteinases production and in vitro invasiveness in human bladder cancer cell lines. J. Urol. 1997, 157, 2351-2355.

155. Hazan, R.B.; Phillips, G.R.; Qiao, R.F.; Norton, L.; Aaronson, S.A. Exogenous expression of $\mathrm{N}$-Cadherin in breast cancer cells induces cell migration, invasion and metastasis. J. Cell Biol. 2000, 148, 779-790.

156. Suyama, K.; Shapiro, I.; Guttman, M.; Hazan, R.B. A signalling pathway leading to metastasis is controlled by $N$-cadherin and the FGF receptor. Cancer Cell 2002, 2, 301-314.

157. Sehgal, G.; Hua, J.; Bernhard, E.J.; Sehgal, I.; Thompson, T.C.; Muschel, R.J. Requirement for matrix metalloproteinase-9 (gelatinase B) expression in metastasis by murine prostate carcinoma. Am. J. Pathol. 1998, 152, 591-596.

158. Siddiqui, F.A.; Siddiqui, T.F.; Francis, J.L. Haemoglobin induces the production and release of matrix metalloproteinase-9 from human malignant cells. Blood Coagul. Fibrinolysis 2003, 14, $449-455$. 
159. Masure, S.; Proost, P.; van Damme, J.; Opdenakker, G. Purification and identification of 91-kDa neutrophil gelatinase. Release by the activating peptide interleukin-8. Eur. J. Biochem. 1991, 198, 391-398.

160. Rehman, A.A.; Ahsan, H.; Kahn, F.H. a-2-Macroglobulin: A physiological guardian. J. Cell. Physiol. 2013, 228, 1665-1675.

161. Gomez, D.E.; Alonso, D.F.; Yoshiji, H.; Thorgeirsson, U.P. Tissue inhibitors of metalloproteinases: Structure, regulation and biological functions. Eur. J. Cell Biol. 1997, 74, 111-122.

162. Murphy, G. Tissue inhibitors of metalloproteinases. Genome Biol. 2011, 12, 233.

163. Roeb, E.; Schleinkofer, K.; Kernebeck, T.; Potsch, S.; Jensen, B.; Behrmann, I.; Matern, S.; Grotzinger, J. The matrix metalloproteinase-9 (mmp-9) hemopexin domain is a novel gelatin-binding domain and acts as an antagonist. J. Biol. Chem. 2002, 277, 50326-50332.

164. Farina, A.R.; Tacconelli, A.; Cappabianca, L.; Masciulli, M.P.; Holmgren, A.; Beckett, G.J.; Gulino, A.; Mackay, A.R. Thioredoxin alters the matrix metalloproteinase/tissue inhibitors of metalloproteinase balance and stimulates human SK-N-SH neuroblastoma cell invasion. Eur. J. Biochem. 2001, 268, 405-413.

165. Hahn-Dantona, E.; Ruiz, J.F.; Bornstein, P.; Strickland, D.K. The low-density lipoprotein receptor-related protein modulates levels of matrix metalloproteinase 9 (MMP-9) by mediating its cellular catabolism. J. Biol. Chem. 2001, 276, 15498-15503.

166. Triebel, S.; Blaser, J.; Reinke, H.; Tschesche, H. A $25 \mathrm{kDa}$ alpha 2-microglobulin-related protein is a component of the $125 \mathrm{kDa}$ form of human gelatinase. FEBS Lett. 1992, 314, 386-388.

167. Chakraborty, S.; Kaur, S.; Guha, S.; Batra, S.K. The multifaceted roles of neutrophil gelatinase associated lipocalin (NGAL) in inflammation and cancer. Biochim. Biophys. Acta 2012, 1826, 129-169.

168. Ardi, V.C.; Kupriyanova, T.A.; Deryugina, E.L.; Quigley, J.P. Human neutrophils uniquely release TIMP-free MMP-9 to provide a potent catalytic stimulator of angiogenesis. Proc. Natl. Acad. Sci. USA 2007, 104, 20262-20267.

169. Ardi, V.C.; van den Steen, P.E.; Opdenakker, G.; Schweighofer, B.; Deryugina, E.I.; Quigley, J.P. Neutrophil MMP-9 proenzyme, unencumbered by TIMP-1, undergoes efficient activation in vivo and catalytically induces angiogenesis via a basic fibroblast growth factor (FGF-2)/FGFR-2 pathway. J. Biol. Chem. 2009, 284, 25854-25866.

170. Huang, S.; van Arsdall, M.; Tedjarati, S.; McCarty, M.; Wu, W.; Langley, R.; Fidler, I.J. Contributions of stromal metalloproteinase-9 to angiogenesis and growth of human ovarian carcinoma in mice. J. Natl. Cancer Inst. 2002, 94, 1134-1142.

171. O’Grady, A.; Dunne, C.; O’Kelly, P.; Murphy, G.M.; Leader, M.; Kay, E. Differential expression of matrix metalloproteinase (MMP)-2, MMP-9 and tissue inhibitor of metalloproteinase (TIMP)-1 and TIMP-2 in non-melanoma skin cancer: Implications for tumour progression. Histopathology 2008, 51, 793-804.

172. Heissenberg, M.C.; Gorogh, T.; Lippert, B.M.; Werner, J.A. Metalloproteinases and their inhibitors in squamous cell carcinoma of the hypopharynx: Indicators of individual tumor aggressiveness. Otolaryngol. Pol. 1998, 52, 521-526. 
173. Roeb, E.; Dietrich, C.G.; Winograd, R.; Arndt, M.; Breuer, B.; Fass, J.; Schumpelick, V.; Matern, S. Activity and cellular origin of gelatinases in patients with colon and rectal carcinoma differential activity of matrix metalloproteinase-9. Cancer 2001, 92, 2680-2691.

174. Asai, M.; Kato, M.; Asai, N.; Iwashita, T.; Murakami, H.; Kawai, K.; Nakashima, I.; Takahashi, M. Differential regulation of MMP-9 and TIMP-2 expression in malignant melanoma developed in metallothionin/RET transgenic mice. Jpn. J. Cancer Res. 1999, 90, 86-92.

175. Dong, Z.; Nemeth, J.A.; Cher, M.L.; Palmer, K.C.; Bright, R.C.; Fridman, R. Differential regulation of matrix metalloproteinase-9, tissue inhibitor of metalloproteinase-1 (TIMP-1) and TIMP-2 expression in co-cultures of prostate cancer and stromal cells. Int. J. Cancer 2001, 93, $507-515$.

176. Schonherr, E.; Schaefer, L.; O’Connel, B.C.; Kresse, H. Matrix metalloproteinase expression by endothelial cells in collagen lattices changes during co-culture with fibroblasts and upon induction of decorin expression. J. Cell Physiol. 2001, 187, 37-47.

177. Smola-Hess, S.; Schnitzler, R.; Hadaschik, D.; Smola, H.; Mauch, C.; Krieg, T.; Pfister, H. CD40L induces matrix metalloproteinase-9 but not tissue inhibitor of metalloproteinase-1 in cervical carcinoma cells: Imbalance between NF-kappaB and STAT3 activation. Exp. Cell Res. 2001, 267, 205-215.

178. O-charoenrat, P.; Rhys-Evans, P.; Court, W.J.; Box, G.M.; Eccles, S.A. Differential modulation of proliferation, matrix metalloproteinase expression and invasion of human head and neck squamous carcinoma cells by c-erbB ligands. Clin. Exp. Metastasis 1999, 17, 631-639.

179. Chang, X.Z.; Li, D.Q.; Hou, Y.F.; Wu, J.; Lu, J.S.; Di, G.H.; Jin, W.; Ou, Z.L.; Shen, Z.Z.; Shao, Z.M. Identification of the functional role of peroxiredoxin 6 in the progression of breast cancer. Breast Cancer Res. 2007, 9, R76.

180. Kim, J.H.; Kim, J.H.; Cho, C.S.; Jun, H.O.; Kim, D.H.; Yu, Y.S.; Kim, K.-W. Differential roles of matrix metalloproteinase-9 and -2 , depending on proliferation or differentiation of retinoblastoma cells. Invest. Opthalmol. Vis. Sci. 2010, 51, 1783-1788.

181. Yu, G.; Wang, X.; Wu, T.; Zhu, J.; Huang, S.; Wan, Y.; Tang, J. MicroRNA-19a targets tissue factor to inhibit colon cancer cells migration and invasion. Mol. Cell. Biochem. 2013, 380, 239-247.

182. Li, S.; Guo, J.; Wu, J.; Sun, Z.; Han, M.; Shan, S.W.; Deng, Z.; Yang, B.B.; Weisel, R.D.; Li, R.K. miR-17 targets tissue inhibitor of metalloproteinase-1 and 2 to modulate cardiac matrix remodelling. FASEB J. 2013, 27, 4254-4265.

183. Oh, J.H.; Chung, A.S.; Steinbrenner, H.; Sies, H.; Brenneisen, P. Thioredoxin secreted upon ultraviolet A irradiation modulates the activities of matrix metalloproteinase-2 and tissue inhibitor of metalloproteinase-2 in human dermal fibroblasts. Arch. Biochem. Biophys. 2004, 423, 218-226.

184. Shabani, F.; McNeil, J.; Tippett, L. The oxidative inactivation of tissue inhibitor of metalloproteinase-1 (TIMP-1) by hypochlorous acid ( $\mathrm{HOCl})$, is suppressed by anti-rheumatic drugs. Free Radic. Res. 1998, 28, 115-123.

185. Wang, Y.; Rosen, H.; Madtes, D.K.; Shao, B.; Martin, T.R.; Heinecke, J.W.; Fu, X. Myeloperoxidase inactivates TIMP-1 by oxidising its $N$-terminal Cystein residue. J. Biol. Chem. 2007, 282, 31826-31834. 
186. Thompson, E.W.; Mackay, A.R. Review of: Opposing effects for specific TIMPs in breast cancer. Breast Cancer Online 2005, 8, e5.

187. Okada, Y.; Watanabe, S.; Nakanishi, I.; Kishi, J.; Hayakawa, T.; Watorek, W.; Travis, J.; Nagase, H. Inactivation of tissue inhibitor of metalloproteinases by neutrophil elastase and other serine proteinases. FEBS Lett. 1988, 229, 157-160.

188. Ferry, G.; Lonchampt, M.; Pennel, L.; de Nanteil, G.; Canet, E.; Tucker, G.C. Activation of MMP-9 by neutrophil elastase in an in vivo model of acute lung injury. FEBS Lett. 1997, 402, $111-115$.

189. Itkonen, O. Human trypsinogens in the pancreas and in cancer. Scand. J. Clin. Lab. Invest. 2010, 70, 136-143.

190. Tsai, J.R.; Wang, H.M.; Liu, P.L.; Chen, Y.H.; Yang, M.C.; Chou, S.H.; Cheng, Y.J.; Yin, W.H.; Hwang, J.J.; Chong, I.W. High expression of heme oxygenase-1 is associated with tumor invasiveness and poor clinical outcome in non-small cell lung cancer patients. Cell. Oncol. 2012, $35,461-471$.

191. Yeghiazaryan, M.; Zybura-Broda, K.; Cabaj, A.; Wlodarczyk, J.; Slaeinska, U.; Rylski, M.; Wilczynski, G.M. Fine-structural distribution of MMP-2 and MMP-9 activities in the rat skeletal muscle upon training: A study of high resolution in situ zymography. Histochem. Cell Biol. 2012, 138, 75-87.

192. Yang, Y.; Candelario-Jalil, E.; Thompson, J.F.; Cuadrado, E.; Estrada, E.Y.; Rosell, A.; Montaner, J.; Rosenberg, G.A. Increased intranuclear metalloproteinase activity in neurons interferes with oxidative DNA repair in focal cerebral ischemia. J. Neurochem. 2010, 112, 134-149.

193. Kwan, J.A.; Schulze, C.J.; Wang, W.; Leon, H.; Sariahmetoglu, M.; Sung, M.; Sawicka, J.; Simms, D.E.; Sawicki, G.; Schulz, R. Matrix metalloproteinase-2 (MMP-2) is present in the nucleus of cardiac myocytes and is capable of cleaving poly (ADP-ribose) polymerase (PARP) in vitro. FASEB J. 2004, 18, 690-692.

194. Hill, J.W.; Poddar, R.; Thompson, J.F.; Rosenberg, G.A.; Yang, Y. Intranuclear matrix metalloproteinases promote DNA damage and apoptosis induced by oxygen-glucose deprivation in neurons. Neuroscience 2012, 18, 277-290.

195. Mannello, F.; Luchetti, F.; Falcieri, E.; Papa, S. Multiple roles of matrix metalloproteinases during apoptosis. Apoptosis 2005, 10, 19-24.

196. Monferran, S.; Paupert, J.; Dauvillier, S.; Salles, B.; Muller, C. The membrane form of the DNA repair protein $\mathrm{Ku}$ interacts at the cell surface with metalloproteinase 9. EMBO J. 2004, 23, 3758-3768.

197. Sans-Fons, G.M.; Sole, S.; Sanfeliu, C.; Planas, A.M. Matrix metalloproteinase-9 and cell division in neuroblastoma cells and bone marrow macrophages. Am. J. Pathol. 2010, 177, 2870-2885.

198. Zhao, W.J.; Zhang, W.; Li, G.L.; Cui, Y.; Shi, Z.F.; Yuan, F. Differential expression of MMP-9 and AQP4 in human glioma samples. Folia Neuropathol. 2012, 50, 176-186. 
199. Moran, A.; Iniesta, P.; de Juan, C.; Gonzales-Quevedo, R.; Sanchez-Pernaute, A.; Diaz-Rubio, E.; Ramon y Cajal, S.; Torres, A.; Balibrea, J.L.; Benito, M. Stromelysin-1 promoter mutations impair gelatinase B activation in high microsatellite instability sporadic colorectal tumors. Cancer Res. 2002, 62, 3855-3860.

200. Moran, A.; Iniesta, P.; de Juan, C.; Garcia-Aranda, C.; Benito, M. Impairment of stromelysin-1 transcriptional activity by promoter mutations in high microsatellite instability colorectal tumors. Cancer Res. 2005, 65, 3811-3814.

201. Thiefin, G.; Dupont, A.; Guillou, P.J.; Vitry, F.; Bouche, O.; Yaziji, N.; Lagarde, S.; Maquart, F.X.; Palot, J.P.; Hornebeck, W.; et al. Beneficial influence of microsatellite instability on gelatinasetissue inhibitors of metalloproteinase balance in colorectal cancer. Anticancer Res. 2007, 27, 583-588.

202. Sinnamon, M.J.; Carter, K.J.; Fingleton, B.; Matrisian, L.M. Matrix metalloproteinase-9 contributes to intestinal tumourigenesis in the adenomatous polyposis coli multiple intestinal neoplasia mouse. Int. J. Exp. Pathol. 2008, 89, 466-475.

203. Opdenakker, G.; van den Steen, P.E.; Dubois, B.; Nielssen, I.; van Coillie, E.; Masure, S.; Proost, P.; van Damme, J. Gelatinase B functions as regulator and effector in leukocyte biology. J. Leukoc. Biol. 2001, 69, 851-859.

204. Radisky, D.C.; Levy, D.D.; Litllepage, L.E.; Liu, H.; Nelson, C.M.; Fata, J.E.; Leake, D.; Godden, E.L.; Albertson, D.G.; Nieto, M.A.; et al. Raclb and reactive oxygen species mediate MMP-3-induced EMT and genomic instability. Nature 2005, 436, 123-127.

205. Samper, E.; Nicholls, D.G.; Melov, S. Mitochondrial oxidative stress causes chromosomal instability of mouse embryonic fibroblasts. Aging Cell 2003, 2, 277-285.

206. Thieringer, F.R.; Maass, T.; Anthon, B.; Meyer, E.; Schirmacher, P.; Longerich, T.; Galle, P.R.; Kanzler, S.; Teufel, A. Liver-specific overexpression of matrix metalloproteinase 9 (MMP-9) in transgenic mice accelerates development of hepatocellular cancer. Mol. Carcinog. 2012, 51, 439-448.

207. Fatunmbi, M.; Shelton, J.; Aronica, S.M. gelatinase B/MMP-9 increases HER2/neu expression and alters apoptosis levels in human mammary epithelia cells. Breast Cancer Res. Treat. 2012, 135, 519-530.

208. Ponnala, S.; Veeravalli, K.K.; Chetty, C.; Dinh, D.H.; Rao, J.S. Regulation of DNA repair mechanism in human glioma xenograft cells both in vitro and in vivo in nude mice. PLoS One 2011, 6, e26191.

209. Hanahan, D.; Weinberg, R.A. Hallmarks of cancer: The next generation. Cell 2011, 144, 646-674.

210. Colotta, F.; Allavena, P.; Sica, A.; Garlanda, C.; Mantovani, A. Cancer-related inflammation, the seventh hallmark of cancer: Links to genetic instability. Carcinogenesis 2009, 30, 1073-1081.

211. Bergers, G.; Brekken, R.; McMahon, G.; Vu, T.H.; Itoh, T.; Tamaki, K.; Tanzawa, K.; Thorpe, P.; Itohara, S.; Werb, Z.; et al. Matrix metalloproteinase-9 triggers the angiogenic switch during carcinogenesis. Nat. Cell. Biol. 2000, 2, 737-744. 
212. Belotti, D.; Paganoni, P.; Manetti, L.; Garofalo, A.; Marchini, S.; Taraboletti, G.; Giavazzi, R. Matrix metalloproteinases (MMP-9 and MMP-2) induce the release of vascular endothelial growth factor (VEGF) by ovarian carcinoma cells: Implications for ascites formation. Cancer Res. 2003, 63, 5224-5229.

213. Mott, J.D.; Werb, Z. Regulation of matrix biology by matrix metalloproteinases. Curr. Opin. Cell Biol. 2004, 16, 558-564.

214. Brauer, P.R. MMPs-Role in cardiovascular development and disease. Front Biosci. 2006, 11, 447-478.

215. Rorive, S.; Berton, A.; D’haene, N.; Takacs, C.N.; Debeir, O.; Decaestecker, C.; Salmon, I. Matrix metalloproteinase-9 interplays with the IGFBP2-IGFII complex to promote cell growth and motility in astrocytomas. Glia 2008, 56, 1679-1690.

216. Alferez, D.; Wilkinson, R.W.; Watkins, J.; Poulsom, R.; Mandir, N.; Wedge, S.R.; Pyrah, I.T.; Smith, N.R.; Jackson, L.; Ryan, A.J.; et al. Dual inhibition of VEGFR and EGFR signalling reduces the incidence and size of intestinal adenomas in Apc(min/+) mice. Mol. Cancer Ther. 2008, 7, 590-598.

217. Ingraham, C.A.; Park, G.C.; Makarenkova, H.P.; Crossin, K.L. Matrix metalloproteinase (MMP)-9 induced by Wnt signalling increases the proliferation and migration of embryonic neural stem cells at low O2 levels. J. Biol. Chem. 2011, 286, 17649-17657.

218. Aguilar-Gallardo, C.; Simon, C. Cells, stem cells and cancer stem cells. Semin. Reprod. Med. 2013, 31, 5-13.

219. Beck, B.; Blanpain, C. Unravelling cancer stem cell potential. Nat. Rev. Cancer 2013, 13, $727-738$.

220. Santamaria-Martinez, A.; Huelsken, J. The niche under siege: Novel targets for metastasis therapy. J. Intern. Med. 2013, 274, 127-136.

221. Seidel, S.; Garvalov, B.K.; Wirta, W.; von Stechow, L.; Schanzer, A.; Meletis, K.; Wolter, M.; Sommerlad, D.; Henze, A.T.; Nister, M.; et al. A hypoxic niche regulates glioblastoma stem cells through hypoxia inducible factor 2 alpha. Brain 2010, 133, 983-995.

222. Wang, J.; Loberg, R.; Taichman, R.S. The pivotal role of CXCL12 (SDF-1)/CXCR4 axis in bone metastasis. Cancer Met. Rev. 2006, 25, 573-587.

223. Wels, J.; Kaplan, R.N.; Rafii, S.; Lyden, D. Migratory neighbors and distant invaders: Tumor-associated niche cells. Genes Dev. 2008, 22, 559-574.

224. Chiang, A.C.; Massague, J. Molecular basis of metastasis. N. Engl. J. Med. 2008, 359, 2814-2823.

225. Van Amerongen, R.; Nusse, R. Towards an integrated view of Wnt signalling in development. Development 2009, 136, 3205-3214.

226. Thiery, J.P. Epithelial-mesenchymal transitions in tumour progression. Nat. Rev. Cancer 2002, 2, 442-454.

227. Reya, T.; Morrison, S.J.; Clarke, M.F.; Weissman, I.L. Stem cells, cancer, and cancer stem cells. Nature 2011, 414, 105-111.

228. Brabletz, T.; Hlubek, F.; Spaderna, S.; Schmalhofer, O.; Hiendlmeyer, E.; Jung, A.; Kirchner, T. Invasion and metastasis in colorectal cancer: Epithelial-mesenchymal transition, mesenchymalepithelial transition, stem cells and beta catenin. Cells Tissues Organs 2005, 179, 56-65. 
229. Pardal, R.; Clarke, M.F.; Morrison, S.J. Applying principles of stem-cell biology to cancer. Nat. Rev. Cancer 2003, 3, 895-902.

230. Margetts, P.J. Twist: A new player in the epithelial-mesenchymal transition of the peritoneal mesothelial cells. Nephrol. Dial. Transplant. 2012, 27, 3978-3981.

231. Lin, C.Y.; Tsai, P.H.; Kandaswami, C.C.; Lee, P.P.; Huang, C.J.; Lee, M.T. Matrix metalloproteinase-9 cooperates with transcription factor snail to induce epithelial-mesenchymal transition. Cancer Sci. 2011, 102, 815-827.

232. Asuthkar, S.; Nalla, A.K.; Gondi, G.S.; Dinh, D.H.; Gujrati, M.; Mohanam, S.; Rao, J.S. Gadd45a sensitizes medulloblastoma cells to irradiation and suppresses MMP-9-mediated EMT. Neuro. Oncol. 2011, 13, 1059-1073.

233. Gao, X.H.; Yang, X.Q.; Wang, B.C.; Liu, S.P.; Wang, F.B. Overexpression of twist and matrix metalloproteinase-9 with metastasis and prognosis in gastric cancer. Asian Pac. J. Cancer Prev. 2013, 14, 5055-5060.

234. Zhao, J.; Guan, J.L. Signal transduction by focal adhesion kinase in cancer. Cancer Metastasis Rev. 2009, 28, 35-49.

235. Li, J.; Li, F.; Wang, H.; Wang, X.; Jiang, Y.; Li, D. Wortmannin reduces metastasis and angiogenesis of human breast cancer cells via nuclear factor-kappaB-dependent matrix metalloproteinase-9 and interleukin-8 pathways. J. Int. Med. Res. 2012, 40, 867-876.

236. Zhao, J.; Guan, J.L. Focal adhesion kinase and its signalling pathways in cell migration and angiogenesis. Adv. Drug Deliv. Rev. 2011, 63, 610-615.

237. Yoo, Y.A.; Kang, M.H.; Lee, H.J.; Kim, B.H.; Park, J.K.; Kim, H.K.; Kim, J.S.; Oh, S.C. Sonic hedgehog pathway promotes metastasis and lymphangiogenesis via activation of Akt, EMT, and MMP-9 pathway in gastric cancer. Cancer Res. 2011, 71, 7061-7070.

238. Opdenakker, G.; van den Steen, P.E.; van Damme, J. Gelatinase B: A tuner and amplifier of immune functions. Trends Immunol. 2001, 22, 571-579.

239. Chakrabarti, S.; Patel, K.D. Regulation of matrix metalloproteinase release from IL-8-stimulated human neutrophils. J. Leukoc. Biol. 2005, 78, 279-288.

240. Chinni, S.R.; Sivalogan, S.; Dong, Z.; Filho, J.C.; Deng, X.; Bonfil, R.D.; Cher, M.L. CXCL12/CXCR4 signaling activates Akt and MMP-9 expression in prostate cancer cells: The role of bone microenvironment-associated CXCL12. Prostate 2006, 66, 32-48.

241. Kwak, Y.E.; Jeon, N.K.; Kim, J.; Lee, E.J. The cyclooxygenase-2 selective inhibitor celecoxib suppresses proliferation and invasiveness in the human oral squamous carcinoma. Ann. NY Acad. Sci. 2007, 1095, 99-112.

242. Ishizaki, T.; Katsumata, K.; Tsuchida, A.; Wada, T.; Mori, Y.; Hisada, M.; Kawakita, H.; Aoki, T. Etodolac, a selective cyclooxygenase-2 inhibitor, inhibits liver metastasis of colorectal cancer cells via the suppression of gelatinase B/MMP-9 activity. Int. J. Mol. Med. 2006, 17, $357-362$.

243. Kim, Y.H.; Kwon, H.J.; Kim, D.S. Matrix metalloproteinase 9 (MMP-9)-dependent processing of Big-h3 protein regulates cell migration, invasion, and adhesion. J. Biol. Chem. 2012, 287, 38957-38969. 
244. Leifer, K.S.; Svensson, S.; Abrahamsson, A.; Bendrick, C.; Robertson, J.; Gauldie, J.; Olsson, A.-K.; Dabrosin, C. Inflammation induced by MMP-9 enhances tumor regression of experimental breast cancer. J. Immunol. 2013, 190, 4420-4430.

245. Farnsworth, R.H.; Lackmann, M.; Achen, M.G.; Stacker, S.A. Vascular remodelling in cancer. Oncogene 2013, doi:10.1038/onc.2013.304.

246. Van Hinsbergh, V.W.; Engelse, M.A.; Quax, P.H. Pericellular proteases in angiogenesis and vasculogenesis. Aterioscler. Thromb. Vasc. Biol. 2006, 26, 716-728.

247. Joyce, J.A. Therapeutic targeting of the tumor microenvironment. Cancer Cell 2005, 7, 513-520.

248. Bergers, G.; Benjamin, L.E. Tumorigenesis and the angiogenic switch. Nat. Rev. Cancer 2003, 3, 401-410.

249. Coussens, L.M.; Tinkle, C.L.; Hanahan, D.; Web, Z. MMP-9 supplied by bone marrow-derived cells contributes to skin carcinogenesis. Cell 2000, 103, 481-490.

250. Heissig, B.; Werb, Z.; Rafii, S.; Hattori, K. Role of c-kit/Kit ligand signalling in regulating vasculogenesis. Thromb. Haemost. 2003, 90, 570-576.

251. Mira, E.; Lacalle, R.A.; Buesa, J.M.; de Buitrago, G.G.; Jimenez-Baranda, S.; Gòmez-Moutòn, C.; Mrtinaz, A.C.; Manes, S. Secreted MMP-9 promotes angiogenesis more efficiently than constitutive active MMP-9 bound to the tumour cell surface. J. Cell Sci. 2004, 117, 1847-1857.

252. Gao, D.; Nolan, D.; McDonnell, K.; Vahdat, L.; Benezra, R.; Attorki, N.; Mittal, V. Bone marrow-derived endothelial progenitor cells contribute to the angiogenic switch in tumor growth and metastatic progression. Biochim. Biophys. Acta 2009, 1796, 33-40.

253. Giraudo, E.; Inoue, M.; Hanahan, D. An amino-bisphosphonate targets MMP-9-expressing macrophages and angiogenesis to impair cervical angiogenesis. J. Clin. Investig. 2004, 114, 623-633.

254. Nosawa, H.; Chiu, C.; Hanahan, D. Infiltrating neutrophils mediate the initial angiogenic switch in a mouse model of multistage carcinogenesis. Proc. Natl. Acad. Sci. USA 2006, 103, 12493-12498.

255. Melani, C.; Sangaletti, S.; Barazzetta, F.M.; Werb, Z.; Colombo, M.P. Amino-bisphosphonatemediated MMP-9 inhibition breaks the tumor-bone marrow axis responsible for myeloid-derived suppressor cell expansion and macrophage infiltration in tumor stroma. Cancer Res. 2007, 67, 11438-11446.

256. Hagemann, T.; Robinson, S.C.; Schultz, M.; Trumper, L.; Balkwill, F.R.; Binder, C. Enhanced invasiveness of breast cancer cell lines upon co-cultivation with macrophages is due to TNF-alpha dependent up-regulation of matrix metalloproteinases. Carcinogenesis 2004, 25, 1543-1549.

257. Morales, J.K.; Kmeiciak, M.; Knutson, K.L.; Bear, H.D.; Manjili, M.H. GM-CSF is one of the main breast tumor-derived soluble factors involved in the differentiation of CD11b-Gr1-bone marrow progenitor cells into myeloid-derived suppressor cells. Breast Cancer Res. Treat. 2010, $123,39-49$.

258. Marigo, I.; Dolcetti, L.; Serafini, P.; Zanovello, P.; Bronte, V. Tumor-induced tolerance and immune suppression by myeloid derived suppressor cells. Immunol. Rev. 2008, 222, 162-179.

259. Gabrilovich, D.I.; Nagaraj, S. Myeloid-derived suppressor cells as regulators of the immune system. Nat. Rev. Immunol. 2009, 9, 162-174. 
260. Urbich, C.; Dimmeler, S. Endothelial progenitor cells: Characterisation and role in vascular biology. Circ. Res. 2004, 95, 343-353.

261. Rafii, S.; Lyden, D. Therapeutic stem and progenitor cell transplantation for organ vascularization and regeneration. Nat. Med. 2003, 9, 702-712.

262. Inoue, T.; Taguchi, I.; Abe, S.; Toyoda, S.; Nakajima, K.; Sakuma, M.; Node, K. Activation of matrix metalloproteinase- 9 is associated with mobilization of bone marrow-derived cells after coronary stent implantation. Int. J. Cardiol. 2011, 152, 332-336.

263. Inoue, T.; Sata, M.; Hikichi, Y.; Sohma, R.; Fukuda, D.; Uchida, T.; Shimizu, M.; Komoda, H.; Node, K. Mobilization of CD34-positive bone marrow-derived cells after coronary stent implantation: Impact on restenosis. Circulation 2007, 115, 553-561.

264. Jodele, S.; Chantrain, C.F.; Blavier, L.; Lutzko, C.; Crooks, G.M.; Shimada, H.; Coussens, L.M.; DeClerck, Y.A. The contribution of bone marrow-derived cells to the tumor vasculature in neuroblastoma is matrix metalloproteinase-9 dependent. Cancer Res. 2005, 65, 3200-3208.

265. Tacconelli, A.; Farina, A.R.; Cappabianca, L.; de Santis, G.; Tessitore, A.; Vetuschi, A.; Sferra, R.; Rucci, N.; Argenti, B.; Screpanti, I.; et al. TrkA alternative splicing: A regulated tumor-promoting switch in human neuroblastoma. Cancer Cell 2004, 6, 347-360.

266. Chantrain, C.F.; Shimada, H.; Jodele, S.; Groshen, S.; Ye, W.; Shalinsky, D.R.; Werb, Z.; Coussens, L.M.; DeClerck, Y.A. Stromal matrix metalloproteinase-9 regulates the vascular architecture in neuroblastoma by promoting pericyte recruitment. Cancer Res. 2004, 64, 1675-1686.

267. Nielsen, B.S.; Sehested, M.; Kjeldsen, L.; Borregaard, N.; Rygaard, J.; Dano, K. Expression of matrix metalloproteinase-9 in vascular pericytes in human breast cancer. Lab. Invest. 1997, 77, $345-355$.

268. Vu, T.H.; Shipley, J.M.; Bergers, G.; Berger, J.E.; Helms, J.A.; Hanahan, D.; Shapiro, S.D.; Senior, R.M.; Werb, Z. MMP-9/gelatinase B is a key regulator of growth plate angiogenesis and apoptosis of hypertrophic chondrocytes. Cell 1998, 93, 411-422.

269. Ahn, G.O.; Brown, J.M. Matrix metalloproteinase-9 is required for tumor vasculogenesis but not for angiogenesis: Role of bone marrow-derived myelomonocytic cells. Cancer Cell 2008, 13, 195-205.

270. Johnson, C.; Sung, H.J.; Lessner, S.M.; Fini, M.E.; Galis, Z.S. Matrix metalloproteinase-9 is required for adequate angiogenic revascularization of ischemic tissues: Potential role in capillary branching. Circ. Res. 2004, 94, 262-268.

271. Shekhar, M.P.; Werdell, J.; Santner, S.J.; Pauley, R.J.; Tait, L. Breast stroma plays a dominant regulatory role in breast epithelial growth and differentiation: Implications for tumor development and progression. Cancer Res. 2001, 61, 1320-1326.

272. Nakamura, T.; Kuwai, T.; Kim, J.S.; Fan, D.; Kim, S.J.; Fidler, I.J. Stromal metalloproteinase-9 is essential to angiogenesis and progressive growth of orthotopic human pancreatic cancer in parabiont nude mice. Neoplasia 2007, 9, 979-986.

273. He, J.Z.; Quan, A.; Xu, Y.; Teoh, H.; Wang, G.; Fish, J.E.; Steer, B.M.; Itohara, S.; Marsden, P.A.; Davidge, S.T.; et al. Induction of matrix metalloproteinase-2 enhances systemic arterial contraction after hypoxia. Am. J. Physiol. 2007, 292, 684-693. 
274. Nakano, D.; Hyashi, T.; Tazawa, N.; Yamashita, C.; Inamoto, S.; Okuda, N.; Mori, T.; Sohmiya, K.; Kitaura, Y.; Okada, Y.; et al. Chronic hypoxia accelerates the progression of atherosclerosis in apoliprotein E-knockout mice. Hypertens. Res. 2005, 28, 837-845.

275. Zalba, G.; Fortuno, A.; Orbe, J.; San Jose, G.; Moreno, M.U.; Belzunce, M.; Rodriguez, J.A.; Beloqui, O.; Paramo, J.A.; Diez, J. Phagocytic NADPH oxidase-dependent superoxide production stimulates metalloproteinase-9: Implications for human atherosclerosis. Arterioscler. Thromb. Vasc. Biol. 2007, 27, 587-593.

276. Jadhav, U.; Chigurupati, S.; Lakka, S.S.; Mohanam, S. Inhibition of matrix metalloproteinase-9 reduces in vitro invasion and angiogenesis in human microvascular endothelial cells. Int. J. Oncol. 2004, 25, 1407-1414.

277. Tallant, C.; Marrero, A.; Gomis-Ruth, F.X. Matrix metalloproteinases: Fold and function of their catalytic domains. Biochim. Biophys. Acta 2010, 1803, 20-28.

278. Li, H.; Liang, J.; Castrillon, D.H.; DePinho, R.A.; Olson, E.N.; Liu, Z.P. FoxO4 regulates tumor necrosis factor alpha-directed smooth muscle cell migration by activating matrix metalloproteinase 9 gene expression. Mol. Cell. Biol. 2007, 27, 2676-2686.

279. Chandrasekar, B.; Mummidi, S.; Mahimainathan, L.; Patel, D.N.; Bailey, S.R.; Imam, S.Z.; Greene, W.C.; Valente, A. J. Interleukin-18-induced human coronary artery smooth muscle cell migration is dependent on NF-kappaB and AP-1-mediated matrix metalloproteinase-9 expression and is inhibited by atorvastatin. J. Biol. Chem. 2006, 281, 15099-15109.

280. Cheng, G.; Wei, L.; Xiurong, W.; Xiangzhen, L.; Shiguang, Z.; Songbin, F. IL-17 stimulates migration of carotid artery smooth muscle cells in an MMP-9 dependent manner via p38 MAPK and ERK1/2-dependent NF-KappaB and AP-1 activation. Cell. Mol. Neurobiol. 2009, 29, $1161-1168$.

281. Galis, Z.S.; Johnson, C.; Godin, D.; Magid, R.; Shipley, J.M.; Senior, R.M.; Ivan, E. Targeted disruption of the matrix metalloproteinase-9 gene impairs smooth muscle cell migration and geometrical arterial remodelling. Circ. Res. 2002, 91, 852-859.

282. Jenkins, G.M.; Crow, M.T.; Bilato, C.; Gluzband, Y.; Ryu, W.S.; Li, Z.; Stetler-Stevenson, W.; Nater, C.; Froehlich, J.P.; Lakatta, E.G.; et al. Increased expression of membrane type matrix metalloproteinase and preferential localization of matrix metalloproteinase- 2 to the neointima of balloon-injured rat carotid arteries. Circulation 1998, 97, 82-90.

283. Xu, J.; Rodriguez, D.; Petitclerc, E.; Kim, J.J.; Hangai, M.; Moon, Y.S.; Davis, G.E.; Brooks, P.C. Proteolytic exposure of a cryptic site within collagen type IV is required for angiogenesis and tumor growth in vivo. J. Cell Biol. 2001, 154, 1069-1080.

284. Hamano, Y.; Zeisberg, M.; Sugimoto, H.; Lively, J.C.; Maeshima, Y.; Yang, C.; Hynes, R.O.; Werb, Z.; Sudhakar, A.; Kalluri, R. Physiological levels of tumstatin, a fragment of collagen IV alpha3 chain, are generated by MMP-9 proteolysis and suppress angiogenesis via alphaV beta3 integrin. Cancer Cell 2003, 3, 589-601.

285. Wahl, M.L.; Kenan, D.J.; Gonzalez-Gronow, M.; Pizzo, S.V. Angiostatin's molecular mechanism: Aspects of specificity and regulation elucidated. J. Cell. Biochem. 2005, 96, 242-261.

286. Kalhuri, R. Basement membranes: Structure, assembly and role in tumor angiogenesis. Nat. Rev. Cancer 2003, 3, 422-433. 
287. Sudhakar, A.; Sugimoto, H.; Yang, C.; Lively, J.; Zeisberg, M.; Kalluri, R. Human tumstatin and human endostatin exhibit distinct anti-angiogenic activities mediated by alpha $\mathrm{V}$ beta 3 and alpha 5 beta 1 integrins. Proc. Natl. Acad. Sci. USA 2003, 100, 4766-4771.

288. Kim, Y.M.; Jang, J.W.; Lee, O.H.; Yeon, J.; Choi, E.Y.; Kim, K.W.; Lee, S.T.; Kwon, Y.G. Endostatin inhibits endothelial and tumor cellular invasion by blocking the activation and catalytic activity of matrix metalloproteinase. Cancer Res. 2000, 60, 5410-5413.

289. Nyberg, P.; Heikkila, P.; Sorsa, T.; Luostarinen, J.; Heljasvaara, R.; Stenman, U.H.; Pihlajaniemi, T.; Salo, T. Endostatin inhibits human tongue carcinoma cell invasion and intravasation and blocks the activation of matrix metalloproteinase-2, -9 , and -13. J. Biol. Chem. 2003, 278, 22404-22411.

290. Guan, K.P.; Ye, H.Y.; Yan, Z.; Wang, Y.; Huo, S.K. Serum levels of endostatin and matrix metalloproteinase-9 associated with high stage and grade primary transitional cell carcinoma of the bladder. Urology 2003, 61, 719-723.

291. Ezhilarasan, R.; Jadhav, U.; Mohaman, I.; Rao, J.S.; Gujrati, M.; Mohaman, S. The hemopexin domain of MMP-9 inhibits angiogenesis and retards the growth of intracranial glioblastoma xenograft in nude mice. Int. J. Cancer 2009, 124, 306-315.

292. Qian, X.; Wang, T.N.; Rothman, V.L.; Nicosia, R.F.; Tuszynski, G.P. Thrombospondin-1 modulates angiogenesis in vitro by up-regulation of matrix metalloproteinase- 9 in epithelial cells. Exp. Cell Res. 1997, 235, 403-412.

293. Asuthkar, S.; Velpula, K.K.; Nalla, A.K.; Gogineni, V.R.; Gondi, C.S.; Rao, J.S. Irradiationinduced angiogenesis is associated with an MMP-9-miR-494-syndecan-1 regulatory loop on medulloblastoma cells. Oncogene 2013, doi:10.1038/onc.2013.151.

294. Wang, X.; Lee, S.O.; Xia, S.; Jiang, Q.; Luo, J.; Li, L.; Yeh, S.; Chang, C. Endothelial cells enhance prostate cancer metastasis via IL-6-androgen receptor-TGF- $\beta$-MMP-9 signals. Mol. Cancer Ther. 2013, 12, 1026-1037.

295. Loukovaara, S.; Robciuc, A.; Holopainen, J.M.; Lehti, K.; Pessi, T.; Liinamaa, J.; Kukkonen, K.T.; Jauhiainen, M.; Koli, K., Keski-Oja, J.; et al. Ang-2 upregulation correlates with increased levels of MMP-9, VEGF, EPO and TGF $\beta$ in diabetic eyes undergoing vitrectomy. Acta Opthalmol. 2013, 91, 531-539.

296. Hiratsuka, S.; Nakamura, K.; Iwai, S.; Murakami, M.; Itoh, T.; Kijima, H.; Shipley, J.M.; Senior, R.M.; Shibuya, M. MMP9 induction by vascular endothelial cell growth factor receptor-1 is involved in lung specific metastasis. Cancer Cell 2002, 2, 289-300.

297. Wang, H.; Keiser, J.A. Vascular endothelial growth factor upregulates the expression of matrix metalloproteinases in vascular smooth muscle cells: Role of flt-1. Circ. Res. 1998, 83, 832-840.

298. Ghosh, S.; Basu, M.; Roy, S.S. ETS-1 protein regulates vascular endothelial cell growth factor-induced matrix metalloproteinase- 9 and matrix metalloproteinase-13 expression in human ovarian carcinoma cell line SKOV-3. J. Biol. Chem. 2012, 287, 15001-15015.

299. Christoffersson, G.; Vagesjo, E.; Vandooren, J.; Liden, M.; Massena, S.; Reinert, R.B.; Brissova, M.; Powers, A.C.; Opdenakker, G.; Phillipson, M. VEGF-A recruits a proangiogenic MMP-9-delivering neutrophil subset that induces angiogenesis in transplanted hypoxic tissue. Blood 2012, 120, 4653-4662. 
300. Lungu, G.; Covaleda, L.; Mendes, O.; Martini-Stoica, H.; Stoica, G. FGF-1-induced matrix metalloproteinase-9 expression in breast cancer cells is mediated by increased activities of NF-kappaB and activating protein-1. Mol. Carcinogen. 2008, 47, 424-435.

301. Mohan, R.; Sivak, J.; Ashton, P.; Russo, L.A.; Pham, B.Q.; Kasahara, N.; Raizman, M.B.; Fini, E.M. Curcuminoids inhibit the angiogenic response stimulated by fibroblast growth factor-2, including expression of matrix metalloproteinase gelatinase B. J. Biol. Chem. 2000, 275, 10405-10412.

302. Tang, L.; Ma, X.; Tian, Q.; Cheng, Y.; Yao, H.; Liu, Z.; Qu, X.; Han, X. Inhibition of angiogenesis and invasion by DMBT is mediated by down regulation of VEGF and MMP-9 through Akt pathway in MDA-MB-231 breast cancer cells. Food Chem. Toxicol. 2013, 56, 204-213.

303. Xu, Y.B.; Du, Q.H.; Zhang, M.Y.; Yun, P.; He, C.Y. Propofol suppresses proliferation, invasion and angiogenesis by down regulating ERK/VEGF/MMP-9 signaling in Eca-109 esophageal squamous cell carcinoma cells. Eur. Rev. Med. Pharmacol. Sci. 2013, 17, 2486-2494.

304. Gorantla, B.; Bhoopathi, P.; Chetty, C.; Gogineni, V.R.; Sailaja, G.S.; Gondi, C.S.; Rao, J.S. Notch signalling regulates tumor-induced angiogenesis in SPARC overexpressed neuroblastoma. Angiogenesis 2013, 16, 85-100.

305. Jia, W.; Gao, X.J.; Zhang, Z.X.; Zhang, G. S100A4 silencing suppresses proliferation, angiogenesis and invasion of thyroid cancer cells through down regulation of MMP-9 and VEGF. Eur. Rev. Med. Pharm. Sci. 2013, 17, 1495-1508.

306. Yi, E.Y.; Kim, Y.J. Xylitol inhibits in vitro and in vivo angiogenesis by suppressing the NF-kB and Akt signalling pathways. Int. J. Oncol. 2013, 43, 315-320.

307. Xu, J.; Zhu, D.; Sonoda, S.; He, S.; Spee, C.; Ryan, S.J.; Hinton, D.R. Over-expression of BMP4 inhibits choroidal neovascularization by modulating VEGF and MMP-9. Angiogenesis 2012, 15, 213-227.

308. Suboj, P.; Babykutty, S.; Valiyaparambil Gopi, D.R.; Nair, R.S.; Srinivas, P.; Gopala, S. Aloe emodin inhibits colon cancer cell migration/angiogenesis by down regulating MMP-2/9, RhoB and VEGF via reduced DNA binding activity of NF-кB. Eur. J. Pharm. Sci. 2012, 45, 581-591.

309. Hendrix, M.J.C.; Seftor, E.A.; Meltzer, P.S.; Gardner, L.M.G.; Hess, A.R.; Kirschmann, D.A.; Schatteman, G.C.; Seftor, R.E.B. Expression and function of VE-cadherin in aggressive human melanoma cells: Role invasculogenic mimicry. Proc. Natl. Acad. Sci. USA 2001, 98, 8018-8023.

310. Karoum, A.; Mirshahi, P.; Faussat, A.-M.; Therwath, A.; Mirshahi, M.; Hatmi, M. Tubular network formation by adriamycin-resistant MCF-7 breast cancer cells is closely linked to MMP-9 and VEGFR-2/VEGFR-3 over-expression. Mol. Cell. Pharmacol. 2012, 685, 1-7.

311. Wong, S.Y.; Hynes, R.O. Lymphatic or hematogenous dissemination: How does a metastatic tumor cell decide? Cell Cycle 2006, 5, 812-817.

312. Christiansen, A.; Detmar, M. Lymphangiogenesis and cancer. Genes Cancer 2011, 2, 1146-1158.

313. Rutkowski, J.M.; Boardman, K.C.; Swarz, M.A. Characterisation of lymphangiogenesis in a model of adult skin regeneration. Am. J. Physiol. Heart Circ. Physiol. 2006, 291, 1402-1410. 
314. Tan, K.W.; Chong, S.Z.; Wong, F.H.; Evrard, M.; Tan, S.M.; Keeble, J.; Kemeny, M.D.; Ng, L.G.; Abastado, J.P.; Angeli, V. Neutrophils contribute to inflammatory lymphangiogenesis by increasing VEGF-A bioavailability and secreting VEGF-D. Blood 2013, 122, 3666-3677.

315. Zheng, S.Q.; Huang, R.Q.; Zhang, Y.J. Role of matrix metalloproteinases (MMP)-2 and -9 and vascular endothelial growth factor $\mathrm{C}$ in lymph node metastasis of breast cancer. Zhonghua Bing Li Xue Za Zhi 2010, 39, 240-244.

316. Elston, C.W.; Ellis, I.O. Pathological prognostic factors in breast cancer. 1. The value of histological grade in breast cancer: Experience from a large study with long-term follow-up. Histopathology 2002, 41, 154-161.

317. Peterson, O.W.; Ronnov-Jessen, L.; Howlett, A.R.; Bissel, M.J. Interaction with basement membrane serves to rapidly distinguish growth and differentiation pattern of normal and malignant human breast epithelial cells. Proc. Natl. Acad. Sci. USA 1992, 89, 9064-9068.

318. Redondo-Munoz, J.; Ugarte-Berzal, E.; Garcia-Marco, J.A.; del Cerro, M.H.; van den Steen, P.E.; Opdenakker, G.; Terol, M.J.; Garcia-Pardo, A. Alpha4Betal integrin and 190-kDa CD44v constitute a cell surface docking complex fro gelatinase B/MMP-9 in chronic leukemia but not in normal B cells. Blood 2008, 112, 169-178.

319. Brooks, P.C.; Silletti, S.; von Schalscha, T.L.; Friedlander, M.; Cheresh, D. Disruption of angiogenesis by Pex, a non catalytic fragment with integrin binding activity. Cell 1998, 92, 683-693.

320. Dufour, A.; Sampson, N.S.; Zucker, S.; Cao, J. Role of the hemopexin domain of matrix metalloproteinases in cell migration. J. Cell Physiol. 2008, 217, 643-651.

321. Paupert, J.; Mansat-De Mas, V.; Demur, C.; Salles, B.; Muller, C. Cell-surface MMP-9 regulates the invasive capacity of leukemia blast cells with Monocytic features. Cell Cycle 2008, 7, 1047-1053.

322. Redondo-Munoz, J.; Ugarte-Berzal, E.; Terol, M.J.; van den Steen, P.E.; Hernandez del Cerro, M.; Roderfeld, M.; Roeb, E.; Opdenakker, G.; Garcia-Marco, J.A.; Garcia-Pardo, A. Matrix metalloproteinase-9 promotes chronic lymphocytic leukemia B cell survival through its hemopexin domain. Cancer Cell 2010, 17, 160-172.

323. Hu, X.; Paik, P.K.; Chen, J.; Yarilina, A.; Kockeritz, L.; Lu, T.T.; Woodgett, J.R.; Ivashkiv, L.B. IFN-gamma suppresses IL-10 production and synergizes with TLR2 by regulating GSK3 and CREB/AP-1 proteins. Immunity 2006, 24, 563-574.

324. Rao, J.S.; Bhoopathi, P.; Chetty, C.; Gujrati, M.; Lakka, S.S. MMP-9 short interfering RNA induced senescence resulting in inhibition of medulloblastoma growth via p16 (INK4a) and mitogen-activated protein kinase pathway. Cancer Res. 2007, 67, 4956-4964.

325. Bhoopathi., P.; Chetty, C.; Kunigal., S.; Vanamala, S.K.; Rao, J.S.; Lakka, S.S. Blockage of tumour growth due to matrix metalloproteinase- 9 inhibition is mediated by sequential activation of $\beta 1$-integrin, ERK, and NF-kB. J. Biol. Chem. 2008, 283, 1545-1552.

326. Wheeler, D.L.; Dunn, E.F.; Harari, P.M. Understanding resistance to EGFR inhibitors-impact on future treatment strategies. Nat. Rev. Clin. Oncol. 2010, 7, 493-507.

327. Frame, M.C.; Patel, H.; Serrels, B.; Lietha, D.; Eck, M.J. The FERM domain: Organizing the structure and function of FAK. Nat. Rev. Mol. Cell. Biol. 2010, 11, 802-814. 
328. Stuelten, C.H.; DaCosta Byfield, S.; Arany, P.R.; Karpova, T.S.; Stetler-Stevenson, W.G.; Roberts, A.B. Breast cancer cells induce stromal fibroblasts to express MMP-9 via secretion of TNF-alpha and TGF-beta. J. Cell Sci. 2005, 118, 2143-2153.

329. Mook, O.R.; Frederiks, W.M.; van Noorden, C.J. The role of gelatinases in colorectal cancer progression and metastasis. Biochim. Biophys. Acta 2004, 1705, 69-89.

330. Jandova, J.; Janda, J.; Sligh, J.E. Changes in mitochondrial DNA alter expression of nuclear encoded genes associated with tumorigenesis. Exp. Cell. Res. 2012, 318, 2215-2225.

331. Friedl, P.; Wolf, K. Tumour-cell invasion and migration: Diversity and escape mechanisms. Nat. Rev. Cancer 2003, 3, 362-374.

332. Sabeh, F.; Shimizu-Hirota, R.; Weiss, S.J. Protease-dependent versus -ndependent cancer cell invasion programs: Three-dimensional amoeboid movement revisited. J. Cell Biol. 2009, 185, 11-19.

333. Legrand, C.; Gilles, C.; Zahm, J.M.; Polette, M.; Buisson, A.C.; Kaplan, H.; Birembaut, P.; Tournier, J.M. Airway epithelial cell migration dynamics. MMP-9 role in cell-extracellular matrix remodelling. J. Cell Biol. 1999, 146, 517-529.

334. Rolli, M.; Fransvea, E.; Pilch, J.; Saven, A.; Felding-Habermann, B. Activated integrin aplphavbeta3 cooperates with metalloproteinase MMP-9 in regulating migration of metastatic breast cancer cells. Proc. Natl. Acad. Sci. USA 2003, 100, 9482-9487.

335. Shibata, K.; Kikkawa, F.; Nawa, A.; Thant, A.A.; Naruse, K.; Mizutani, S.; Hamaguchi, M. Both focal adhesion kinase and c-Ras are required for the enhanced matrix metalloproteinase 9 secretion by fibronectin in ovarian cancer cells. Cancer Res. 1998, 58, 900-903.

336. Ozanne, B.W.; McGarry, L.; Spence, H.J.; Johnston, I.; Winnie, J.; Meagher, L.; Stapleton, G. Transcriptional regulation of cell invasion: AP-1 regulation of a multigenic invasion programme. Eur. J. Cancer 2000, 36, 1640-1648.

337. Shin, E.Y.; Ma, E.K.; Kim, C.K.; Kwak, S.J.; Kim, E.G. Src/ERK but not phospholipase D is involved in keratinocyte growth factor-stimulated secretion of matrix metalloproteinase-9 and urokinase-type plasminogen activator in SNU-16 human stomach cancer cells. J. Cancer Res. Clin. Oncol. 2002, 128, 596-602.

338. Thomas, G.J.; Poomsawat, S.; Lewis, M.P.; Hart, I.R.; Speight, P.M.; Marshall, J.F. Alpha v beta 6 integrin upregulates matrix metalloproteinase 9 and promotes migration of normal oral keratinocytes. J. Invest. Dermatol. 2001, 11, 898-904.

339. Thomas, G.J.; Lewis, M.P.; Hart, I.R.; Marshall, J.F.; Speight, P.M. AlphaVbeta6 integrin promotes invasion of squamous carcinoma cells through up-regulation of matrix metalloproteinase-9. Int. J. Cancer 2001, 92, 641-650.

340. Sil, H.; Sen, T.; Chatterjee, A. Fibronectin-integrin (alpha5beta1) modulates migration and invasion of murine melanoma cell line B16F10 by involving MMP-9. Oncol. Res. 2011, 19, 335-348.

341. Mackay, A.R.; Gomez, D.E.; Nason, A.M.; Thorgeirsson, U.P. Sudies on the effects of laminin, E-8 fragment of laminin and synthetic laminin peptides PA22-2 and YIGRS on matrix metalloproteinase and tissue inhibitor of metalloproteinase expression. Lab. Invest. 1994, 70, 800-806. 
342. Kahn, K.M.; Falcone, D.J. Role of laminin in matrix induction of macrophage urokinase-type plasminogen activator and 92-kDa metalloproteinase expression. J. Biol. Chem. 1997, 272, 8270-8275.

343. Anderson, R.B. Matrix metalloproteinase- 2 is involved in the migration and network formation of enteric neural crest-derived cells. Int. J. Dev. Biol. 2010, 54, 63-69.

344. Fortier, A.M.; Asselin, E.; Cadrin, M. Keratin 8 and 18 loss in epithelial cancer cells increases collective cell migration and cisplatin sensitivity through claudin up-regulation. J. Biol. Chem. 2013, 288, 11555-11571.

345. Xu, D.; McKee, C.M.; Cai, Y.; Ding, Y.; Kessler, B.M.; Muschel R.J. Matrix metalloproteinase-9 regulates tumor cell invasion through cleavage of protease nexin-1. Cancer Res. 2010, 70, 6988-6998.

346. Pal-Ghosh, S.; Blanco, T.; Tadvalkar, G.; Pajoohesh-Ganji, A.; Parthasarathy, A.; Zieske, J.D.; Stepp, M.A. MMP-9 cleavage of the $\beta 4$ integrin ectodomain leads to recurrent epithelial erosions in mice. J. Cell Sci. 2011, 124, 2666-2675.

347. Taddei, M.L.; Parri, M.; Angelucci, A.; Bianchini, F.; Marconi, C.; Giannoni, E.; Raugei, G.; Bologna, M.; Calorini, L.; Chiarugi, P. EphA2 induces metastatic growth regulating amoeboid motility and clonogenic potential in prostate carcinoma cells. Mol. Cancer Res. 2011, 9, 149.

348. Wyckoff, J.; Wang, W.; Lin, E.Y.; Wang, Y.; Pixley, F.; Stanley, E.R.; Graf, T.; Pollard, J.W.; Segall, J.; Condeelis, J. A paracrine loop between tumor cells and macrophages is required for tumor cell migration in mammary tumors. Cancer Res. 2004, 64, 7022-7029.

349. Gherardi, E.; Birchmeier, W.; Birchmeier, C.; vande Woude, G. Tageting MET in cancer: Rational and progress. Nat. Rev. Cancer 2012, 12, 89-103.

350. Wang, M.; Qin, X.; Mudgett, J.S.; Ferguson, T.A.; Senior, R.M.; Welgus, H.G. Matrix metalloproteinase deficiencies affect contact hypersensitivity: Stromelysin-1 deficiency prevents the response and gelatinase B deficiency prolongs the response. Proc. Natl. Acad. Sci. USA 1999, 96, 6885-6889.

351. Creighton, C.; Hanash, S. Expression of matrix metalloproteinase 9 (MMP-9/gelatinase B) in adenocarcinomas strongly correlated with expression of immune response genes. In Silico Biol. 2003, 3, 301-311.

352. Zhu, X.S.; Shi, W.; An, G.Y.; Zhang, H.M.; Song, Y.G.; Li, Y.B. Matrix metalloproteinase-9 was involved in the immune-modulatory defect of mesenchymal stem cell from chronic myeloid leukemia patients. Chin. Med. J. 2011, 124, 2423.

353. Bratcher, P.E.; Weathington, N.M.; Nick, H.J.; Jackson, P.L.; Snelgrove, R.J.; Gaggar, A. Gelatinase B/MMP-9 cleaves SP-D and abrogates its innate immune functions in vitro. PLoS One 2012, 7, e41881.

354. Geiger, T.; Rordorf, C.; Galakatos, N.; Seligmann, B.; Henn, R.; Lazdins, J.; Vosbeck, K. Recombinant human C5a induces transcription but not translation of interleukin-1 beta mRNA in human monocytes. Res. Immunol. 1992, 143, 117-123.

355. Wu, G.; Chen, T.; Shahsafaei, A.; Hu, W.; Bronson, R.T.; Shi, G.P.; Halperin, J.A.; Aktas, H.; Qin, X. Complement regulator CD59 protects against angiotensin II-induced abdominal aortic aneurisms in mice. Circulation 2010, 121, 1338-1346. 
356. Voskoboinik, I.; Dunstone, M.A.; Baran, K.; Whisstock, J.C.; Trapani, J.A. Perforin: Structure function and role in human immunopathology. Immunol. Rev. 2010, 235, 35-54.

357. Nishikawa, H.; Sakaguchi, S. Regulatory T cells in tumor immunity. Int. J. Cancer 2010, 127, 759-767.

358. Wang, J.; Ke, X.Y. The four types of Tregs in malignant lymphomas. J. Hematol. Oncol. 2011, 4, 50 .

359. Tan, W.; Zhang, W.; Strasner, A.; Grivennikov, S.; Cheng, J.Q.; Hoffman, R.M.; Karin, M. Tumour-infiltrating regulatory $\mathrm{T}$ cells stimulate mammary cancer metastasis through RANKL.RANK signalling. Nature 2011, 470, 548-553.

360. Shah, W.; Yan, X.; Jing, L.; Zhou, Y.; Chen, H.; Wang, Y. A reversed CD4/CD8 ratio of tumor-infiltrating lymphocytes and a high percentage of CD4(+)FOXP3(+) regulatory $\mathrm{T}$ cells are significantly associated with clinical outcome in squamous cell carcinoma of the cervix. Cell. Mol. Immunol. 2011, 8, 59-66.

361. Piersma, S.J.; Welters, M.J.; van den Burg, S.H. Tumor-specific regulatory T cells in cancer patients. Hum. Immunol. 2008, 69, 241-249.

362. Kim, J.; Yu, W.; Kovalski, K.; Ossowski, L. Requirement for specific proteases in cancer cell intravasation as revealed by a novel semi-quantitative PCR-based assay. Cell 1998, 94, 353-362.

363. Bekes, E.M.; Schweighofer, B.; Kupriyanova, T.A.; Zajac, E.; Ardi, V.C.; Quigley, J.P.; Deryugina, E.L. Tumor-recruited neutrophils and neutrophil TIMP-free MMP-9 regulate co-ordinately the levels of tumor angiogenesis and efficiency of malignant cell intravasation. Am. J. Pathol. 2011, 179, 1455-1470.

364. Cho, K.; Matsuda, Y.; Ueda, J.; Uchida, E.; Naito, Z.; Ishiwata, T. Keratinocyte growth factor induces matrix metalloproteinase-9 expression and correlates with venous invasion in pancreatic cancer. Int. J. Oncol. 2012, 40, 1040-1048.

365. Li, J.; Sun, R.; Tao, K.; Wang, G. The CCL21/CCR7 pathway plays a key role in human colon cancer metastasis through regulation of matrix metalloproteinase-9. Dig. Liver Dis. 2011, 43, 40-47.

366. Sugino, T.; Kusakabe, T.; Hoshi, N.; Yamaguchi, T.; Kawaguchi, T.; Goodison, S.; Sekimata, M.; Homma, Y.; Suzuki, T. An invasion-independent pathway of blood-borne metastasis: A new murine mammary tumor model. Am. J. Pathol. 2002, 160, 1973-1980.

367. Mook, O.R.; van Marle, J.; Vreeling-Sindelarova, H.; Jonges, R.; Frederiks, W.M.; van Noorden, C.J. Visualization of early events in tumor formation of eGFP-transfected rat colon cancer cells in liver. Hepatology 2003, 38, 295-304.

368. Chambers, A.F.; Groom, A.C.; MacDonald, I.C. Dissemination of cancer cells in metastatic sites. Nat. Rev. Cancer 2002, 2, 563-572.

369. Rundhaug, J.E. Matrix metalloproteinases and angiogenesis. J. Cell Mol. Med. 2005, 9, 267-285.

370. Kopp, H.G.; Ramos, C.A.; Rafii, S. Contribution of endothelial progenitors and proangiogenic haematopoietic cells to vascularization of tumors and ischemic tissue. Curr. Opin. Hematol. 2006, 13, 175-181.

371. Kollet, O.; Dar, A.; Shivtiel, S.; Kalinkovich, A.; Lapid, K.; Sztainberg, Y.; Tesio, M.; Samstein, R.M.; Goichberg, P.; Spiegel, A.; et al. Osteoclasts degrade endosteal components and promote mobilization of hematopoietic progenitor cells. Nat. Med. 2006, 12, 657-664. 
372. Chen, X.; Su, Y.; Fingleton, B.; Acuff, H.; Matrisian, L.M.; Zent, R.; Pozzi, A. An orthotopic model of lung cancer to analyse primary and metastatic NSCL growth in integrin alpha1-null mice. Clin. Exp. Metastasis 2005, 22, 185-193.

373. Kaplan, R.N.; Psaila, B.; Lyden, D. Niche-to-niche migration of bone-marrow-derived cell. Trends Mol. Med. 2007, 13, 72-81.

374. Van Kempen, L.C.L.; Coussens, L.M. MMP-9 potentiates pulmonary metastasis formation. Cancer Cell 2002, 2, 251-252.

375. Grange, C.; Tapparo, M.; Collino, F.; Vitillo, L.; Damasco, C.; Deregibus, M.C.; Tetta, C.; Bussolati, B.; Camussi, G. Microvesicles released from human renal cancer stem cells stimulate angiogenesis and formation of lung pre-metastatic niche. Cancer Res. 2011, 71, 5346-5356.

376. Van Deventer, H.W.; Palmieri, D.A.; Wu, Q.P.; McCook, E.C.; Serody, J.S. Circulating fibrocytes prepare the lung for cancer metastasis by recruiting Ly-6C+ monocytes via CCL2. J. Immunol. 2013, 190, 4861-4867.

377. Kucia, M.; Reca, R.; Miekus, K.; Wanzeck, J.; Wojakowski, W.; Janowska-Wieczorek, A.; Ratajczak, J.; Ratajczak, M.Z. Trafficking of normal stem cells and cancer stem cells involve similar mechanisms: Pivotal role for the SDF-1/CXCR4 axis. Stem Cells 2005, 23, 879-894.

378. Kaplan, R.N.; Rifil, S.; Lyden, D. Preparing the "soil": The pre-metastatic niche. Cancer Res. 2006, 66, 11089-11093.

379. Mannello, F.; Tonti, G.A.; Bagnara, G.P.; Papa, S. Role and function of matrix metalloproteinases in the differentiation and biological characterisation of mesenchymal stem cells. Stem Cells $\mathbf{2 0 0 5}$, 24, 475-481.

380. Lee, R.; Kermani, P.; Teng, K.K.; Hempstead, B.L. Regulation of cell survival by secreted proneurotrophins. Science 2001, 294, 1945-1948.

381. Vaillant, C.; Meissirel, C.; Mutin, M.; Belin, F.; Lund, L.R.; Thomasset, N. MMP-9 deficiency affects axonal outgrowth, migration, and apoptosis in the developing cerebellum. Mol. Cell. Neurosci. 2003, 24, 395-408.

382. Chintala, S.K.; Zhang, X.; Austin, J.S.; Fini, M.E. Deficiency in matrix metalloproteinase gelatinase B (MMP-9) protects against retinal ganglion cell death after optic nerve ligation. J. Biol. Chem. 2002, 277, 47461-47468.

383. Gazzanelli, G.; Luchetti, F.; Burattini, S.; Mannello, F.; Falcieri, E.; Papa, S. Matrix metalloproteinases expression in HL-60 promyelocytic leukaemia cell during apoptosis. Apoptosis 2000, 5, 165-172.

384. Moshal., K.S.; Tipparaju, S.M.; Vacek, T.P.; Kumar, M.; Singh, M.; Franke, I.E.; Patibandla, P.K.; Tyagi, N.; Rai, J.; Metreveli, N.; et al. Mitochondrial matrix metalloproteinase activation decreases myocyte contractility in hyperhomocysteinemia. Am. J. Physiol. Heart Circ. Physiol. 2008, 295, H890-H897.

385. Kowluru, R.A.; Mohammad, G.; dos Santos, J.M.; Zhong, Q. Abrogation of gelatinase B/MMP-9 gene protects against the development of retinopathy in diabetic mice by preventing mitochondrial damage. Diabetes 2011, 60, 3023-3033.

386. Overchin, A.V.; Tyagi, N.; Rodriguez, W.E.; Hyden, M.R.; Moshal, K.S.; Tyagi, S.C. Role of matrix metalloproteinase-9 in endothelial apoptosis in chronic heart failure in mice. J. Appl. Physiol. 2005, 99, 2398-2405. 
387. Chetty, C.; Lakka, S.S.; Bhoopathi, P.; Gondi, C.S.; Veeravalli, K.K.; Fassett, D.; Klopfenstein, J.D.; Dinh, D.H.; Gujrati, M.; Rao, J.S. Urokinase plasminogen activator and /or matrix metalloproteinase-9 inhibition induces apoptosis signalling through lipid rafts in glioblastoma xenograft cells. Mol. Cancer Ther. 2010, 9, 2605-2617.

388. Shchors, K.; Nozawa, H.; Xu, J.; Rostker, F.; Swigart-Brown, L.; Evan, G.; Hanahan, D. Increased invasiveness of MMP-9-deficient tumors in two mouse models of neuroendocrine tumorigenesis. Oncogene 2013, 32, 502-513.

389. Deryugina, E.L.; Quigley, J.P. Matrix metalloproteinases and tumor metastasis. Cancer Metastasis Rev. 2006, 25, 9-34.

390. Acuff, H.B.; Carter, K.J.; Fingleton, B.; Gorden, D.L.; Matrisian, L.M. Matrix metalloproteinase-9 from bone marrow-derived cells contributes to survival but not growth of tumor cells in lung microenvironment. Cancer Res. 2006, 66, 259-266.

391. Itoh, T.; Tanioka, M.; Matsuda, H.; Nishimoto, H.; Yoshioka, T.; Suzuki, R.; Uehira, M. Experimental metastasis is suppressed in MMP-9-deficient mice. Clin. Exp. Metastasis 1999, 17, 177-181.

392. Pozzi, A.; Moberg, P.E.; Miles, L.A.; Wagner, S.; Soloway, P.; Gardner, H.A. Elevated matrix metalloproteinase and angiostatin levels in integrin alpha 1 knockout mice cause reduced tumor vascularization. Proc. Natl. Acad. Sci. USA 2000, 97, 2202-2207.

393. Pozzi, A.; LeVine, W.F.; Gardner, H.A. Low plasma levels of matrix metalloproteinase 9 permit increased tumor angiogenesis. Oncogene 2002, 21, 272-281.

394. Chen, X.; Su, Y.; Fingleton, B.; Acuff, H.; Matrisian, L.M.; Zent, R.; Pozzi, A. Increased plasma MMP9 in integrin alpha1-null mice enhances lung metastasis of colon carcinoma cells. Int. J. Cancer 2005, 116, 52-61.

395. Buck, T.B.; Yoshiji, H.; Harris, S.R.; Bunce, O.R.; Thorgeirsson, U.P. The effects of sustained elevated levels of circulating tissue inhibitor of metalloproteinase-1 on the development of breast cancer in mice. Ann. NY Acad. Sci. USA 1999, 878, 732-735.

396. De Lornzo, M.S.; Ripoll, G.V.; Yoshiji, H.; Yamazaki, M.; Thorgeirsson, U.P.; Alonso, D.F.; Gomez, D.E. Altered tumor angiogenesis and metastasis of B16 melanoma in transgenic mice overexpressing tissue inhibitor of metalloproteinase-1. In Vivo 2003, 17, 45-50.

397. Yoshiji, H.; Kuriyama, S.; Miyamoto, Y.; Thorgeirsson, U.P.; Gomez, D.E.; Kawata, M.; Yoshii, J.; Ikenaka, Y.; Noguchi, R.; Tsujinoue, H.; et al. Tissue inhibitor of metalloproteinase-1 promotes liver fibrosis development in a transgenic mouse model. Hepatology 2000, 32, 1248-1254.

398. Dziembowska, M.; Wlodarczyk, J. MMP9: Novel function in synaptic plasticity. Int. J. Biochem. Cell Biol. 2012, 44, 709-713.

399. Zucker, S.; Cao, J.; Chen, W.-T. Critical appraisal of the use of matrix metalloproteinase inhibitors in cancer treatment. Oncogene 2001, 19, 6642-6650.

400. Pavlaki, M.; Zucker, S. Matrix metalloproteinase inhibitors (MMPIs): The beginning of phase I or the termination of phase III clinical trials. Cancer Metastasis Rev. 2003, 22, 177-203.

401. Overall, C.M.; Kleifeld, O. Validating matrix metalloproteinases as drug targets and anti-targets for cancer therapy. Nat. Rev. Cancer 2006, 6, 227-239. 
402. McCawley, L.J.; Wright, J.; LaFleur, B.J.; Crawford, H.C.; Matrisian, L.M. Keratinocyte expression of MMP-3 enhances differentiation and prevents tumor establishment. Am. J. Pathol. 2008, 173, 1528-1529.

403. McCawley, L.J.; Crawford, H.C.; King, L.E., Jr.; Mudgett, J.; Matrisian, L.M. A protective role for matrix metalloproteinase-3 in squamous cell carcinoma. Cancer Res. 2004, 64, 6965-6972.

404. Kopitz, C.; Gerg, M.; Bandapalli, O.R.; Ister, D.; Pennington, C.J.; Hauser, S.; Flecgsig, C.; Krell, H.W.; Antolovic, D.; Brew, K.; et al. Tissue inhibitor of metalloproteinases-1 promotes liver metastasis by inducing hepatocyte growth factor signalling. Cancer Res. 2007, 67, 8615-8623.

405. Wolf, K.; Mazo, I.; Leung, H.; Engelke, K.; von Andrian, U.H.; Deryugina, E.L.; Strongin, A.Y.; Brocker, E.B.; Friedl, P. Compensation mechanism in tumor cell migration: Mesenchymal-amoeboid transition after blocking of peri-cellular proteolysis. J. Cell Biol. 2003, 160, 267-277.

406. Hu, J.; van den Steen, P.E.; Sang, Q.X.; Opdenakker, G. Matrix metalloproteinase inhibitors as therapy for inflammatory and vascular diseases. Nat. Rev. Drug Discov. 2007, 6, 480-498.

407. Martens, E.; Leyssen, A.; van Aelst, I.; Fiten, P.; Piccard, H.; Hu, J.; Descamps, F.J.; van den Steen, P.E.; Proost, P.; van Damme, J.; et al. A monoclonal antibody inhibits gelatinase B/MMP-9 by selective binding to part of the catalytic domain and not to the fibronectin or zinc binding domains. Biochim. Biophys. Acta 2007, 1770, 178-186.

408. Stefanidakis, M.; Karjalainen, K.; Jaalouk, D.E.; Gahmberg, C.G.; O’Brien, S.; Pasqualini, R.; Arap, W.; Koivunen, E. Role of leukemia cell invadosome in extramedullary infiltration. Blood 2009, 114, 3008-3017.

409. Suojanen, J.; Vilen, S.-T.; Nyberg, P.; Heikkila, P.; Penate-Medina, O.; Saris, P.E.J.; Hagstrom, J.; Ranta, T.-M.; Salo, T.; Sorsa, T.; et al. Selective gelatinase inhibitor peptide is effective in targeting tongue carcinoma cell tumors in vivo. Anticancer Res. 2011, 31, 3659-3664.

410. Burg-Roderfeld, M.; Roderfeld, M.; Wagner, S.; Henkel, C.; Grotzinger, J.; Roeb, E. MMP-9hemopexin domain hampers adhesion and migration of colorectal cancer cells. Int. J. Oncol. 2007, 30, 985-992.

411. Urgate-Berzal, E.; Bailon, E.; Amigo-Jiminez, I.; Vituri, C.L.; Hernandez del Cerro, M.; Terol, M.J.; Albar, J.P.; Rivas, G.; Barcia-Marco, J.A.; Garcia-Pardo, A. A 17-residue sequence from the matrix metalloproteinase-9 (MMP-9) hemopexin domain binds $\alpha 4 \beta 1$ integrin and inhibits MMP-9-induced functions in chronic Lymphocytic Leukaemia B cells. J. Biol. Chem. 2012, 287, 27601-27613.

412. Bjorklund, M.; Heikkila, P.; Koivunen, E. Peptide inhibition of catalytic and non-catalytic activities of matrix metalloproteinase-9 blocks tumor cell migration and invasion. J. Biol. Chem. 2004, 279, 29589-29597.

413. Vandooren, J.; Geurts, N.; Opdenakker, G. Gelatin degradation assay reveals MMP-9 inhibitors and function of $O$-glycosylated domain. World J. Biol. Chem. 2011, 26, 14-24.

(C) 2014 by the authors; licensee MDPI, Basel, Switzerland. This article is an open ssaccess article distributed under the terms and conditions of the Creative Commons Attribution license (http://creativecommons.org/licenses/by/3.0/). 